\title{
Synthesis and Cytotoxicity Studies of Artemisinin Derivatives Containing Lipophilic Alkyl Carbon Chains
}

\author{
Yungen Liu, Vincent Kam-Wai Wong, Ben Chi-Bun Ko, Man-Kin Wong, * and Chi-Ming Che* \\ Department of Chemistry, The University of Hong Kong, Pokfulam Road, Hong Kong, China. \\ cmche@hku.hk; mkwong@hkusua.hku.hk
}

\section{SUPPORTING INFORMATION}

\section{Table of Contents}

(I) Synthetic Schemes of Artemisinin Derivatives

$\mathrm{S} 2-\mathrm{S} 5$

(II) Literature References for Compounds 2 - 5, $\alpha-8 \mathbf{a}, \beta-8 \mathbf{a}, 9 \mathbf{a}$, and $14-15$

(III) Preparation and Characterization Data of Compounds 4-22

$\mathrm{S} 7-\mathrm{S} 25$

(IV) Cytotoxicity Studies (MTT Assay)

S26

(V) ${ }^{1} \mathrm{H}$ NMR Spectra of $\mathbf{6}-\mathbf{1 3}$ and $\mathbf{1 6}-\mathbf{2 2}$

S27 - S59 


\section{(I) Synthetic Schemes of Artemisinin Derivatives}

To conduct systematic investigations on the relationship between alkyl carbon chains and antitumor activities, a series of structurally related artemisinin analogues were synthesized by using a modular approach of "artemisinin + linker + lipophilic alkyl carbon chain". To maximize the efficiency of synthesis and the structural diversity of artemisinin analogues, aldehyde $\mathbf{4}$ and acid $\mathbf{5}$ derived from $\mathbf{1}$ were selected as the key intermediates (Scheme 1). Starting from $\mathbf{4}$ and $\mathbf{5}$, amides $6,12,13$, esters 7 , alcohols 8 , and ketones 9 - 11 bearing alkyl carbon chains of different length have been synthesized.

Using artemisinin $\mathbf{1}$ as the starting material, $10 \beta$-allylartemisinin $\mathbf{3}$ was synthesized in three steps according to the literature procedures (Scheme 1) [O'Neill, P. M., et al, J. Chem. Soc., Perkin Trans. 1 2001, 2682 - 2689; Hindley, S., et al, J. Med. Chem. 2002, 45, 1052 - 1063]. Nevertheless, some $10 \%$ of inseparable $10 \alpha$-isomer was obtained along with the desired $10 \beta$ isomer. Several attempts to optimize the reaction conditions failed to increase the ratio of the $\beta$ isomer. Thus, we decided to employ this $\beta$-major isomer for the following steps. Oxidative cleavage of 3 using $\mathrm{RuCl}_{3} / \mathrm{NaIO}_{4}$ afforded aldehyde $\mathbf{4}$ as a key intermediate in $75 \%$ yield [Ma, J., et al, J. Med. Chem. 2000, 43, 4228 - 4232; Yang, D., et al, J. Org. Chem. 2001, 66, 4814 4818]. Subsequent oxidation of 4 with $\mathrm{Oxone} / \mathrm{NaHCO}_{3}$ provided another key intermediate carboxylic acid $\mathbf{5}$ in $90 \%$ yield. Starting from 5, amides 6, 12 and esters 7 were synthesized by coupling reactions with various aliphatic amines and alcohols respectively, in high yields. Treatment of the aldehyde 4 with Grignard reagents offered a series of $\alpha$ - and $\beta$-alcohols 8 according to a literature report [Ma, J., et al, J. Med. Chem. 2000, 43, 4228 - 4232]. Ketones 9 could be obtained by oxidation of alcohols $\mathbf{8}$ with PDC in good yields. Similarly, ketone $\mathbf{1 0}$ was prepared from 4 through addition reaction with Grignard reagent, alcohol oxidation, and 
deprotection of tert-butyldimethylsilyl (TBDMS) ether. Carboxylic acid $\mathbf{1 1}$ was obtained from oxidation of the terminal alcohol group of $\mathbf{1 0}$ in $90 \%$ yield using Jones reagent. Compound $\mathbf{1 3}$ was prepared through oxidation of $\mathbf{1 2}$ using $\mathrm{RuCl}_{3} / \mathrm{NaIO}_{4}$ in $\mathrm{THF} / \mathrm{H}_{2} \mathrm{O}(5: 1)$ in $65 \%$ yield.

\section{Scheme 1}
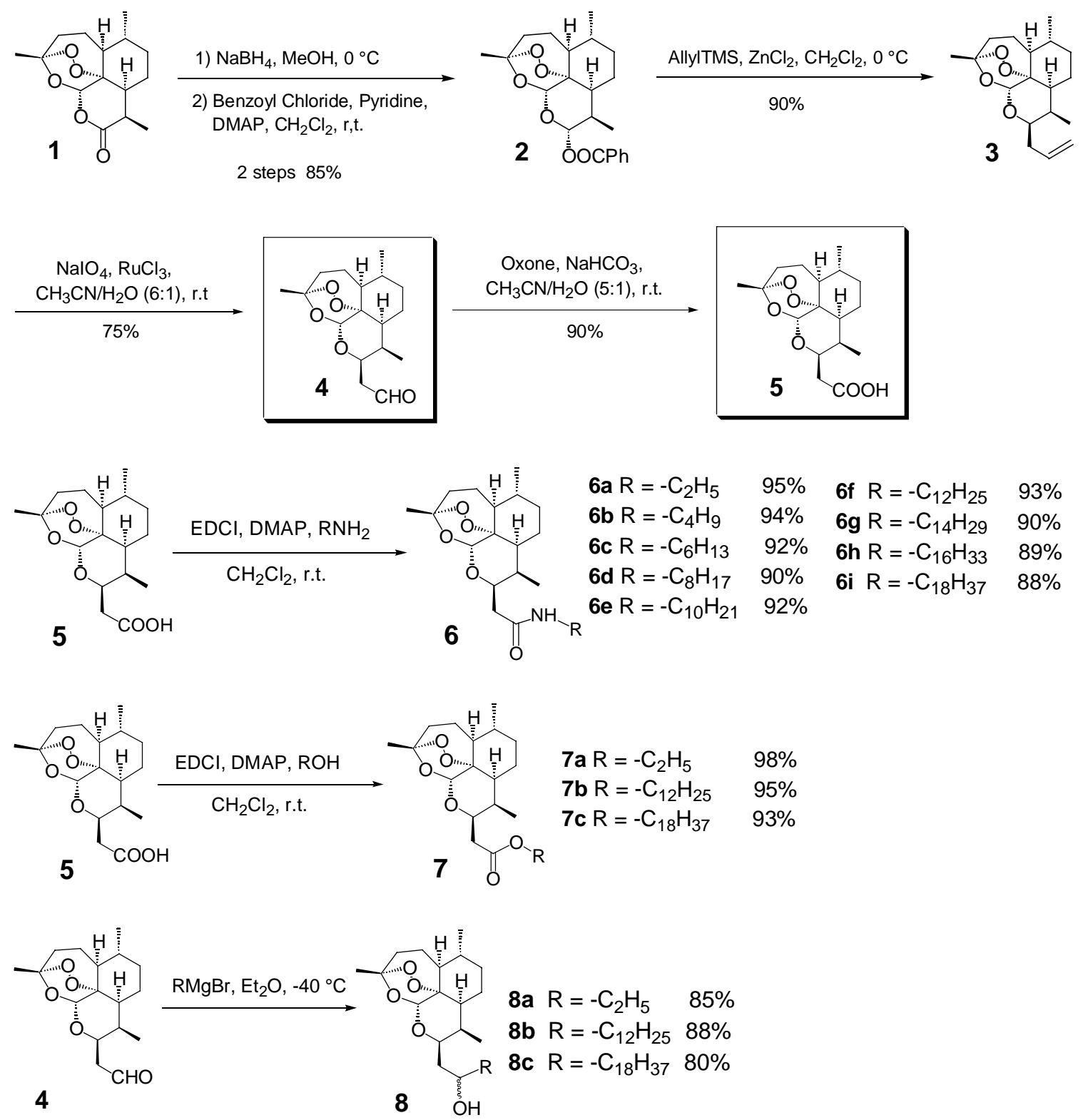

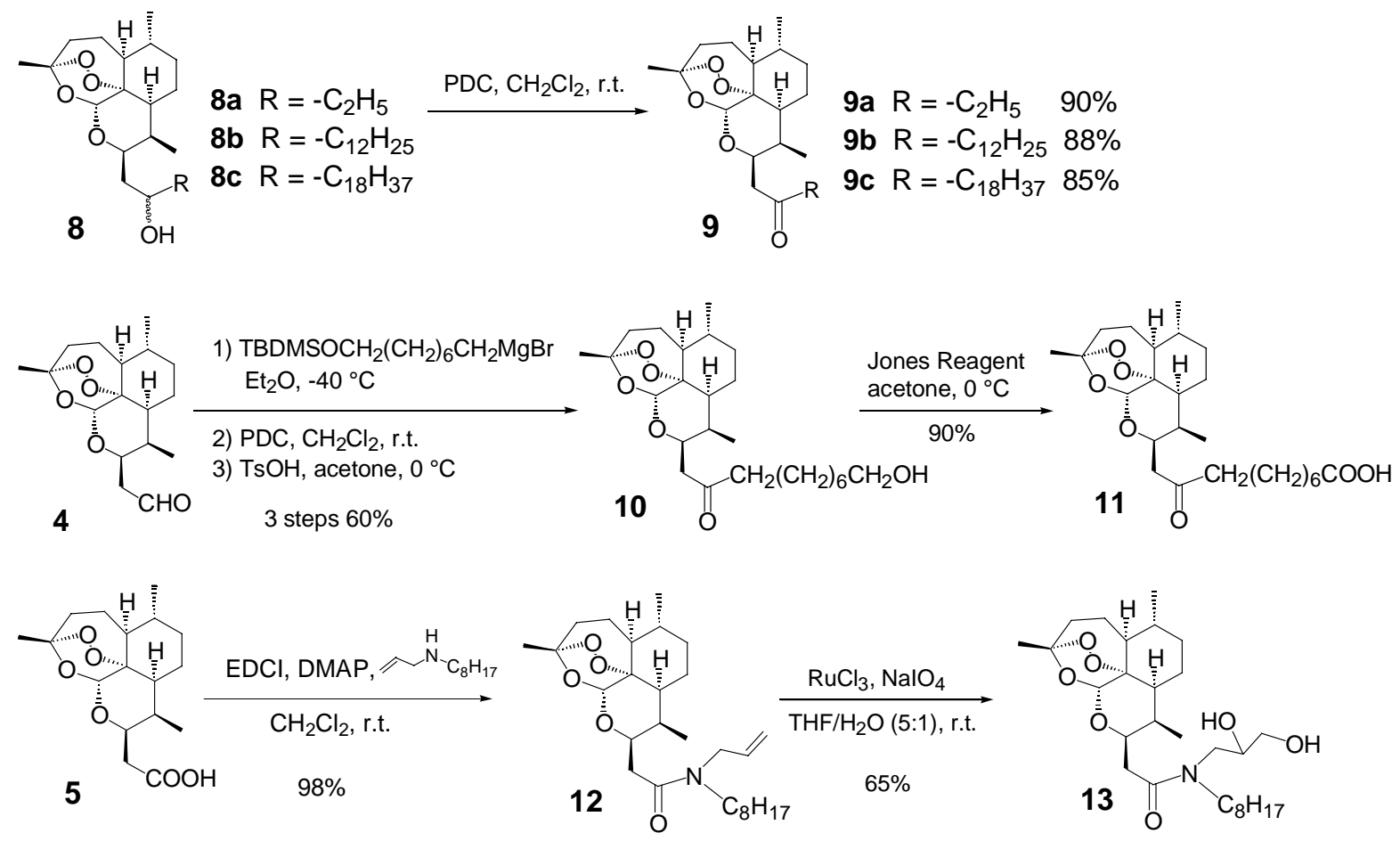

Apart form the naturally occurring D-6-membered ring artemisinin, a series of D-5membered ring artemisinin derivatives were synthesized. As depicted in Scheme 2, 15 was prepared from 2 via removal of benzoate group and subsequent oxidative cleavage of $\mathrm{C}=\mathrm{C}$ double bond with $\mathrm{RuCl}_{3} / \mathrm{NaIO}_{4}$ in $54 \%$ overall yield. Treatment of $\mathbf{1 5}$ with allyltrimethylsilane in the presence of $\mathrm{ZnCl}_{2}$ as catalyst afforded 16 in $95 \%$ yield. The stereochemistry of the newly generated quaternary carbon centre of 16 was established by ${ }^{1} \mathrm{H}-{ }^{1} \mathrm{H}$ NOESY analysis. Oxidative cleavage of $\mathbf{1 6}$ achieved key intermediate aldehyde $\mathbf{1 7}$ in $75 \%$ yield. Key intermediate acid $\mathbf{1 8}$ was obtained in $95 \%$ yield through oxidation of aldehyde 17 with Oxone/ $\mathrm{NaHCO}_{3}$. Amides 19 and esters 20 could be synthesized by coupling reactions of acid $\mathbf{1 8}$ with various amines and alcohols, respectively. Treatment of $\mathbf{1 7}$ with $n$-dodecylmagnesium bromide and subsequent oxidation with PDC gave ketone 21 in high yield. 


\section{Scheme 2}
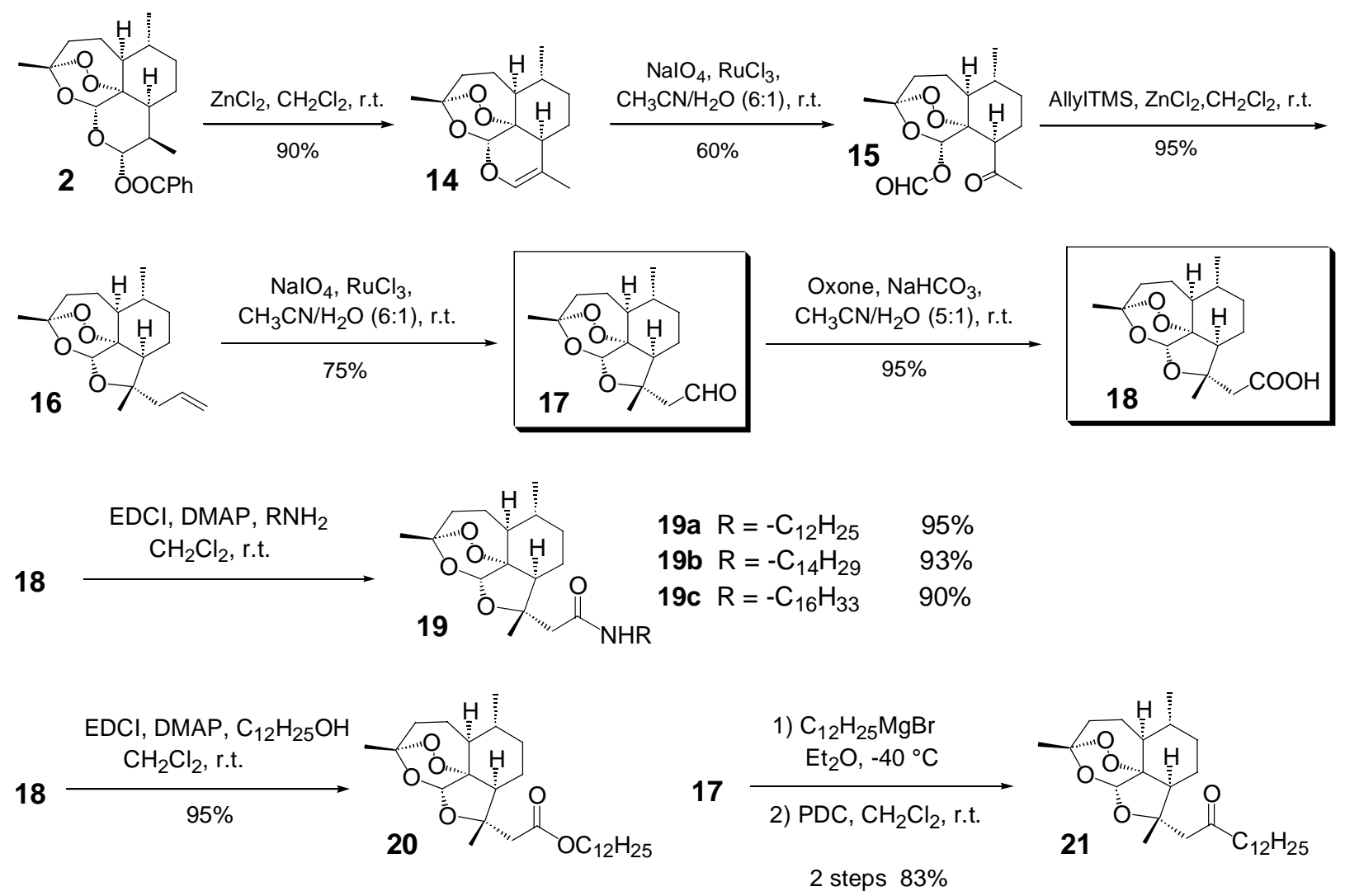

To demonstrate the importance of the peroxide functionality on the antitumor activities, deoxygenated analogue 22 was prepared from $\mathbf{6 h}$ according to Scheme 3 [Avery, M. A., et al, J. Med. Chem. 2003, 46, 4244 - 4258; Jung, M., et al, J. Med. Chem. 1990, 33, 1516 - 1518].

\section{Scheme 3}
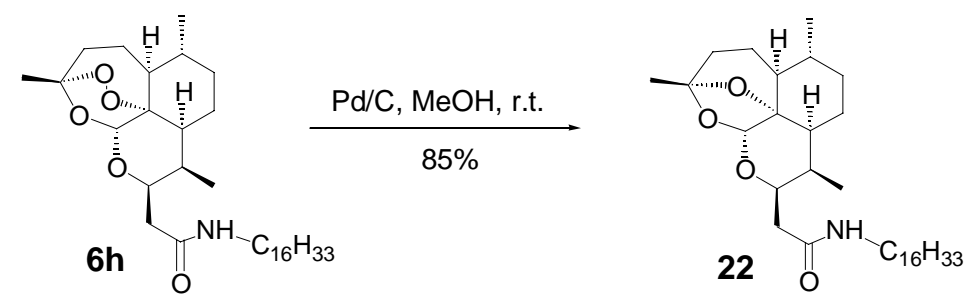
(II) Literature References for compounds $2-5, \alpha-8 a, \beta-8 a, 9 a$ and $14-15$

\begin{tabular}{|c|c|}
\hline Compounds & References \\
\hline 2 & O'Neill, P. M., et al, J. Chem. Soc., Perkin Trans.1 2001, $2682-2689$. \\
\hline 3 & $\begin{array}{l}\text { (a) O'Neill, P. M., et al, J. Chem. Soc., Perkin Trans. } 1 \text { 2001, } 2682- \\
2689 . \\
\text { (b) Hindley, S., et al, J. Med. Chem. 2002, 45, } 1052-1063 .\end{array}$ \\
\hline 4 & Ma, J., et al, J. Med. Chem. 2000, 43, 4228-4232. \\
\hline 5 & Jung, M., et al, Heterocycles 1994, 39, 23 - 29. \\
\hline$\alpha-8 \mathbf{a}$ and $\beta-8 \mathbf{a}$ & Ma, J., et al, J. Med. Chem. 2000, 43, $4228-4232$. \\
\hline 9a & Ma, J., et al, J. Med. Chem. 2000, 43, 4228 - 4232. \\
\hline 14 & $\begin{array}{l}\text { (a) O'Neill, P. M., et al, J. Chem. Soc., Perkin Trans. } 1 \text { 2001, } 2682- \\
2689 . \\
\text { (b) Sy, L.-K., et al, J. Chem. Soc., Perkin Trans. } 1 \text { 2001, } 2421-2429 . \\
\text { (c) Haynes, R. K., et al, Eur. J. Org. Chem. 2003, } 2098 \text { - } 2114 .\end{array}$ \\
\hline 15 & $\begin{array}{l}\text { (a) El-Feraly, F. S., et al, J. Nat. Prod. 1990, 53, } 920-925 . \\
\text { (b) Sy, L.-K., et al, J. Chem. Soc., Perkin Trans. } 1 \text { 2001, } 2421-2429 .\end{array}$ \\
\hline
\end{tabular}




\section{(III) Preparation and Characterization Data of Compounds 4-22}

\section{Preparation of 4}

To a mixture of 10 $\beta$-allylartemisinin $3(62 \mathrm{mg}, 0.20 \mathrm{mmol})$ and $\mathrm{NaIO}_{4}(86 \mathrm{mg}, 0.40 \mathrm{mmol})$ in acetonitrile $(12 \mathrm{~mL})$ and water $(2 \mathrm{~mL})$ was added a $\mathrm{RuCl}_{3}$ solution $(0.007 \mathrm{mmol}, 70 \mu \mathrm{L}, 0.1 \mathrm{M}$ in water) at room temperature. After the disappearance of $\mathbf{3}$ in $3 \mathrm{~h}$ as indicated by TLC, brine (15 $\mathrm{mL}$ ) was added to the reaction mixture, and two layers were separated. The aqueous layer was extracted with ethyl acetate $(3 \times 20 \mathrm{~mL})$, and the combined organic layers were washed with water and brine, dried over anhydrous $\mathrm{MgSO}_{4}$, filtered, and concentrated under reduced pressure. The residue was purified by flash column chromatography to give 4 (47 mg, $0.15 \mathrm{mmol}, 75 \%$ yield) as a colorless oil. The characterization data matched those reported in literature.

\section{Preparation of 5}

To a mixture of 4 (62 mg, $0.20 \mathrm{mmol})$ and $\mathrm{NaHCO}_{3}(104 \mathrm{mg}, 1.24 \mathrm{mmol})$ in acetonitrile (10 $\mathrm{mL})$ and water $(2 \mathrm{~mL})$, was added a solution of Oxone $(246 \mathrm{mg}, 0.40 \mathrm{mmol}$, dissolved in $0.5 \mathrm{~mL}$ water) in portions over $0.5 \mathrm{~h}$ at room temperature. After stirring for an additional $2.5 \mathrm{~h}$, the reaction mixture was diluted with water $(10 \mathrm{~mL})$ and washed with diethyl ether $(20 \mathrm{~mL})$, and the organic layer was discarded. The aqueous layer was adjusted to $\mathrm{pH} 2$ by adding hydrochloride acid $(3 \mathrm{M})$ and extracted with ethyl acetate $(3 \times 20 \mathrm{~mL})$. The combined organic layers were washed with water and brine, dried over anhydrous $\mathrm{MgSO}_{4}$, filtered, and concentrated under reduced pressure. The residue was pure enough for the following steps. Alternatively, the residue could be purified by flash column chromatography to give 5 (59 $\mathrm{mg}, 0.18 \mathrm{mmol}, 90 \%$ yield) as a

colorless oil. ${ }^{1} \mathrm{H}$ NMR $\left(300 \mathrm{MHz}, \mathrm{CDCl}_{3}\right) \delta 8.58(\mathrm{br} \mathrm{s}, 1 \mathrm{H}), 5.36(\mathrm{~s}, 1 \mathrm{H}), 4.84(\mathrm{~m}, 1 \mathrm{H}), 2.75-$ 
$2.64(\mathrm{~m}, 2 \mathrm{H}), 2.56-2.25$ (m, 2H), 2.07-1.19 (m, $9 \mathrm{H}), 1.41$ (s, $3 \mathrm{H}), 0.97$ (d, J = 5.8 Hz, 3H), $0.88(\mathrm{~d}, J=7.5 \mathrm{~Hz}, 3 \mathrm{H}), 1.02-0.88(\mathrm{~m}, 1 \mathrm{H}) ;{ }^{13} \mathrm{C} \mathrm{NMR}\left(75 \mathrm{MHz}, \mathrm{CDCl}_{3}\right) \delta 176.56,103.26$, $89.25,80.82,71.09,52.11,43.93,37.40,36.43,35.82,34.34,29.69,25.81,24.68,24.63,20.08$ 12.79; IR $\left(\mathrm{CH}_{2} \mathrm{Cl}_{2}\right)$ 2920, 1733, 1463, $1378 \mathrm{~cm}^{-1}$; MS (EI) $\mathrm{m} / 2.294\left(\left[\mathrm{M}-\mathrm{O}_{2}\right]^{+}\right) ;$HRMS (FAB) $m / z$ for $\mathrm{C}_{17} \mathrm{H}_{26} \mathrm{O}_{4}\left(\left[\mathrm{M}-\mathrm{O}_{2}\right]^{+}\right)$, calcd 294.1831, found 294.1828.

\section{General Procedure 1: preparation of 6 (synthesis of $\mathbf{6} \boldsymbol{a}$ was chosen as an example)}

To a solution of $5(33 \mathrm{mg}, 0.10 \mathrm{mmol})$ in $\mathrm{CH}_{2} \mathrm{Cl}_{2}(10 \mathrm{~mL})$ at room temperature was added 1(3-dimethylaminopropyl)-3-ethylcarbodiimide hydrochloride (EDCI) (58 mg, $0.30 \mathrm{mmol})$. After stirring for $5 \mathrm{~min}$, 4-dimethylaminopyridine (DMAP) $(61 \mathrm{mg}, 0.50 \mathrm{mmol})$ and ethylamine hydrochloride $(25 \mathrm{mg}, 0.30 \mathrm{mmol})$ were added to this solution. The resulting mixture was stirred overnight at room temperature. The reaction mixture was diluted with ethyl acetate $(30 \mathrm{~mL})$, washed with saturated $\mathrm{NH}_{4} \mathrm{Cl}$ solution, water, and brine, dried over anhydrous $\mathrm{Na}_{2} \mathrm{SO}_{4}$, filtered, and concentrated under reduced pressure. The residue was purified by flash column chromatography to afford $\mathbf{6 a}$ (34 mg, $0.095 \mathrm{mmol}, 95 \%$ yield) as a colorless oil. ${ }^{1} \mathrm{H}$ NMR (300 $\left.\mathrm{MHz}, \mathrm{CDCl}_{3}\right) \delta 6.98(\mathrm{br} \mathrm{s}, 1 \mathrm{H}), 5.39(\mathrm{~s}, 1 \mathrm{H}), 4.79(\mathrm{~m}, 1 \mathrm{H}), 3.38-3.17(\mathrm{~m}, 2 \mathrm{H}), 2.57-2.44(\mathrm{~m}$, $2 \mathrm{H}), 2.36-2.27$ (m, 2H), 2.09-1.93 (m, $2 \mathrm{H}), 1.83-1.17$ (m, $7 \mathrm{H}), 1.41(\mathrm{~s}, 3 \mathrm{H}), 1.15$ (t, $J=7.3$ $\mathrm{Hz}, 3 \mathrm{H}), 0.98(\mathrm{~d}, J=5.6 \mathrm{~Hz}, 3 \mathrm{H}), 0.87(\mathrm{~d}, J=7.6 \mathrm{~Hz}, 3 \mathrm{H}), 1.00-0.88(\mathrm{~m}, 1 \mathrm{H}) ;{ }^{13} \mathrm{C}$ NMR $(75$ $\left.\mathrm{MHz}, \mathrm{CDCl}_{3}\right) \delta 171.53,102.88,90.26,80.85,69.61,51.81,43.44,37.60,37.48,36.57,34.24$ 30.50, 25.78, 24.84, 19.99, 14.74, 12.01; IR $\left(\mathrm{CH}_{2} \mathrm{Cl}_{2}\right) 2918,1654,1458,1377 \mathrm{~cm}^{-1}$; MS (FAB) $m / z 354\left([\mathrm{M}+\mathrm{H}]^{+}\right)$; HRMS $(\mathrm{FAB}) \mathrm{m} / z$ for $\mathrm{C}_{19} \mathrm{H}_{32} \mathrm{O}_{5} \mathrm{~N}\left([\mathrm{M}+\mathrm{H}]^{+}\right)$, calcd 354.2280, found 354.2264 . 
6b was prepared according to the General Procedure 1 using $n$-butylamine. (Colorless oil, 94\% yield). ${ }^{1} \mathrm{H}$ NMR (300 MHz, $\left.\mathrm{CDCl}_{3}\right) \delta 7.01$ (br s, $\left.1 \mathrm{H}\right), 5.38(\mathrm{~s}, 1 \mathrm{H}), 4.75(\mathrm{~m}, 1 \mathrm{H}), 3.34(\mathrm{~m}, 1 \mathrm{H})$, 3.17 (m, 1 H), 2.62-2.47 (m, 2 H), 2.36-2.27 (m, 2 H), 2.11-1.93 (m, 2 H), 1.83-1.17 (m, 11 H), $1.40(\mathrm{~s}, 3 \mathrm{H}), 0.98(\mathrm{~d}, J=5.5 \mathrm{~Hz}, 3 \mathrm{H}), 0.92(\mathrm{t}, J=7.3 \mathrm{~Hz}, 3 \mathrm{H}), 0.87(\mathrm{~d}, J=7.6 \mathrm{~Hz}, 3 \mathrm{H}), 1.00-$ $0.88(\mathrm{~m}, 1 \mathrm{H}) ;{ }^{13} \mathrm{C}$ NMR $\left(75 \mathrm{MHz}, \mathrm{CDCl}_{3}\right) \delta 171.47,102.86,90.01,80.78,69.81,51.77,43.45$, $39.10,37.51,37.29,36.48,34.19,31.51,30.38,25.73,24.75,20.08,19.95,13.73,12.06$; IR $\left(\mathrm{CH}_{2} \mathrm{Cl}_{2}\right) 2918,1653,1458,1377 \mathrm{~cm}^{-1}$; MS (EI) $\mathrm{m} / z 381\left(\mathrm{M}^{+}\right)$; HRMS (EI) $\mathrm{m} / z$ for $\mathrm{C}_{21} \mathrm{H}_{35} \mathrm{O}_{5} \mathrm{~N}$ $\left(\mathrm{M}^{+}\right)$, calcd 381.2515, found 381.2520.

6c was prepared according to the General Procedure 1 using $n$-hexylamine. (Colorless oil, 92\% yield). ${ }^{1} \mathrm{H}$ NMR (300 MHz, $\left.\mathrm{CDCl}_{3}\right) \delta 7.01$ (br s, $\left.1 \mathrm{H}\right), 5.38(\mathrm{~s}, 1 \mathrm{H}), 4.75(\mathrm{~m}, 1 \mathrm{H}), 3.33(\mathrm{~m}, 1 \mathrm{H})$, 3.15 (m, 1 H), 2.62-2.46 (m, 2 H), 2.38-2.27 (m, 2 H), 2.10-1.93 (m, 2 H), 1.83-1.19 (m, 9 H), 1.40 (s, $3 \mathrm{H}), 1.29$ (br s, $6 \mathrm{H}), 0.98(\mathrm{~d}, J=5.6 \mathrm{~Hz}, 3 \mathrm{H}), 0.88(\mathrm{t}, J=7.5 \mathrm{~Hz}, 3 \mathrm{H}), 0.87(\mathrm{~d}, J=7.6$ $\mathrm{Hz}, 3 \mathrm{H}), 1.00-0.88(\mathrm{~m}, 1 \mathrm{H}) ;{ }^{13} \mathrm{C} \mathrm{NMR}\left(75 \mathrm{MHz}, \mathrm{CDCl}_{3}\right) \delta 171.44,102.85,90.00,80.77,69.83$, $51.78,43.45,39.42,37.50,37.29,36.48,34.19,31.45,30.38,29.41,26.60,25.74,24.75,22.49$, 19.97, 13.97, 12.06; IR $\left(\mathrm{CH}_{2} \mathrm{Cl}_{2}\right) 2918,1654,1458,1377 \mathrm{~cm}^{-1}$; MS (EI) $\mathrm{m} / z, 409\left(\mathrm{M}^{+}\right)$; HRMS (EI) $m / z$ for $\mathrm{C}_{23} \mathrm{H}_{39} \mathrm{O}_{5} \mathrm{~N}\left(\mathrm{M}^{+}\right)$, calcd 409.2828 , found 409.2826 .

6d was prepared according to the General Procedure 1 using $n$-octylamine. (Colorless oil, $90 \%$ yield). ${ }^{1} \mathrm{H}$ NMR (300 MHz, $\left.\mathrm{CDCl}_{3}\right) \delta 7.01$ (br s, $\left.1 \mathrm{H}\right), 5.38(\mathrm{~s}, 1 \mathrm{H}), 4.75(\mathrm{~m}, 1 \mathrm{H}), 3.33(\mathrm{~m}, 1 \mathrm{H})$, 3.15 (m, 1 H), 2.62-2.46 (m, 2 H), 2.38-2.27 (m, 2 H), 2.10-1.94 (m, 2 H), 1.83-1.19 (m, 9 H), $1.40(\mathrm{~s}, 3 \mathrm{H}), 1.26$ (br s, $10 \mathrm{H}), 0.98(\mathrm{~d}, J=5.7 \mathrm{~Hz}, 3 \mathrm{H}), 0.88$ (t, $J=7.4 \mathrm{~Hz}, 3 \mathrm{H}), 0.87$ (d, $J=$ $7.6 \mathrm{~Hz}, 3 \mathrm{H}), 1.00-0.88(\mathrm{~m}, 1 \mathrm{H}) ;{ }^{13} \mathrm{C} \mathrm{NMR}\left(75 \mathrm{MHz}, \mathrm{CDCl}_{3}\right) \delta 171.43,102.83,89.99,80.76$, 
$69.81,51.76,43.44,39.41,37.49,37.28,36.47,34.18,31.73,30.37,29.42,29.20,29.13,26.92$, 25.73, 24.74, 22.58, 19.94, 14.03, 12.05; IR $\left(\mathrm{CH}_{2} \mathrm{Cl}_{2}\right) 2923,1654,1458,1377 \mathrm{~cm}^{-1} ; \mathrm{MS}(\mathrm{EI}) \mathrm{m} / \mathrm{z}$ $437\left(\mathrm{M}^{+}\right)$; HRMS (EI) $\mathrm{m} / z$ for $\mathrm{C}_{25} \mathrm{H}_{43} \mathrm{O}_{5} \mathrm{~N}\left(\mathrm{M}^{+}\right)$, calcd 437.3141, found 437.3118 .

6e was prepared according to the General Procedure 1 using $n$-decylamine. (Colorless oil, 92\% yield). ${ }^{1} \mathrm{H}$ NMR (300 MHz, $\left.\mathrm{CDCl}_{3}\right) \delta 7.01(\mathrm{br} \mathrm{s}, 1 \mathrm{H}), 5.38(\mathrm{~s}, 1 \mathrm{H}), 4.75(\mathrm{~m}, 1 \mathrm{H}), 3.33(\mathrm{~m}, 1 \mathrm{H})$, 3.15 (m, $1 \mathrm{H}), 2.62-2.46$ (m, $2 \mathrm{H}), 2.38-2.27$ (m, 2 H), 2.10-1.94 (m, $2 \mathrm{H}), 1.83-1.19$ (m, $9 \mathrm{H})$, 1.39 (s, $3 \mathrm{H}), 1.26$ (br s, $14 \mathrm{H}), 0.98(\mathrm{~d}, J=5.7 \mathrm{~Hz}, 3 \mathrm{H}), 0.88$ (t, $J=7.4 \mathrm{~Hz}, 3 \mathrm{H}), 0.87$ (d, $J=$ 7.6 Hz, $3 \mathrm{H}), 1.00-0.88(\mathrm{~m}, 1 \mathrm{H}) ;{ }^{13} \mathrm{C}$ NMR $\left(75 \mathrm{MHz}, \mathrm{CDCl}_{3}\right) \delta 171.45,102.84,90.01,80.74$, $69.81,51.78,43.45,39.42,37.49,37.45,37.29,36.49,34.19,31.85,30.37,29.49,29.43,29.25$, 26.93, 25.74, 24.75, 22.62, 19.94, 14.05, 12.05; IR $\left(\mathrm{CH}_{2} \mathrm{Cl}_{2}\right) 2920,1654,1458,1377 \mathrm{~cm}^{-1}$; MS (EI) $m / z 465\left(\mathrm{M}^{+}\right)$; HRMS (EI) $m / z$ for $\mathrm{C}_{27} \mathrm{H}_{47} \mathrm{O}_{5} \mathrm{~N}\left(\mathrm{M}^{+}\right)$, calcd 465.3454 , found 465.3452 .

6f was prepared according to the General Procedure 1 using $n$-dodecylamine. (Colorless oil, 93\% yield). ${ }^{1} \mathrm{H}$ NMR (300 MHz, $\left.\mathrm{CDCl}_{3}\right) \delta 7.04$ (br s, $\left.1 \mathrm{H}\right), 5.38(\mathrm{~s}, 1 \mathrm{H}), 4.75(\mathrm{~m}, 1 \mathrm{H}), 3.31(\mathrm{~m}, 1 \mathrm{H})$, 3.14 (m, 1 H), 2.62-2.46 (m, 2 H), 2.34-2.25 (m, 2 H), 2.08-1.92 (m, 2 H), 1.83-1.19 (m, 9 H), 1.39 (s, $3 \mathrm{H}), 1.26$ (br s, $18 \mathrm{H}), 0.97$ (d, $J=5.6 \mathrm{~Hz}, 3 \mathrm{H}), 0.88$ (t, $J=7.4 \mathrm{~Hz}, 3 \mathrm{H}), 0.87$ (d, $J=$ $7.6 \mathrm{~Hz}, 3 \mathrm{H}), 1.00-0.88(\mathrm{~m}, 1 \mathrm{H}) ;{ }^{13} \mathrm{C} \mathrm{NMR}\left(\mathrm{CDCl}_{3}, 75 \mathrm{MHz}\right) \delta 171.35,102.71,89.87,80.63$, $69.75,51.67,43.37,39.31,37.38,37.19,36.38,34.10,31.77,30.27,29.51,29.50,29.44,29.39$, $29.32,29.20,29.16,26.83,25.63,24.66,24.62,22.52,19.84,13.96,11.97 ; \mathrm{IR}\left(\mathrm{CH}_{2} \mathrm{Cl}_{2}\right) 2921$, $1653,1458,1377 \mathrm{~cm}^{-1}$; MS (FAB) $m / z 494\left([\mathrm{M}+\mathrm{H}]^{+}\right)$; HRMS (FAB) $m / z$ for $\mathrm{C}_{29} \mathrm{H}_{52} \mathrm{O}_{5} \mathrm{~N}([\mathrm{M}+$ $\mathrm{H}]^{+}$), calcd 494.3845, found 494.3849. 
6g was prepared according to the General Procedure 1 using $n$-tetradecylamine. (Colorless oil, 90\% yield). ${ }^{1} \mathrm{H}$ NMR (300 MHz, $\left.\mathrm{CDCl}_{3}\right) \delta 7.00$ (br s, $\left.1 \mathrm{H}\right), 5.37(\mathrm{~s}, 1 \mathrm{H}), 4.75(\mathrm{~m}, 1 \mathrm{H}), 3.33(\mathrm{~m}$, $1 \mathrm{H}), 3.15$ (m, $1 \mathrm{H}), 2.62-2.46$ (m, $2 \mathrm{H}), 2.34-2.25$ (m, $2 \mathrm{H}), 2.08-1.93$ (m, $2 \mathrm{H}), 1.83-1.19$ (m, $9 \mathrm{H}), 1.39$ (s, $3 \mathrm{H}), 1.25$ (br s, $22 \mathrm{H}), 0.97$ (d, J = 5.6 Hz, $3 \mathrm{H}), 0.88$ (t, J = 7.4 Hz, $3 \mathrm{H}), 0.87$ (d, $J=7.4 \mathrm{~Hz}, 3 \mathrm{H}), 1.00-0.88(\mathrm{~m}, 1 \mathrm{H}) ;{ }^{13} \mathrm{C} \mathrm{NMR}\left(75 \mathrm{MHz}, \mathrm{CDCl}_{3}\right) \delta 171.49,102.87,90.05,80.79$, $69.82,51.80,43.48,39.46,37.48,37.33,36.52,34.22,31.90,30.42,29.68,29.65,29.58,29.52$, 29.46, 29.34, 29.29, 26.97, 25.77, 24.79, 22.66, 19.97, 14.09, 12.07; IR $\left(\mathrm{CH}_{2} \mathrm{Cl}_{2}\right)$ 2922, 1654, 1458, $1377 \mathrm{~cm}^{-1}$; MS (EI) $\mathrm{m} / z, 521\left(\mathrm{M}^{+}\right)$; HRMS (EI) $\mathrm{m} / z$ for $\mathrm{C}_{31} \mathrm{H}_{55} \mathrm{O}_{5} \mathrm{~N}\left(\mathrm{M}^{+}\right)$, calcd 521.4080 found 521.4076 .

6h was prepared according to the General Procedure 1 using $n$-hexadecylamine. (Colorless oil, 89\% yield). ${ }^{1} \mathrm{H}$ NMR (300 MHz, $\left.\mathrm{CDCl}_{3}\right) \delta 7.02$ (br s, $\left.1 \mathrm{H}\right), 5.38(\mathrm{~s}, 1 \mathrm{H}), 4.76(\mathrm{~m}, 1 \mathrm{H}), 3.33(\mathrm{~m}$, $1 \mathrm{H}), 3.15$ (m, $1 \mathrm{H}), 2.62-2.46$ (m, $2 \mathrm{H}), 2.34-2.25$ (m, $2 \mathrm{H}), 2.08-1.95$ (m, $2 \mathrm{H}), 1.83-1.19$ (m, $9 \mathrm{H}), 1.39$ (s, $3 \mathrm{H}), 1.25$ (br s, $26 \mathrm{H}), 0.97$ (d, J = 5.6 Hz, $3 \mathrm{H}), 0.88$ (t, $J=6.0 \mathrm{~Hz}, 3 \mathrm{H}), 0.87$ (d, $J=7.4 \mathrm{~Hz}, 3 \mathrm{H}), 1.00-0.88(\mathrm{~m}, 1 \mathrm{H}) ;{ }^{13} \mathrm{C} \mathrm{NMR}\left(75 \mathrm{MHz}, \mathrm{CDCl}_{3}\right) \delta 171.45,102.83,90.01,80.76$, $69.80,51.77,43.45,39.43,37.50,37.29,36.49,34.19,31.87,30.38,29.65,29.61,29.55,29.49$, 29.43, 29.31, 29.26, 26.94, 25.74, 24.75, 22.63, 19.94, 14.06, 12.05; IR $\left(\mathrm{CH}_{2} \mathrm{Cl}_{2}\right) 2923,1654$, 1458, $1377 \mathrm{~cm}^{-1}$; MS (EI) $\mathrm{m} / z, 549\left(\mathrm{M}^{+}\right)$; HRMS (EI) $\mathrm{m} / z$ for $\mathrm{C}_{33} \mathrm{H}_{59} \mathrm{O}_{5} \mathrm{~N}\left(\mathrm{M}^{+}\right)$, calcd 549.4393, found 549.4394 .

6i was prepared according to the General Procedure 1 using $n$-octadecylamine. (Colorless oil, 88\% yield). ${ }^{1} \mathrm{H}$ NMR (300 MHz, $\left.\mathrm{CDCl}_{3}\right) \delta 7.01$ (br s, $\left.1 \mathrm{H}\right), 5.38(\mathrm{~s}, 1 \mathrm{H}), 4.76(\mathrm{~m}, 1 \mathrm{H}), 3.33(\mathrm{~m}$, $1 \mathrm{H}), 3.15$ (m, $1 \mathrm{H}), 2.62-2.46$ (m, $2 \mathrm{H}), 2.36-2.27$ (m, $2 \mathrm{H}), 2.08-1.95$ (m, $2 \mathrm{H}), 1.83-1.19$ (m, 
$9 \mathrm{H}), 1.39$ (s, $3 \mathrm{H}), 1.25$ (br s, $30 \mathrm{H}), 0.97(\mathrm{~d}, J=5.5 \mathrm{~Hz}, 3 \mathrm{H}), 0.88$ (t, $J=6.1 \mathrm{~Hz}, 3 \mathrm{H}), 0.87$ (d, $J=7.4 \mathrm{~Hz}, 3 \mathrm{H}), 1.00-0.88(\mathrm{~m}, 1 \mathrm{H}) ;{ }^{13} \mathrm{C} \mathrm{NMR}\left(75 \mathrm{MHz}, \mathrm{CDCl}_{3}\right) \delta 171.47,102.85,90.03,80.77$, $69.81,51.79,43.46,39.44,37.52,37.31,36.50,34.21,31.89,30.40,29.67,29.57,29.51,29.44$ 29.32, 29.28, 26.95, 25.76, 24.77, 22.65, 19.96, 14.08, 12.06; IR $\left(\mathrm{CH}_{2} \mathrm{Cl}_{2}\right)$ 2920, 1654, 1458, $1377 \mathrm{~cm}^{-1}$; MS (EI) $\mathrm{m} / z 577\left(\mathrm{M}^{+}\right)$; HRMS (EI) $\mathrm{m} / z$ for $\mathrm{C}_{35} \mathrm{H}_{63} \mathrm{O}_{5} \mathrm{~N}\left(\mathrm{M}^{+}\right)$, calcd 577.4706, found 577.4702.

General Procedure 2: preparation of 7 (preparation of 7 a was chosen as an example)

To a solution of $5(33 \mathrm{mg}, 0.10 \mathrm{mmol})$ in $\mathrm{CH}_{2} \mathrm{Cl}_{2}(10 \mathrm{~mL})$ at room temperature was added 1(3-dimethylaminopropyl)-3-ethylcarbodiimide hydrochloride (EDCI) (58 mg, $0.30 \mathrm{mmol}$ ). After stirring for $5 \mathrm{~min}$, 4-dimethylaminopyridine (DMAP) $(61 \mathrm{mg}, 0.50 \mathrm{mmol})$ and anhydrous ethanol (20 $\mu \mathrm{L}, 0.30 \mathrm{mmol})$ were added. The resulting mixture was stirred overnight at room temperature. The mixture was diluted with ethyl acetate $(20 \mathrm{~mL})$, washed with saturated $\mathrm{NH}_{4} \mathrm{Cl}$ solution, water, and brine, dried over anhydrous $\mathrm{Na}_{2} \mathrm{SO}_{4}$, filtered, and concentrated under reduced pressure. The residue was purified by flash column chromatography to give 7a (35 mg, 0.098 mmol, 98\% yield) as a colorless oil. ${ }^{1} \mathrm{H}$ NMR $\left(300 \mathrm{MHz}, \mathrm{CDCl}_{3}\right) \delta 5.33(\mathrm{~s}, 1 \mathrm{H}), 4.81(\mathrm{~m}, 1 \mathrm{H})$, 4.16 (m, $2 \mathrm{H}), 2.79-2.54(\mathrm{~m}, 2 \mathrm{H}), 2.49-2.26(\mathrm{~m}, 2 \mathrm{H}), 2.05-1.21(\mathrm{~m}, 9 \mathrm{H}), 1.41(\mathrm{~s}, 3 \mathrm{H}), 1.27$ (t, $J=7.1 \mathrm{~Hz}, 3 \mathrm{H}), 0.96(\mathrm{~d}, J=5.9 \mathrm{~Hz}, 3 \mathrm{H}), 0.87(\mathrm{~d}, J=7.5 \mathrm{~Hz}, 3 \mathrm{H}), 1.00-0.88(\mathrm{~m}, 1 \mathrm{H}) ;{ }^{13} \mathrm{C}$ NMR (75 MHz, $\left.\mathrm{CDCl}_{3}\right) \delta 171.58,103.17,89.04,80.81,71.54,60.58,52.21,44.18,37.41,36.47$, 36.03, 34.39, 29.67, 25.91, 24.67, 24.60, 20.11, 14.17, 12.97; IR $\left(\mathrm{CH}_{2} \mathrm{Cl}_{2}\right) 2919,1739,1463$, 1378, 1094, 1016, $873 \mathrm{~cm}^{-1}$; MS (EI) $\mathrm{m} / z 322\left(\left[\mathrm{M}-\mathrm{O}_{2}\right]^{+}\right)$; HRMS (EI) $\mathrm{m} / z$ for $\mathrm{C}_{29} \mathrm{H}_{50} \mathrm{O}_{6}([\mathrm{M}-$ $\left.\mathrm{O}_{2}\right]^{+}$), calcd 322.2144, found 322.2133. 
7b was prepared according to the General Procedure 2 using $n$-dodecanol. (Colorless oil, 95\% yield). ${ }^{1} \mathrm{H}$ NMR (300 MHz, $\left.\mathrm{CDCl}_{3}\right) \delta 5.32(\mathrm{~s}, 1 \mathrm{H}), 4.79(\mathrm{~m}, 1 \mathrm{H}), 4.10(\mathrm{~m}, 2 \mathrm{H}), 2.79-2.54(\mathrm{~m}, 2$ H), 2.47-2.27 (m, 2 H), 2.05-1.21 (m, $11 \mathrm{H}), 1.41(\mathrm{~s}, 3 \mathrm{H}), 1.26(\mathrm{br} \mathrm{s}, 18 \mathrm{H}), 0.96(\mathrm{~d}, J=5.8 \mathrm{~Hz}$ $3 \mathrm{H}), 0.88(\mathrm{t}, J=6.5 \mathrm{~Hz}, 3 \mathrm{H}), 0.86(\mathrm{~d}, J=7.9 \mathrm{~Hz}, 3 \mathrm{H}), 1.00-0.88(\mathrm{~m}, 1 \mathrm{H}) ;{ }^{13} \mathrm{C} \mathrm{NMR}(75 \mathrm{MHz}$, $\left.\mathrm{CDCl}_{3}\right) \delta 171.69,103.24,89.06,80.86,71.66,64.90,52.31,44.28,37.47,36.54,36.07,34.47$, $31.92,29.73,29.66,29.64,29.59,29.53,29.35,29.29,28.63,25.98,25.91,24.73,24.67,22.69$, 20.16, 14.11, 13.04; IR $\left(\mathrm{CH}_{2} \mathrm{Cl}_{2}\right) 2919,1735,1458,1377,1092,1016 \mathrm{~cm}^{-1} ; \mathrm{MS}(\mathrm{EI}) \mathrm{m} / \mathrm{z} 494$ $\left(\mathrm{M}^{+}\right)$; HRMS (EI) $m / z$ for $\mathrm{C}_{29} \mathrm{H}_{50} \mathrm{O}_{6}\left(\mathbf{M}^{+}\right)$, calcd 494.3607, found 494.3608.

7c was prepared according to the General Procedure 2 using $n$-octadecanol. (Colorless oil, 93\% yield). ${ }^{1} \mathrm{H}$ NMR (300 MHz, $\left.\mathrm{CDCl}_{3}\right) \delta 5.32(\mathrm{~s}, 1 \mathrm{H}), 4.80(\mathrm{~m}, 1 \mathrm{H}), 4.10(\mathrm{~m}, 2 \mathrm{H}), 2.78-2.55$ (m, 2 H), 2.49-2.28 (m, 2 H), 2.06-1.21 (m, $11 \mathrm{H}), 1.41(\mathrm{~s}, 3 \mathrm{H}), 1.26$ (br s, $30 \mathrm{H}), 0.96(\mathrm{~d}, J=5.9 \mathrm{~Hz}$ $3 \mathrm{H}), 0.88(\mathrm{t}, J=6.5 \mathrm{~Hz}, 3 \mathrm{H}), 0.86(\mathrm{~d}, J=7.5 \mathrm{~Hz}, 3 \mathrm{H}), 1.00-0.88(\mathrm{~m}, 1 \mathrm{H}) ;{ }^{13} \mathrm{C} \mathrm{NMR}(75 \mathrm{MHz}$, $\left.\mathrm{CDCl}_{3}\right) \delta 171.69,103.23,89.03,80.84,71.67,64.89,52.28,44.25,37.45,36.51,36.02,34.45$, $31.92,29.70,29.66,29.60,29.53,29.36,29.28,28.61,25.97,25.90,24.71,24.65,22.69,20.16$, 14.12, 13.04; IR $\left(\mathrm{CH}_{2} \mathrm{Cl}_{2}\right)$ 2922, 1739, 1463, 1378, 1094, $1015 \mathrm{~cm}^{-1}$; MS (EI) $\mathrm{m} / \mathrm{z} 578\left(\mathrm{M}^{+}\right)$; HRMS (EI) $m / z$ for $\mathrm{C}_{35} \mathrm{H}_{62} \mathrm{O}_{6}\left(\mathrm{M}^{+}\right)$, calcd 578.4546, found 578.4553 .

General Procedure 3: preparation of $\mathbf{8}$ (preparation of $\mathbf{8 b}$ was chosen as an example)

A solution of dodecylmagnesium bromide (calcd as $0.2 \mathrm{M}$ ) in diethyl ether was freshly prepared from the reaction of acid-washed anhydrous magnesium powder $(50 \mathrm{mg}, 2.1 \mathrm{mmol}$ ) with dodecylbromide (550 mg, $2.2 \mathrm{mmol})$ in $10 \mathrm{~mL}$ of dried diethyl ether. 
To a solution of $4(31 \mathrm{mg}, 0.10 \mathrm{mmol})$ in dried diethyl ether $(5 \mathrm{~mL})$ at $-40{ }^{\circ} \mathrm{C}$ under argon was added the freshly prepared dodecylmagnesium bromide solution $(0.2 \mathrm{mmol}, 1 \mathrm{~mL}$ of $0.2 \mathrm{M}$ solution in diethyl ether), and the reaction mixture was stirred at $-40{ }^{\circ} \mathrm{C}$. After the starting material 4 disappeared in $0.5 \mathrm{~h}$ as indicated by TLC, the reaction was quenched with saturated $\mathrm{NH}_{4} \mathrm{Cl}$ solution. The mixture was extracted with ether $(3 \times 20 \mathrm{~mL})$, and the combined organic layers were washed with brine, dried over anhydrous $\mathrm{Na}_{2} \mathrm{SO}_{4}$ and concentrated. Flash column chromatography of the residue provided two diastereomeric alcohols in a ratio of around 2:1.

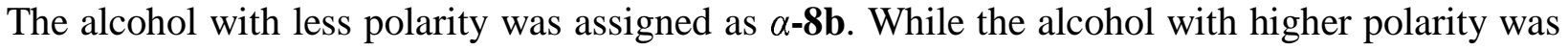
assigned as $\beta-8 \mathbf{b}$ (i.e. $\alpha-8 \mathbf{b}: \beta-8 \mathbf{b} \approx 2: 1$ ). $\alpha-8 \mathbf{b}$ (Colorless oil, $30 \mathrm{mg}, 0.062 \mathrm{mmol}, 62 \%$ yield). ${ }^{1} \mathrm{H}$ NMR (400 MHz, $\left.\mathrm{CDCl}_{3}\right) \delta 5.37(\mathrm{~s}, 1 \mathrm{H}), 4.51(\mathrm{~m}, 1 \mathrm{H}), 3.81(\mathrm{~m}, 1 \mathrm{H}), 3.68(\mathrm{~s}, 1 \mathrm{H}), 2.62(\mathrm{~m}, 1$ H), $2.32(\mathrm{~m}, 1 \mathrm{H}), 2.07-1.86(\mathrm{~m}, 2 \mathrm{H}), 1.83-1.21(\mathrm{~m}, 13 \mathrm{H}), 1.40$ (s, $3 \mathrm{H}), 1.26$ (br s, $18 \mathrm{H}), 0.96$ $(\mathrm{d}, J=5.8 \mathrm{~Hz}, 3 \mathrm{H}), 0.88(\mathrm{t}, J=6.6 \mathrm{~Hz}, 3 \mathrm{H}), 0.86(\mathrm{~d}, J=7.6 \mathrm{~Hz}, 3 \mathrm{H}), 1.00-0.88(\mathrm{~m}, 1 \mathrm{H}) ;{ }^{13} \mathrm{C}$ NMR $\left(100 \mathrm{MHz}, \mathrm{CDCl}_{3}\right) \delta 103.14,89.26,81.03,76.18,73.36,52.20,43.97,37.48,36.51,36.22$, $34.40,31.94,30.64,29.79,29.70,29.67,29.38,25.99,25.56,24.81,24.77,22.71,20.16,14.14$, 12.82; IR $\left(\mathrm{CH}_{2} \mathrm{Cl}_{2}\right)$ 2921, 1464, 1377, $1015 \mathrm{~cm}^{-1}$; MS (FAB) $\mathrm{m} / z 481\left([\mathrm{M}+\mathrm{H}]^{+}\right)$; HRMS (EI) $m / z$ for $\mathrm{C}_{29} \mathrm{H}_{50} \mathrm{O}_{4}\left(\left[\mathrm{M}-\mathrm{H}_{2} \mathrm{O}\right]^{+}\right)$, calcd 462.3709 , found 462.3716 .

$\beta$-8b (Colorless oil, $12 \mathrm{mg}, 0.026 \mathrm{mmol}, 26 \%$ yield). ${ }^{1} \mathrm{H} \mathrm{NMR}\left(300 \mathrm{MHz}, \mathrm{CDCl}_{3}\right) \delta 5.32(\mathrm{~s}, 1 \mathrm{H}$ ), $4.62(\mathrm{~m}, 1 \mathrm{H}), 3.87$ (m, $1 \mathrm{H}), 2.63$ (m, $1 \mathrm{H}), 2.37-2.28$ (m, $2 \mathrm{H}), 2.07-1.87$ (m, $2 \mathrm{H}), 1.85-1.21$ $(\mathrm{m}, 13 \mathrm{H}), 1.41(\mathrm{~s}, 3 \mathrm{H}), 1.26(\mathrm{br} \mathrm{s}, 18 \mathrm{H}), 0.96(\mathrm{~d}, J=5.7 \mathrm{~Hz}, 3 \mathrm{H}), 0.88(\mathrm{t}, J=6.5 \mathrm{~Hz}, 3 \mathrm{H})$, $0.84(\mathrm{~d}, J=8.0 \mathrm{~Hz}, 3 \mathrm{H}), 1.00-0.88(\mathrm{~m}, 1 \mathrm{H}) ;{ }^{13} \mathrm{C} \mathrm{NMR}\left(75 \mathrm{MHz}, \mathrm{CDCl}_{3}\right) \delta 103.11,89.50,81.08$, $71.00,69.44,52.30,44.17,37.53,37.10,36.61,35.87,34.43,31.94,30.22,29.78,29.69,29.66$, 29.37, 26.05, 24.86, 24.78, 22.70, 20.14, 14.12, 12.83; $\mathrm{IR}\left(\mathrm{CH}_{2} \mathrm{Cl}_{2}\right) 2918,1464,1378,1019 \mathrm{~cm}^{-1}$; 
MS (FAB) $m / z 481\left([\mathrm{M}+\mathrm{H}]^{+}\right)$; HRMS (EI) $m / z$ for $\mathrm{C}_{29} \mathrm{H}_{50} \mathrm{O}_{4}\left(\left[\mathrm{M}-\mathrm{H}_{2} \mathrm{O}\right]^{+}\right)$, calcd 462.3709, found 462.3706 .

$\alpha-8 \mathbf{c}$ was prepared according to the General Procedure 3 using $n$-octadecylbromide. (Colorless oil, $60 \%$ yield). ${ }^{1} \mathrm{H}$ NMR (300 MHz, $\left.\mathrm{CDCl}_{3}\right) \delta 5.37(\mathrm{~s}, 1 \mathrm{H}), 4.51(\mathrm{~m}, 1 \mathrm{H}), 3.80(\mathrm{~m}, 1 \mathrm{H}), 3.67(\mathrm{~s}$, $1 \mathrm{H}), 2.62(\mathrm{~m}, 1 \mathrm{H}), 2.30(\mathrm{~m}, 1 \mathrm{H}), 2.06-1.86(\mathrm{~m}, 2 \mathrm{H}), 1.83-1.21$ (m, $13 \mathrm{H}), 1.40(\mathrm{~s}, 3 \mathrm{H}), 1.25$ (br s, $30 \mathrm{H}), 0.96(\mathrm{~d}, J=5.8 \mathrm{~Hz}, 3 \mathrm{H}), 0.88(\mathrm{t}, J=6.5 \mathrm{~Hz}, 3 \mathrm{H}), 0.86(\mathrm{~d}, J=7.6 \mathrm{~Hz}, 3 \mathrm{H}), 1.00$ $0.88(\mathrm{~m}, 1 \mathrm{H}) ;{ }^{13} \mathrm{C} \mathrm{NMR}\left(75 \mathrm{MHz}, \mathrm{CDCl}_{3}\right) \delta 103.05,89.27,81.02,76.13,73.34,52.22,43.97$, $37.48,36.52,36.25,34.45,31.95,30.71,29.80,29.72,29.68,29.39,25.99,25.56,24.81,24.78$ 22.71, 20.15, 14.13, 12.80; IR $\left(\mathrm{CH}_{2} \mathrm{Cl}_{2}\right) 2922,1464,1377,1015 \mathrm{~cm}^{-1}$; MS (EI) $\mathrm{m} / z 564\left(\mathrm{M}^{+}\right)$; HRMS (EI) $m / z$ for $\mathrm{C}_{35} \mathrm{H}_{64} \mathrm{O}_{5}\left(\mathrm{M}^{+}\right)$, calcd 564.4754, found 564.4745.

$\beta$-8c (Colorless oil, 20\% yield). ${ }^{1} \mathrm{H}$ NMR $\left(300 \mathrm{MHz}, \mathrm{CDCl}_{3}\right) \delta 5.32(\mathrm{~s}, 1 \mathrm{H}), 4.62(\mathrm{~m}, 1 \mathrm{H}), 3.87$ (m, $1 \mathrm{H}), 2.62(\mathrm{~m}, 1 \mathrm{H}), 2.37-2.28(\mathrm{~m}, 2 \mathrm{H}), 2.07-1.87$ (m, $2 \mathrm{H}), 1.85-1.21(\mathrm{~m}, 13 \mathrm{H}), 1.41(\mathrm{~s}, 3$ H), $1.26(\mathrm{br} \mathrm{s}, 30 \mathrm{H}), 0.96(\mathrm{~d}, J=5.8 \mathrm{~Hz}, 3 \mathrm{H}), 0.88(\mathrm{t}, J=6.5 \mathrm{~Hz}, 3 \mathrm{H}), 0.84(\mathrm{~d}, J=8.0 \mathrm{~Hz}, 3 \mathrm{H})$, $1.00-0.88(\mathrm{~m}, 1 \mathrm{H}) ;{ }^{13} \mathrm{C}$ NMR $\left(75 \mathrm{MHz}, \mathrm{CDCl}_{3}\right) \delta 103.12,89.52,81.10,71.00,69.42,52.24$, $44.19,37.55,37.16,36.63,35.94,34.45,31.96,30.34,29.80,29.73,29.69,29.39,26.06,24.89$, 24.80, 22.72, 20.15, 14.14, 12.84; IR $\left(\mathrm{CH}_{2} \mathrm{Cl}_{2}\right)$ 2922, 1465, 1377, $1016 \mathrm{~cm}^{-1}$; MS (EI) $\mathrm{m} / z 564$ $\left(\mathrm{M}^{+}\right)$; HRMS (EI) $\mathrm{m} / z$ for $\mathrm{C}_{35} \mathrm{H}_{64} \mathrm{O}_{5}\left(\mathrm{M}^{+}\right)$, calcd 564.4754, found 564.4746.

General Procedure 4: synthesis of 9 (synthesis of $\mathbf{9 b}$ was chosen as an example)

To a solution of $\mathbf{8 b}(48 \mathrm{mg}, 0.10 \mathrm{mmol})$ in $\mathrm{CH}_{2} \mathrm{Cl}_{2}(10 \mathrm{~mL})$ at room temperature was added pyridinium dichromate (PDC) $(75 \mathrm{mg}, 0.20 \mathrm{mmol})$. After the disappearance of starting material 
$\mathbf{8 b}$ as indicated by TLC, the reaction mixture was diluted with diethyl ether $(30 \mathrm{~mL})$, washed with saturated $\mathrm{NH}_{4} \mathrm{Cl}$ solution, water, and brine, dried over anhydrous $\mathrm{Na}_{2} \mathrm{SO}_{4}$, filtered, and concentrated under reduced pressure. The residue was purified by flash column chromatography to give $9 \mathbf{b}$ (42 mg, $0.088 \mathrm{mmol}, 88 \%$ yield) as a colorless oil. ${ }^{1} \mathrm{H}$ NMR (300 MHz, $\left.\mathrm{CDCl}_{3}\right) \delta 5.30$ (s, $1 \mathrm{H}), 4.88(\mathrm{~m}, 1 \mathrm{H}), 2.76-2.65(\mathrm{~m}, 2 \mathrm{H}), 2.54-2.27(\mathrm{~m}, 4 \mathrm{H}), 2.07-1.87(\mathrm{~m}, 2 \mathrm{H}), 1.82-1.21$ (m, $9 \mathrm{H}), 1.41(\mathrm{~s}, 3 \mathrm{H}), 1.25$ (br s, $18 \mathrm{H}), 0.97$ (d, $J=5.8 \mathrm{~Hz}, 3 \mathrm{H}), 0.88(\mathrm{t}, J=6.5 \mathrm{~Hz}, 3 \mathrm{H}), 0.84$ $(\mathrm{d}, J=7.6 \mathrm{~Hz}, 3 \mathrm{H}), 1.00-0.88(\mathrm{~m}, 1 \mathrm{H}) ;{ }^{13} \mathrm{C} \mathrm{NMR}\left(75 \mathrm{MHz}, \mathrm{CDCl}_{3}\right) \delta 209.40,103.04,89.49$, $80.93,70.25,52.09,44.33,44.04,42.71,37.54,36.58,34.42,31.93,29.94,29.67,29.64,29.51$, 29.48, 29.36, 29.23, 25.93, 24.80, 24.69, 23.57, 22.70, 20.11, 14.12, 12.90; IR $\left(\mathrm{CH}_{2} \mathrm{Cl}_{2}\right) 2922$, 1716, 1465, 1377, $1012 \mathrm{~cm}^{-1}$; MS (FAB) $m / z 479\left([\mathrm{M}+\mathrm{H}]^{+}\right)$; HRMS (EI) $m / z$ for $\mathrm{C}_{29} \mathrm{H}_{50} \mathrm{O}_{5}\left(\mathrm{M}^{+}\right)$, calcd 478.3658, found 478.3652.

9c was prepared from 8c according to the General Procedure 4. (Colorless oil, $85 \%$ yield). ${ }^{1} \mathrm{H}$ NMR $\left(300 \mathrm{MHz}, \mathrm{CDCl}_{3}\right) \delta 5.30(\mathrm{~s}, 1 \mathrm{H}), 4.88(\mathrm{~m}, 1 \mathrm{H}), 2.76-2.65(\mathrm{~m}, 2 \mathrm{H}), 2.54-2.27(\mathrm{~m}, 4 \mathrm{H})$, 2.06-1.87 (m, 2 H), 1.82-1.21 (m, 9 H), 1.40 (s, $3 \mathrm{H}), 1.25$ (br s, $32 \mathrm{H}), 0.98(\mathrm{~d}, J=5.6 \mathrm{~Hz}, 3 \mathrm{H})$, $0.88(\mathrm{t}, J=6.4 \mathrm{~Hz}, 3 \mathrm{H}), 0.84(\mathrm{~d}, J=7.8 \mathrm{~Hz}, 3 \mathrm{H}), 1.00-0.88(\mathrm{~m}, 1 \mathrm{H}) ;{ }^{13} \mathrm{C} \mathrm{NMR}(75 \mathrm{MHz}$, $\left.\mathrm{CDCl}_{3}\right) \delta 209.42,103.05,89.52,80.95,70.27,52.12,44.36,44.07,42.73,37.57,36.61,34.44$ $31.96,29.94,29.73,29.70,29.66,29.53,29.50,29.39,29.26,25.95,24.82,24.71,23.60,22.72$, 20.13, 14.14, 12.92; IR $\left(\mathrm{CH}_{2} \mathrm{Cl}_{2}\right) 2920,1716,1464,1377,1017 \mathrm{~cm}^{-1} ; \mathrm{MS}(\mathrm{FAB}) \mathrm{m} / \mathrm{z}, 563([\mathrm{M}+$ $\left.\mathrm{H}]^{+}\right)$; HRMS (FAB) $m / z$ for $\mathrm{C}_{35} \mathrm{H}_{62} \mathrm{O}_{5}\left([\mathrm{M}+\mathrm{H}]^{+}\right)$, calcd 563.4676, found 563.4672.

9d was prepared according to the General Procedures 3 and 4 using $n$-octylbromide. (Colorless oil, $82 \%$ yield for 2 steps). ${ }^{1} \mathrm{H}$ NMR $\left(300 \mathrm{MHz}, \mathrm{CDCl}_{3}\right) \delta 5.30(\mathrm{~s}, 1 \mathrm{H}), 4.88(\mathrm{~m}, 1 \mathrm{H}), 2.76-2.68$ 
(m, 2 H), 2.55-2.48 (m, 2 H), 2.41-2.20 (m, 2 H), 2.06-1.89 (m, 2 H), 1.81-1.21 (m, 9 H), 1.40 $(\mathrm{s}, 3 \mathrm{H}), 1.26(\mathrm{br} \mathrm{s}, 10 \mathrm{H}), 0.96(\mathrm{~d}, J=5.7 \mathrm{~Hz}, 3 \mathrm{H}), 0.88(\mathrm{t}, J=6.3 \mathrm{~Hz}, 3 \mathrm{H}), 0.83(\mathrm{~d}, J=7.5 \mathrm{~Hz}$, $3 \mathrm{H}), 1.00-0.88(\mathrm{~m}, 1 \mathrm{H}) ;{ }^{13} \mathrm{C} \mathrm{NMR}\left(75 \mathrm{MHz}, \mathrm{CDCl}_{3}\right) \delta 209.38,103.03,89.49,80.94,70.25$, $52.09,44.34,44.04,42.70,37.54,36.58,34.42,31.84,29.94,29.44,29.23,29.16,25.93,24.80$, 24.69, 23.56, 21.66, 20.11, 14.10, 12.90; IR $\left(\mathrm{CH}_{2} \mathrm{Cl}_{2}\right) 2918,1716,1465,1377,1016 \mathrm{~cm}^{-1}$; MS (EI) $m / z 422\left(\mathrm{M}^{+}\right)$; HRMS (EI) $m / z$ for $\mathrm{C}_{25} \mathrm{H}_{42} \mathrm{O}_{5}\left(\mathrm{M}^{+}\right)$, calcd 422.3032, found 422.3020 .

\section{Preparation of 10}

To a solution of $4(31 \mathrm{mg}, 0.10 \mathrm{mmol})$ in dried diethyl ether $(10 \mathrm{~mL})$ at $-40{ }^{\circ} \mathrm{C}$ under argon was added a solution of ( $\omega$-tert-butyldimethylsilanoxyl) octyl magnesium bromide (TBDMSOCH $2\left(\mathrm{CH}_{2}\right)_{6} \mathrm{CH}_{2} \mathrm{MgBr}, 0.2 \mathrm{mmol}$, freshly prepared according to the General Procedure 3) in diethyl ether. After the disappearance of starting material $\mathbf{4}$ as indicated by TLC, the reaction was quenched with saturated aqueous $\mathrm{NH}_{4} \mathrm{Cl}$ solution. The mixture was extracted with ether $(3 \times 20 \mathrm{~mL})$, and the combined organic layers were washed with brine, dried over anhydrous $\mathrm{Na}_{2} \mathrm{SO}_{4}$ and concentrated. The alcohol was dissolved in $\mathrm{CH}_{2} \mathrm{Cl}_{2}(10 \mathrm{~mL})$ and oxidized by pyridine dichromate (PDC) $(75 \mathrm{mg}, 0.20 \mathrm{mmol})$ at room temperature. After completion, the mixture was diluted with diethyl ether $(30 \mathrm{~mL})$, washed with saturated $\mathrm{NH}_{4} \mathrm{Cl}$ solution, water, and brine, dried over anhydrous $\mathrm{Na}_{2} \mathrm{SO}_{4}$, filtered, and concentrated under reduced pressure. The resulting ketone was dissolved in acetone $(5 \mathrm{~mL})$ and treated with a catalytic amount of $p$ toluene sulfonic acid at room temperature, and the deprotection of TBDMS ether was monitored by TLC. After completion, the mixture was diluted with water $(20 \mathrm{~mL})$ and extracted with ethyl acetate $(3 \times 20 \mathrm{~mL})$. The combined organic layers were washed with water, brine, dried over anhydrous $\mathrm{Na}_{2} \mathrm{SO}_{4}$, filtered, and concentrated under reduced pressure. The residue was purified 
by flash column chromatography to give $\mathbf{1 0}(26 \mathrm{mg}, 0.06 \mathrm{mmol}, 60 \%$ total yield for 3 steps) as a colorless oil. ${ }^{1} \mathrm{H}$ NMR (300 MHz, $\left.\mathrm{CDCl}_{3}\right) \delta 5.30(\mathrm{~s}, 1 \mathrm{H}), 4.87(\mathrm{~m}, 1 \mathrm{H}), 3.63(\mathrm{t}, J=6.6 \mathrm{~Hz}, 2 \mathrm{H})$, 2.67-2.62 (m, 2H), 2.55-2.48 (m, $2 \mathrm{H}), 2.44-2.22(\mathrm{~m}, 2 \mathrm{H}), 2.06-1.82(\mathrm{~m}, 2 \mathrm{H}), 1.81-1.21(\mathrm{~m}$, $11 \mathrm{H}), 1.40(\mathrm{~s}, 3 \mathrm{H}), 1.30(\mathrm{br} \mathrm{s}, 8 \mathrm{H}), 0.96(\mathrm{~d}, J=5.8 \mathrm{~Hz}, 3 \mathrm{H}), 0.83(\mathrm{~d}, J=7.5 \mathrm{~Hz}, 3 \mathrm{H}), 1.00$ $0.88(\mathrm{~m}, 1 \mathrm{H}) ;{ }^{13} \mathrm{C}$ NMR $\left(75 \mathrm{MHz}, \mathrm{CDCl}_{3}\right) \delta 209.39,103.05,89.48,80.93,70.28,63.01,52.08$, $44.33,44.02,42.64,37.53,36.56,34.40,32.75,29.93,29.36,29.19,29.08,25.92,25.65,24.78$, 24.68, 23.46, 20.11, 12.90; IR $\left(\mathrm{CH}_{2} \mathrm{Cl}_{2}\right) 2918,1716,1464,1378,1017 \mathrm{~cm}^{-1}$; MS (EI) $\mathrm{m} / z, 420$ ([M - $\left.\left.\mathrm{H}_{2} \mathrm{O}\right]^{+}\right)$; HRMS (EI) $\mathrm{m} / z$ for $\mathrm{C}_{25} \mathrm{H}_{40} \mathrm{O}_{5}\left(\left[\mathrm{M}-\mathrm{H}_{2} \mathrm{O}\right]^{+}\right)$, calcd 420.2876, found 420.2869 .

\section{Preparation of 11}

To a solution of $10(44 \mathrm{mg}, 0.10 \mathrm{mmol})$ in acetone $(5 \mathrm{~mL})$ was added Jones reagent in portions $\left(0.1 \mathrm{~mL}, 5 \mathrm{M}\right.$ in water) at $0{ }^{\circ} \mathrm{C}$. After the disappearance of starting material $\mathbf{1 0}$ as indicated by TLC, the reaction mixture was diluted with water $(20 \mathrm{~mL})$. The mixture was extracted with ethyl acetate $(3 \times 20 \mathrm{~mL})$, and the combined organic layers were washed with brine, dried over anhydrous $\mathrm{Na}_{2} \mathrm{SO}_{4}$ and concentrated. The residue was purified by flash column chromatography to afford 11 (41 mg, 0.09 mmol, 90\% yield) as a colorless oil. ${ }^{1} \mathrm{H}$ NMR (300 $\left.\mathrm{MHz}, \mathrm{CDCl}_{3}\right) \delta 5.31(\mathrm{~s}, 1 \mathrm{H}), 4.87(\mathrm{~m}, 1 \mathrm{H}), 2.77-2.64(\mathrm{~m}, 2 \mathrm{H}), 2.55-2.48(\mathrm{~m}, 2 \mathrm{H}), 2.44-2.22$ (m, $2 \mathrm{H}), 2.06-1.84(\mathrm{~m}, 2 \mathrm{H}), 1.81-1.21(\mathrm{~m}, 11 \mathrm{H}), 1.40(\mathrm{~s}, 3 \mathrm{H}), 1.31$ (br s, $8 \mathrm{H}), 0.96$ (d, $J=5.6$ $\mathrm{Hz}, 3 \mathrm{H}), 0.84(\mathrm{~d}, J=7.5 \mathrm{~Hz}, 3 \mathrm{H}), 1.00-0.88(\mathrm{~m}, 1 \mathrm{H}) ;{ }^{13} \mathrm{C} \mathrm{NMR}\left(75 \mathrm{MHz}, \mathrm{CDCl}_{3}\right) \delta 209.39$, $178.84,103.10,89.46,80.94,70.36,52.09,44.29,44.04,42.60,37.52,36.56,34.41,33.86,29.94$, 28.97, 28.90, 28.83, 25.91, 24.78, 24.68, 24.61, 23.35, 20.12, 12.91; IR $\left(\mathrm{CH}_{2} \mathrm{Cl}_{2}\right) 2919,1733$, 1709, 1465, 1377, $1015 \mathrm{~cm}^{-1}$; MS (EI) $\mathrm{m} / z 406\left(\left[\mathrm{M}-\mathrm{H}_{2} \mathrm{O}-\mathrm{CO}\right]^{+}\right)$; HRMS (EI) $\mathrm{m} / \mathrm{z}$ for $\mathrm{C}_{24} \mathrm{H}_{38} \mathrm{O}_{3}\left(\left[\mathrm{M}-\mathrm{H}_{2} \mathrm{O}-\mathrm{CO}\right]^{+}\right)$, calcd 406.2719, found 406.2716. 


\section{Preparation of 12}

12 was prepared according to the General Procedure 1 using N-Allyl-N-octylamine. (Colorless oil, 98\% yield). Tertiary amide $\mathbf{1 2}$ gave two sets of data in ${ }^{1} \mathrm{H}$ NMR and ${ }^{13} \mathrm{C}$ NMR spectroscopy. ${ }^{1} \mathrm{H}$ NMR (400 MHz, $\left.\mathrm{CDCl}_{3}\right) \delta 5.72(\mathrm{~m}, 1 \mathrm{H}), 5.27$ (s, 1/2 H), 5.23 (s, 1/2 H), 5.18-5.04 (m, $\left.2 \mathrm{H}\right)$, 4.85 (m, $1 \mathrm{H}), 4.00-3.78$ (m, $2 \mathrm{H}), 3.32-3.10(\mathrm{~m}, 2 \mathrm{H}), 2.73-2.59$ (m, $2 \mathrm{H}), 2.41-2.23(\mathrm{~m}, 2 \mathrm{H})$, 1.98-1.19 (m, 11 H), 1.34 (s, 3 H), 1.21 (br s, 10 H), 0.90 (m, 3 H), 0.82-0.78 (m, 6 H), 1.00$0.88(\mathrm{~m}, 1 \mathrm{H}) ;{ }^{13} \mathrm{C}$ NMR $\left(100 \mathrm{MHz}, \mathrm{CDCl}_{3}\right) \delta 170.81,170.41,133.51,116.49,116.27,102.80$, $102.75,89.55,89.41,80.66,71.17,70.99,51.94,51.87,50.26,47.86,47.29,46.24,44.01,43.91$, $37.49,37.46,36.46,34.68,34.33,31.68,29.77,29.27,29.18,29.11,28.70,27.61,26.89,26.80$, 25.83, 25.79, 24.71, 24.69, 24.61, 22.50, 20.00, 13.96, 12.64, 12.59; IR $\left(\mathrm{CH}_{2} \mathrm{Cl}_{2}\right) 2922,1651$, 1463, 1377, $1014 \mathrm{~cm}^{-1}$; MS (EI) $\mathrm{m} / z 477\left(\mathrm{M}^{+}\right)$; HRMS (EI) $\mathrm{m} / z$ for $\mathrm{C}_{28} \mathrm{H}_{47} \mathrm{O}_{5} \mathrm{~N}\left(\mathrm{M}^{+}\right)$, calcd 477.3454, found 477.3436.

\section{Preparation of 13}

To a mixture of $12(48 \mathrm{mg}, 0.10 \mathrm{mmol})$ and $\mathrm{NaIO}_{4}(43 \mathrm{mg}, 0.20 \mathrm{mmol})$ in tetrahydrofuran $(10 \mathrm{~mL})$ and water $(2 \mathrm{~mL})$, was added a solution of $\mathrm{RuCl}_{3}(0.0035 \mathrm{mmol}, 35 \mu \mathrm{L}, 0.1 \mathrm{M}$ in water $)$ at room temperature, and the reaction was monitored by TLC. After completion in $1 \mathrm{~h}$, brine (15 $\mathrm{mL}$ ) was added to the reaction mixture, and two layers were separated. The aqueous layer was extracted with ethyl acetate $(3 \times 20 \mathrm{~mL})$, and the combined organic layers were washed with water and brine, dried over anhydrous $\mathrm{Na}_{2} \mathrm{SO}_{4}$, filtered, and concentrated under reduced pressure. The residue was purified by flash column chromatography to give $\mathbf{1 3}$ (33 mg, $0.065 \mathrm{mmol}, 65 \%$ yield) as a colorless oil. ${ }^{1} \mathrm{H}$ NMR $\left(300 \mathrm{MHz}, \mathrm{CDCl}_{3}\right) \delta 5.35(\mathrm{~s}, 1 / 2 \mathrm{H}), 5.30(\mathrm{~s}, 1 / 2 \mathrm{H}), 4.92(\mathrm{~m}, 1$ H), 3.84-3.10 (m, 7 H), 2.73-2.61 (m, 2 H), 2.47-2.23 (m, 2 H), 2.05-1.19 (m, 11 H), 1.40 (s, 
3/2 H), 1.35 (s, 3/2 H), 1.29 (br s, $10 \mathrm{H}), 0.97$ (m, $3 \mathrm{H}), 0.89-0.82$ (m, $6 \mathrm{H}), 1.00-0.88$ (m, $1 \mathrm{H})$;

${ }^{13} \mathrm{C}$ NMR $\left(75 \mathrm{MHz}, \mathrm{CDCl}_{3}\right) \delta 173.55,173.31,102.71,90.19,89.89,80.67,70.93,70.74,70.67$, $69.89,63.47,63.12,51.88,51.68,50.06,49.97,48.99,48.77,43.87,43.65,37.61,37.57,36.60$ $36.55,35.25,35.14,34.38,34.31,31.77,30.09,29.92,29.28,29.21,28.93,26.80,25.79,25.68$, 24.88, 24.78, 22.62, 20.06, 20.00, 14.08, 12.67, 12.51; IR $\left(\mathrm{CH}_{2} \mathrm{Cl}_{2}\right) 3375,2921,1654,1463$, $1378 \mathrm{~cm}^{-1}$; MS (FAB) $\mathrm{m} / z 512\left([\mathrm{M}+\mathrm{H}]^{+}\right)$; HRMS (FAB) $\mathrm{m} / z$ for $\mathrm{C}_{28} \mathrm{H}_{51} \mathrm{O}_{7} \mathrm{~N}\left([\mathrm{M}+\mathrm{H}]^{+}\right)$, calcd 512.3587, found 512.3578.

\section{Preparation of 14}

To a solution of $2(39 \mathrm{mg}, 0.10 \mathrm{mmol})$ in $\mathrm{CH}_{2} \mathrm{Cl}_{2}(10 \mathrm{~mL})$ was added anhydrous $\mathrm{ZnCl}_{2}(16$ $\mathrm{mg}, 0.12 \mathrm{mmol}$ ) at room temperature. After stirring overnight, the reaction mixture was diluted with water $(10 \mathrm{~mL})$ and extracted with ethyl acetate $(3 \times 20 \mathrm{~mL})$. The combined organic layers were washed with brine, dried over anhydrous $\mathrm{Na}_{2} \mathrm{SO}_{4}$ and concentrated. The residue was purified by flash column chromatography to give $\mathbf{1 4}(24 \mathrm{mg}, 0.09 \mathrm{mmol}, 90 \%$ yield). The characterization data matched those reported in literature.

\section{Preparation of 15}

15 was prepared from 14 according to the oxidative cleavage procedure of 4.15 was isolated as a colorless oil in $60 \%$ yield. The characterization data matched those reported in literature.

\section{Preparation of 16}

To a solution of allyltrimethylsilane $(0.20 \mathrm{mmol})$ in dried $\mathrm{CH}_{2} \mathrm{Cl}_{2}(10 \mathrm{~mL})$ was added anhydrous $\mathrm{ZnCl}_{2}(16 \mathrm{mg}, 0.12 \mathrm{mmol})$ and $4 \AA$ molecular sieves under argon. To the 
allyltrimethylsilane solution was added a solution of $\mathbf{1 5}(30 \mathrm{mg}, 0.10 \mathrm{mmol})$ in $\mathrm{CH}_{2} \mathrm{Cl}_{2}(2 \mathrm{~mL})$ at $0{ }^{\circ} \mathrm{C}$. After stirring overnight at room temperature, the reaction mixture was diluted with diethyl ether $(20 \mathrm{~mL})$ and quenched by saturated $\mathrm{NH}_{4} \mathrm{Cl}$ solution. The organic layer was collected, and the aqueous layer was extracted with diethyl ether $(3 \times 20 \mathrm{~mL})$. The combined organic layers were washed with brine, dried over anhydrous $\mathrm{MgSO}_{4}$ and concentrated under reduced pressure. The residue was purified by flash column chromatography to give $\mathbf{1 6}$ (28 mg, $0.095 \mathrm{mmol}, 95 \%$ yield) as a colorless oil. ${ }^{1} \mathrm{H}$ NMR $\left(400 \mathrm{MHz}, \mathrm{CDCl}_{3}\right) \delta 5.71(\mathrm{~m}, 1 \mathrm{H}), 5.52(\mathrm{~s}, 1 \mathrm{H}), 5.01(\mathrm{~m}, 2$ H), $2.75(\mathrm{dd}, J=13.3,8.5 \mathrm{~Hz}, 1 \mathrm{H}), 2.59(\mathrm{dd}, J=13.3,6.5 \mathrm{~Hz}, 1 \mathrm{H}), 2.20(\mathrm{~m}, 1 \mathrm{H}), 2.03-1.95(\mathrm{~m}$, $2 \mathrm{H}), 1.88$ (m, $1 \mathrm{H}), 1.60-1.51(\mathrm{~m}, 2 \mathrm{H}), 1.41$ (m, $1 \mathrm{H}), 1.40-1.19$ (m, $2 \mathrm{H}), 1.35$ (s, $3 \mathrm{H}), 1.17-$ $1.08(\mathrm{~m}, 1 \mathrm{H}), 1.13(\mathrm{~s}, 3 \mathrm{H}), 1.00-0.88(\mathrm{~m}, 1 \mathrm{H}), 0.91(\mathrm{~d}, J=6.4 \mathrm{~Hz}, 3 \mathrm{H}),{ }^{13} \mathrm{C}$ NMR $(100 \mathrm{MHz}$, $\left.\mathrm{CDCl}_{3}\right) \delta 135.03,117.76,103.12,95.77,86.89,84.92,48.98,48.88,46.56,37.12,36.63,32.53$, 26.16, 25.18, 24.18, 22.71, 19.77; IR $\left(\mathrm{CH}_{2} \mathrm{Cl}_{2}\right)$ 2939, 1653, 1456, $1376 \mathrm{~cm}^{-1}$; MS (EI) $\mathrm{m} / z 253$ ([M $\left.\left.-\mathrm{CH}_{2} \mathrm{CH}=\mathrm{CH}_{2}\right]^{+}\right)$; HRMS (EI) $\mathrm{m} / z$ for $\mathrm{C}_{14} \mathrm{H}_{21} \mathrm{O}_{4}\left(\left[\mathrm{M}-\mathrm{CH}_{2} \mathrm{CH}=\mathrm{CH}_{2}\right]^{+}\right)$, calcd 253.1440, found 253.1436 .

\section{Preparation of 17}

17 was prepared from $\mathbf{1 6}$ according to the procedure of the synthesis of $\mathbf{4}$. (Colorless oil, $75 \%$ yield). ${ }^{1} \mathrm{H}$ NMR $\left(300 \mathrm{MHz}, \mathrm{CDCl}_{3}\right) \delta 9.74(\mathrm{~s}, 1 \mathrm{H}), 5.55(\mathrm{~s}, 1 \mathrm{H}), 3.18-3.06(\mathrm{~m}, 2 \mathrm{H}), 2.28-1.85$ (m, $4 \mathrm{H}), 1.73(\mathrm{~m}, 1 \mathrm{H}), 1.55(\mathrm{~m}, 1 \mathrm{H}), 1.48-1.08(\mathrm{~m}, 4 \mathrm{H}), 1.35$ (s, $3 \mathrm{H}), 1.23$ (s, $3 \mathrm{H}), 1.02-0.88$ $(\mathrm{m}, 1 \mathrm{H}), 0.91(\mathrm{~d}, J=6.3 \mathrm{~Hz}, 3 \mathrm{H}) ;{ }^{13} \mathrm{C} \mathrm{NMR}\left(75 \mathrm{MHz}, \mathrm{CDCl}_{3}\right) \delta 202.34,103.40,95.90,87.05$, 83.06, 55.70, 50.50, 48.67, 37.04, 36.65, 32.38, 25.70, 25.12, 24.22, 23.76, 19.71; $\mathbb{I R}\left(\mathrm{CH}_{2} \mathrm{Cl}_{2}\right)$ 2923, 1719, 1457, $1376 \mathrm{~cm}^{-1}$; MS (EI) $\mathrm{m} / z 264\left(\left[\mathrm{M}-\mathrm{O}_{2}\right]^{+}\right)$; HRMS (EI) $\mathrm{m} / z$ for $\mathrm{C}_{16} \mathrm{H}_{24} \mathrm{O}_{3}([\mathrm{M}-$ $\left.\mathrm{O}_{2}\right]^{+}$), calcd 264.1725, found 264.1717. 


\section{Preparation of 18}

18 was prepared from $\mathbf{1 7}$ according to the procedure of the synthesis of $\mathbf{5}$. (Colorless oil, 95\% yield). ${ }^{1} \mathrm{H}$ NMR (400 MHz, $\left.\mathrm{CDCl}_{3}\right) \delta 10.19$ (br s, $\left.1 \mathrm{H}\right), 5.62(\mathrm{~s}, 1 \mathrm{H}), 3.24(\mathrm{~d}, J=15.9 \mathrm{~Hz}, 1 \mathrm{H})$, $2.93(\mathrm{~d}, J=15.9 \mathrm{~Hz}, 1 \mathrm{H}), 2.32-1.18$ (m, $2 \mathrm{H}), 2.02-1.87$ (m, $2 \mathrm{H}), 1.73(\mathrm{~m}, 1 \mathrm{H}), 1.57$ (m, $1 \mathrm{H})$, $1.44(\mathrm{~m}, 1 \mathrm{H}), 1.35-1.12(\mathrm{~m}, 3 \mathrm{H}), 1.35(\mathrm{~s}, 3 \mathrm{H}), 1.29(\mathrm{~s}, 3 \mathrm{H}), 1.02-0.90(\mathrm{~m}, 1 \mathrm{H}), 0.92(\mathrm{~d}, J=$ $6.4 \mathrm{~Hz}, 3 \mathrm{H}) ;{ }^{13} \mathrm{C} \mathrm{NMR}\left(\mathrm{CDCl}_{3}, 100 \mathrm{MHz}\right) \delta 176.11,103.56,95.98,87.00,83.24,49.73,48.56$, 46.07, 36.95, 36.67, 32.39, 25.82, 25.07, 24.23, 23.08, 19.70; IR $\left(\mathrm{CH}_{2} \mathrm{Cl}_{2}\right) 2924,1733,1558$, $1457 \mathrm{~cm}^{-1}$; MS (EI) $\mathrm{m} / z 280\left(\left[\mathrm{M}-\mathrm{O}_{2}\right]^{+}\right)$; HRMS (EI) $\mathrm{m} / z$ for $\mathrm{C}_{16} \mathrm{H}_{24} \mathrm{O}_{4}\left(\left[\mathrm{M}-\mathrm{O}_{2}\right]^{+}\right)$, calcd 280.1675 , found 280.1668 .

\section{Preparation of 19a}

19a was prepared according to the General Procedure 1 using $n$-dodecylamine. (Colorless oil, 95\% yield). ${ }^{1} \mathrm{H}$ NMR (400 MHz, $\left.\mathrm{CDCl}_{3}\right) \delta 6.46($ br s, $1 \mathrm{H}), 5.62(\mathrm{~s}, 1 \mathrm{H}), 3.23-3.19(\mathrm{~m}, 3 \mathrm{H})$, $2.42(\mathrm{~d}, J=13.9 \mathrm{~Hz}, 1 \mathrm{H}), 2.37-2.21(\mathrm{~m}, 2 \mathrm{H}), 2.08-1.95(\mathrm{~m}, 2 \mathrm{H}), 1.78(\mathrm{~m}, 1 \mathrm{H}), 1.63(\mathrm{~m}, 1 \mathrm{H})$, 1.54-1.19 (m, $6 \mathrm{H}), 1.42$ (s, $3 \mathrm{H}), 1.33$ (s, $3 \mathrm{H}), 1.25$ (br s, $18 \mathrm{H}), 1.07-0.96$ (m, $1 \mathrm{H}), 0.98$ (d, J $=6.4 \mathrm{~Hz}, 3 \mathrm{H}), 0.88(\mathrm{t}, J=6.8 \mathrm{~Hz}, 3 \mathrm{H}) ;{ }^{13} \mathrm{C} \mathrm{NMR}\left(100 \mathrm{MHz}, \mathrm{CDCl}_{3}\right) \delta 170.92,103.62,96.24$, $87.32,83.78,51.47,48.65,39.27,37.01,36.83,32.50,31.87,29.58,29.54,29.52,29.30,29.27$, 26.91, 25.90, 25.31, 24.39, 22.68, 22.64, 19.79, 14.07; IR $\left(\mathrm{CH}_{2} \mathrm{Cl}_{2}\right) 2921,1653,1458,1377 \mathrm{~cm}^{-1}$; MS (EI) $m / z 479\left(\mathrm{M}^{+}\right)$; HRMS (EI) $\mathrm{m} / z$ for $\mathrm{C}_{28} \mathrm{H}_{49} \mathrm{O}_{5} \mathrm{~N}\left(\mathrm{M}^{+}\right)$, calcd 479.3611, found 479.3605 .

\section{Preparation of 19b}

19b was prepared according to the General Procedure 1 using $n$-tetradecylamine. (Colorless oil,

93\% yield). ${ }^{1} \mathrm{H}$ NMR (400 MHz, $\left.\mathrm{CDCl}_{3}\right) \delta 6.47$ (br s, $\left.1 \mathrm{H}\right), 5.62(\mathrm{~s}, 1 \mathrm{H}), 3.31-3.23(\mathrm{~m}, 3 \mathrm{H})$, 
$2.42(\mathrm{~d}, J=13.9 \mathrm{~Hz}, 1 \mathrm{H}), 2.37-2.22(\mathrm{~m}, 2 \mathrm{H}), 2.09-1.95(\mathrm{~m}, 2 \mathrm{H}), 1.78(\mathrm{~m}, 1 \mathrm{H}), 1.63(\mathrm{~m}, 1 \mathrm{H})$, 1.55-1.19 (m, $6 \mathrm{H}), 1.42$ (s, $3 \mathrm{H}), 1.33$ (s, $3 \mathrm{H}), 1.25$ (br s, $22 \mathrm{H}), 1.08-0.96$ (m, $1 \mathrm{H}), 0.98$ (d, $J$ $=6.4 \mathrm{~Hz}, 3 \mathrm{H}), 0.88(\mathrm{t}, J=6.8 \mathrm{~Hz}, 3 \mathrm{H}) ;{ }^{13} \mathrm{C} \mathrm{NMR}\left(100 \mathrm{MHz}, \mathrm{CDCl}_{3}\right) \delta 170.89,103.60,96.22$, $87.30,83.76,51.46,48.64,39.25,37.00,36.82,32.49,31.86,29.62,29.60,29.56,29.53,29.51$, 29.30, 29.26, 26.90, 25.89, 25.29, 24.38, 22.66, 22.62, 19.78, 14.06; IR $\left(\mathrm{CH}_{2} \mathrm{Cl}_{2}\right) 2918,1654$, 1458, $1377 \mathrm{~cm}^{-1}$; MS (EI) $\mathrm{m} / z 507\left(\mathrm{M}^{+}\right)$; HRMS (EI) $\mathrm{m} / z$ for $\mathrm{C}_{30} \mathrm{H}_{53} \mathrm{O}_{5} \mathrm{~N}\left(\mathrm{M}^{+}\right)$, calcd 507.3924, found 507.3914 .

\section{Preparation of 19c}

19c was prepared according to the General Procedure 1 using $n$-hexadecylamine. (Colorless oil, 90\% yield). ${ }^{1} \mathrm{H}$ NMR (400 MHz, $\left.\mathrm{CDCl}_{3}\right) \delta 6.46(\mathrm{br} \mathrm{s}, 1 \mathrm{H}), 5.62(\mathrm{~s}, 1 \mathrm{H}), 3.32-3.23(\mathrm{~m}, 3 \mathrm{H})$, $2.42(\mathrm{~d}, J=13.8 \mathrm{~Hz}, 1 \mathrm{H}), 2.36-2.22(\mathrm{~m}, 2 \mathrm{H}), 2.09-1.94(\mathrm{~m}, 2 \mathrm{H}), 1.78(\mathrm{~m}, 1 \mathrm{H}), 1.63(\mathrm{~m}, 1 \mathrm{H})$, 1.56-1.19 (m, $6 \mathrm{H}), 1.42$ (s, $3 \mathrm{H}), 1.33$ (s, $3 \mathrm{H}), 1.25$ (br s, $26 \mathrm{H}), 1.08-0.97$ (m, $1 \mathrm{H}), 0.98$ (d, $J$ $=6.4 \mathrm{~Hz}, 3 \mathrm{H}), 0.88(\mathrm{t}, J=6.8 \mathrm{~Hz}, 3 \mathrm{H}) ;{ }^{13} \mathrm{C} \mathrm{NMR}\left(100 \mathrm{MHz}, \mathrm{CDCl}_{3}\right) \delta$ 170.91, 103.62, 96.24, $87.32,83.78,51.47,48.66,39.27,37.02,36.84,32.51,31.89,29.66,29.62,29.58,29.55,29.53$, 29.32, 29.28, 26.92, 25.91, 25.31, 24.40, 22.69, 22.65, 19.80, 14.08; IR $\left(\mathrm{CH}_{2} \mathrm{Cl}_{2}\right)$ 2920, 1652, 1458, $1378 \mathrm{~cm}^{-1}$; MS (EI) $\mathrm{m} / z 535\left(\mathrm{M}^{+}\right)$; HRMS (EI) $\mathrm{m} / z$ for $\mathrm{C}_{32} \mathrm{H}_{57} \mathrm{O}_{5} \mathrm{~N}\left(\mathrm{M}^{+}\right)$, calcd 535.4237, found 535.4220 .

\section{Preparation of 20}

20 was prepared following the General Procedure 2 using $n$-dodecanol. (Colorless oil, 95\% yield). ${ }^{1} \mathrm{H}$ NMR (300 MHz, $\left.\mathrm{CDCl}_{3}\right) \delta 5.59(\mathrm{~s}, 1 \mathrm{H}), 4.03(\mathrm{t}, J=6.7 \mathrm{~Hz}, 2 \mathrm{H}), 3.53(\mathrm{~d}, J=16.0 \mathrm{~Hz}$, $1 \mathrm{H}), 2.72(\mathrm{~d}, J=16.0 \mathrm{~Hz}, 1 \mathrm{H}), 2.50(\mathrm{~m}, 1 \mathrm{H}), 2.32-2.21(\mathrm{~m}, 2 \mathrm{H}), 2.08-1.91(\mathrm{~m}, 2 \mathrm{H}), 1.79(\mathrm{~m}$, 
$1 \mathrm{H}), 1.64-1.19$ (m, $6 \mathrm{H}), 1.42$ (s, $3 \mathrm{H}), 1.34$ (s, $3 \mathrm{H}), 1.26$ (br s, $18 \mathrm{H}), 1.12-0.98$ (m, $1 \mathrm{H}), 0.98$ $(\mathrm{d}, J=6.3 \mathrm{~Hz}, 3 \mathrm{H}), 0.88(\mathrm{t}, J=6.7 \mathrm{~Hz}, 3 \mathrm{H}) ;{ }^{13} \mathrm{C} \mathrm{NMR}\left(\mathrm{CDCl}_{3}, 75 \mathrm{MHz}\right) \delta 172.00,103.43$, $95.86,87.19,83.48,64.25,49.33,48.91,46.39,37.24,36.89,32.67,31.88,29.62,29.59,29.53$, $29.50,29.32,29.22,28.58,26.16,25.93,25.31,24.38,23.34,22.66,19.87,14.08 ; \mathrm{IR}\left(\mathrm{CH}_{2} \mathrm{Cl}_{2}\right)$ 2920, 1733, 1464, 1378, $1020 \mathrm{~cm}^{-1}$; MS (EI) $\mathrm{m} / z 448\left(\left[\mathrm{M}-\mathrm{O}_{2}\right]^{+}\right)$; HRMS (EI) $\mathrm{m} / z$ for $\mathrm{C}_{28} \mathrm{H}_{48} \mathrm{O}_{4}$ $\left(\left[\mathrm{M}-\mathrm{O}_{2}\right]^{+}\right)$, calcd 448.3553, found 448.3543.

\section{Preparation of 21}

21 was prepared following the General Procedures 3 and 4 in $83 \%$ total yield (for 2 steps) as a colorless oil. ${ }^{1} \mathrm{H}$ NMR $\left(300 \mathrm{MHz}, \mathrm{CDCl}_{3}\right) \delta 5.58(\mathrm{~s}, 1 \mathrm{H}), 3.46(\mathrm{~d}, J=17.3 \mathrm{~Hz}, 1 \mathrm{H}), 3.02(\mathrm{~d}, J=$ $17.3 \mathrm{~Hz}, 1 \mathrm{H}), 2.44-2.39$ (m, $2 \mathrm{H}), 2.32-2.21$ (m, $3 \mathrm{H}), 2.08-1.79$ (m, $3 \mathrm{H}), 1.64-1.18$ (m, $6 \mathrm{H})$, 1.43 (s, $3 \mathrm{H}), 1.30$ (s, $3 \mathrm{H}), 1.25$ (br s, $18 \mathrm{H}), 1.10-0.94$ (m, $1 \mathrm{H}), 0.97$ (d, $J=6.3 \mathrm{~Hz}, 3 \mathrm{H}), 0.88$ $(\mathrm{t}, J=6.7 \mathrm{~Hz}, 3 \mathrm{H}) ;{ }^{13} \mathrm{C} \mathrm{NMR}\left(75 \mathrm{MHz}, \mathrm{CDCl}_{3}\right) \delta 211.01,103.39,95.73,87.28,83.91,54.41$, $49.92,48.94,44.06,37.28,36.89,32.64,31.88,29.62,29.60,29.58,29.44,29.39,29.31,29.14$ 26.02, 25.35, 24.37, 23.65, 23.48, 22.65, 20.41, 14.08; IR $\left(\mathrm{CH}_{2} \mathrm{Cl}_{2}\right)$ 2919, 1716, 1463, 1377, $1019 \mathrm{~cm}^{-1}$; MS (EI) $\mathrm{m} / z 432\left(\left[\mathrm{M}-\mathrm{O}_{2}\right]^{+}\right)$; HRMS (EI) $\mathrm{m} / z$ for $\mathrm{C}_{28} \mathrm{H}_{48} \mathrm{O}_{3}\left(\left[\mathrm{M}-\mathrm{O}_{2}\right]^{+}\right)$, calcd 432.3603, found 432.3599 .

\section{Preparation of 22}

A solution of $\mathbf{6 h}(55 \mathrm{mg}, 0.10 \mathrm{mmol})$ in ethyl acetate $(10 \mathrm{~mL})$ was added $\mathrm{Pd} / \mathrm{C}(10 \mathrm{mg}, 10 \%$ w/w) and hydrogenolyzed under a hydrogen atmosphere $(1 \mathrm{~atm})$ overnight. The reaction mixture was filtered, and the filtrate was concentrated under reduced pressure. The residue was purified by flash column chromatography to give 22 ( $45 \mathrm{mg}, 0.085 \mathrm{mmol}, 85 \%$ yield) as a colorless oil. 
${ }^{1} \mathrm{H}$ NMR (300 MHz, $\left.\mathrm{CDCl}_{3}\right) \delta 6.71(\mathrm{br} \mathrm{s}, 1 \mathrm{H}), 5.30(\mathrm{~s}, 1 \mathrm{H}), 4.50(\mathrm{~m}, 1 \mathrm{H}), 3.32(\mathrm{~m}, 1 \mathrm{H}), 3.16$ (m, $1 \mathrm{H}), 2.36(\mathrm{~m}, 1 \mathrm{H}), 2.25(\mathrm{~m}, 1 \mathrm{H}), 2.03-1.19(\mathrm{~m}, 13 \mathrm{H}), 1.52(\mathrm{~s}, 3 \mathrm{H}), 1.25$ (br s, $26 \mathrm{H})$, $0.92-0.84(\mathrm{~m}, 9 \mathrm{H}), 1.02-0.88(\mathrm{~m}, 1 \mathrm{H}) ;{ }^{13} \mathrm{C} \mathrm{NMR}\left(75 \mathrm{MHz}, \mathrm{CDCl}_{3}\right) \delta$ 171.57, 107.65, 97.19, $82.59,65.40,45.26,39.88,39.44,38.25,35.66,34.47,31.94,29.72,29.64,29.60,29.55,29.37$, 26.99, 25.28, 23.61, 22.70, 22.21, 18.75, 14.12, 11.84; $\mathrm{IR}_{\left(\mathrm{CH}_{2} \mathrm{Cl}_{2}\right)} 2922,1654,1463,1378 \mathrm{~cm}^{-1}$; MS (EI) $m / z 533\left(\mathrm{M}^{+}\right)$; HRMS (EI) $\mathrm{m} / z$ for $\mathrm{C}_{33} \mathrm{H}_{59} \mathrm{O}_{4} \mathrm{~N}\left(\mathrm{M}^{+}\right)$, calcd 533.4444, found 533.4439 . 


\section{(IV) Cytotoxicity Studies (MTT Assay)}

Human hepatocellular carcinoma (HepG2) was maintained in a minimum essential medium with Earle's balanced salts (MEM). All the media were supplemented with $2 \mathrm{mM} \mathrm{L}$-glutamine and $10 \%$ fetal boviene serum. Penicillin $(100 \mathrm{U} / \mathrm{mL})$ and Streptomycin $(100 \mu \mathrm{g} / \mathrm{mL})$ were added to all media. Cultures were incubated at $37{ }^{\circ} \mathrm{C}$ in a $5 \% \mathrm{CO}_{2} / 95 \%$ air humidified atmosphere.

Assays on the cytotoxic effects were conducted in 96-well flat-bottomed microtitre plates. The supplemented culture medium $(100 \mu \mathrm{L})$ with cells $\left(4 \times 10^{4}\right.$ cells/ mL) was added into each well and was incubated $\left(37{ }^{\circ} \mathrm{C}, 5 \% \mathrm{CO}_{2} / 95 \%\right.$ air) for $24 \mathrm{~h}$. All the media were then removed and fresh supplemented medium $(100 \mu \mathrm{L})$ was added into each well. Compounds $\mathbf{6}-\mathbf{1 1}, \mathbf{1 3}$ and $19-22$ dissolved in the culture medium $(100 \mu \mathrm{L}+<1 \%$ ethanol $)$ were added into a set of wells. After mixing, the sample-containing media $(100 \mu \mathrm{L})$ were drawn and added to another set of wells. Such processes were repeated to provide a set of two-fold dilution series. Controlled wells only contained $100 \mu \mathrm{L}$ of supplemented media. Microtitre plates were incubated at $37^{\circ} \mathrm{C}$ in a $5 \%$ $\mathrm{CO}_{2} / 95 \%$ air humidified atmosphere for further 6 days. All the cytotoxicity assays were run in parallel with a negative control (i.e., untreated population). Assessment of the cytotoxicity was carried out using a modified method of Mosmann based 3-(4, 5-Dimethylthiazol-2-yl)-2, 5diphenyltetrazolium bromide (MTT) Assay [Mosmann, T. J. Immunol. Methods 1983, 65, 55 63.]. At the end of each incubation period, $10 \mu \mathrm{L}$ of the MTT solution (Cell Proliferation Kit I, Roche) were added into each well and the cultures were further incubated for $4 \mathrm{~h}$ at $37{ }^{\circ} \mathrm{C}$ in a $5 \% \mathrm{CO}_{2} / 95 \%$ air humidified atmosphere. Then $100 \mu \mathrm{L}$ of the solubilization solution was added into the wells to lyse the cells and solubilize the formazan complex formed. The microtitre plates were maintained in a dark and humidified chamber overnight. The formation of formazan was measured with a microtitre plate reader at $550 \mathrm{~nm}$, and the percentages of cell survival were determined. The cytotoxicity was evaluated based on the percentage cell survival in a dosedependence manner relative to the negative control. 
(V) ${ }^{1} \mathrm{H}$ NMR Spectra of $6-13$ and $16-22$

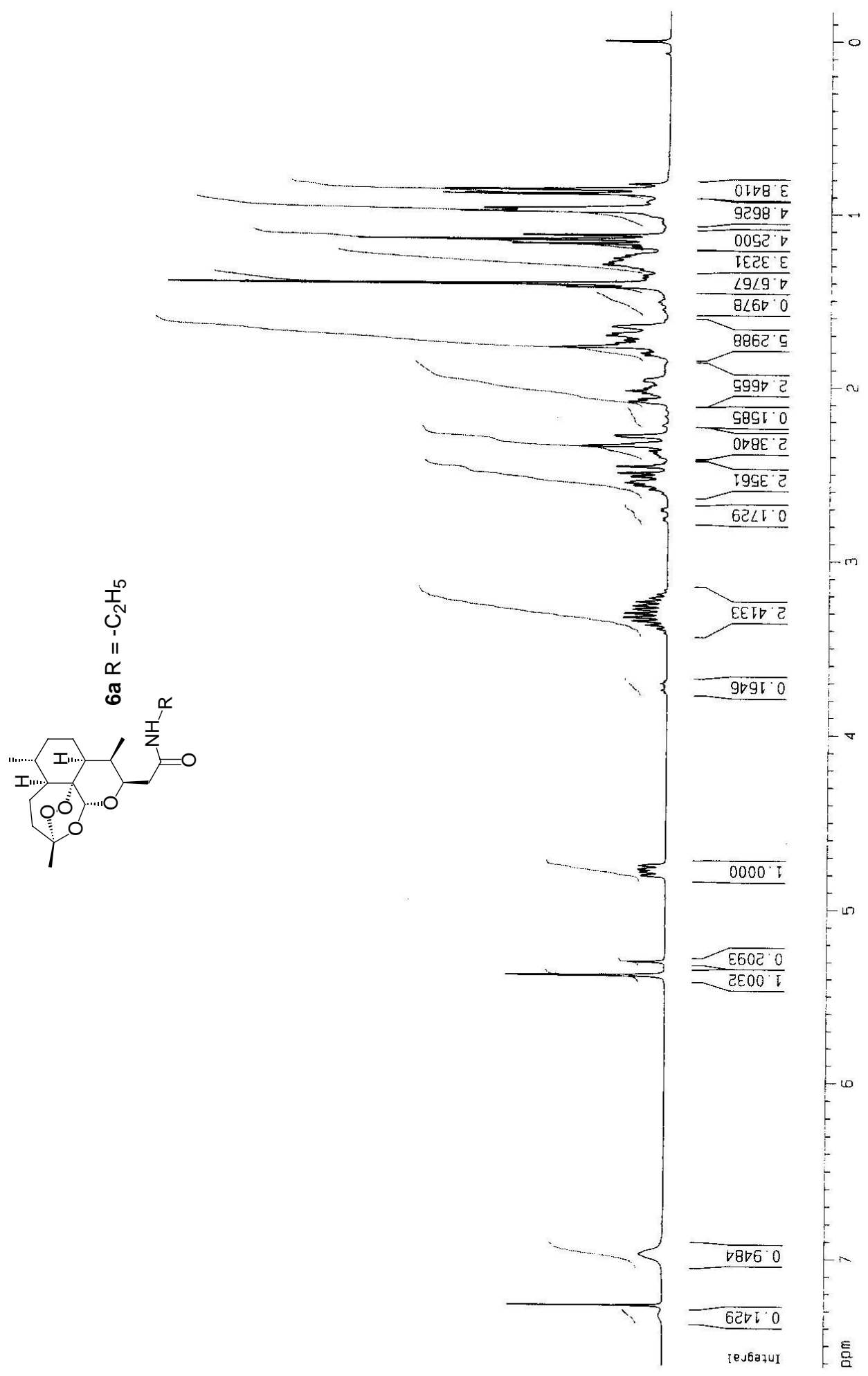




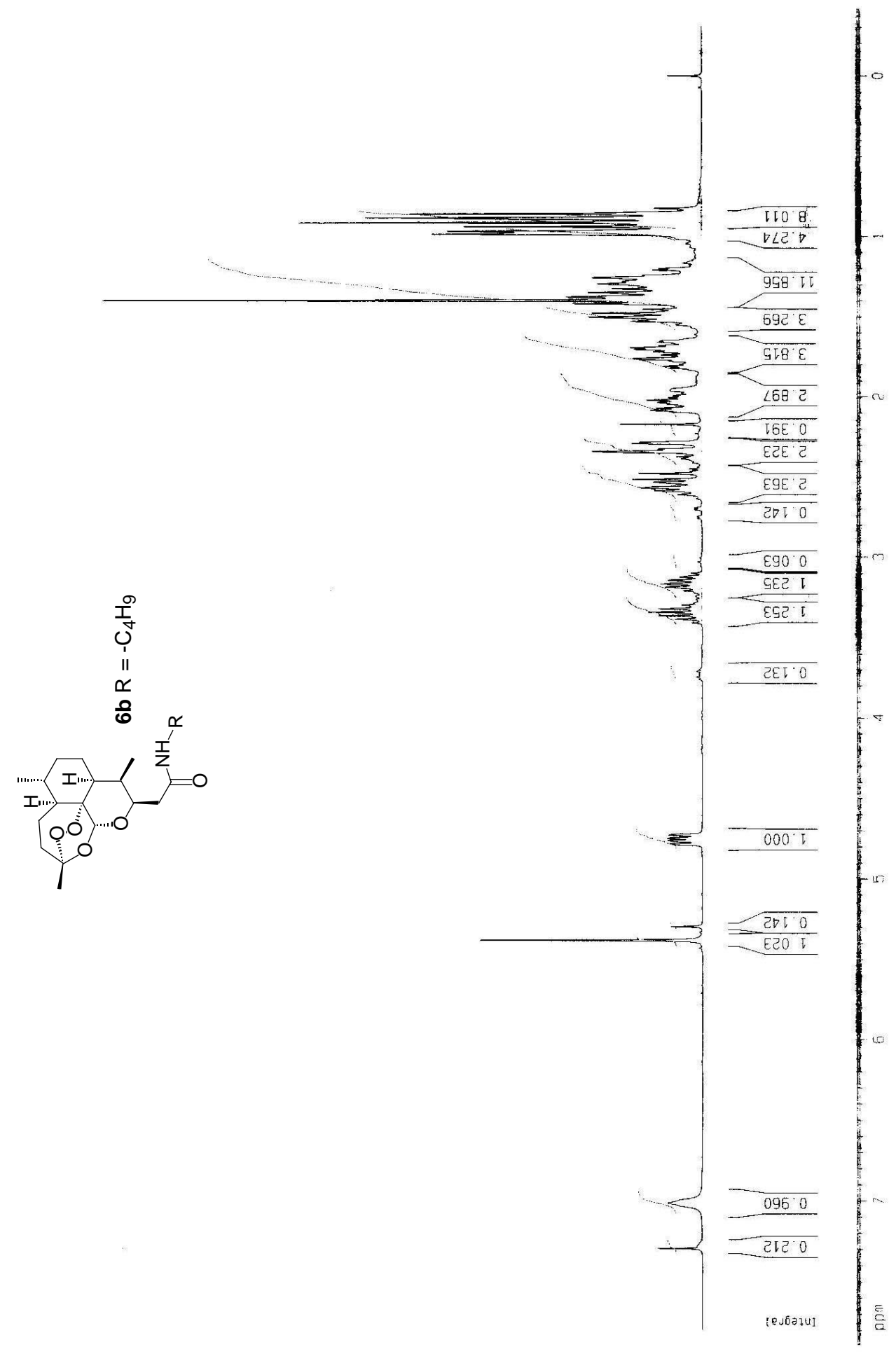




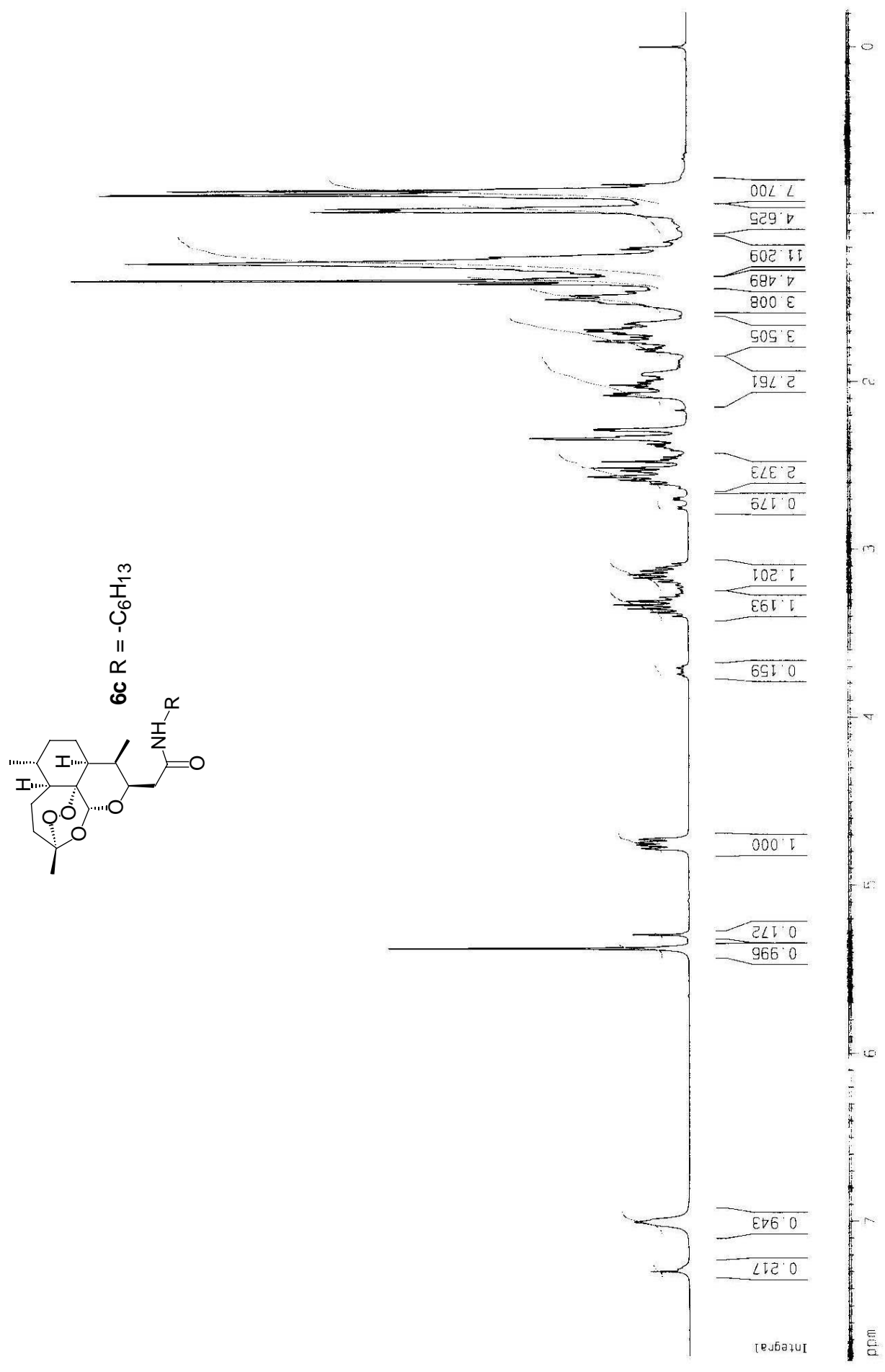




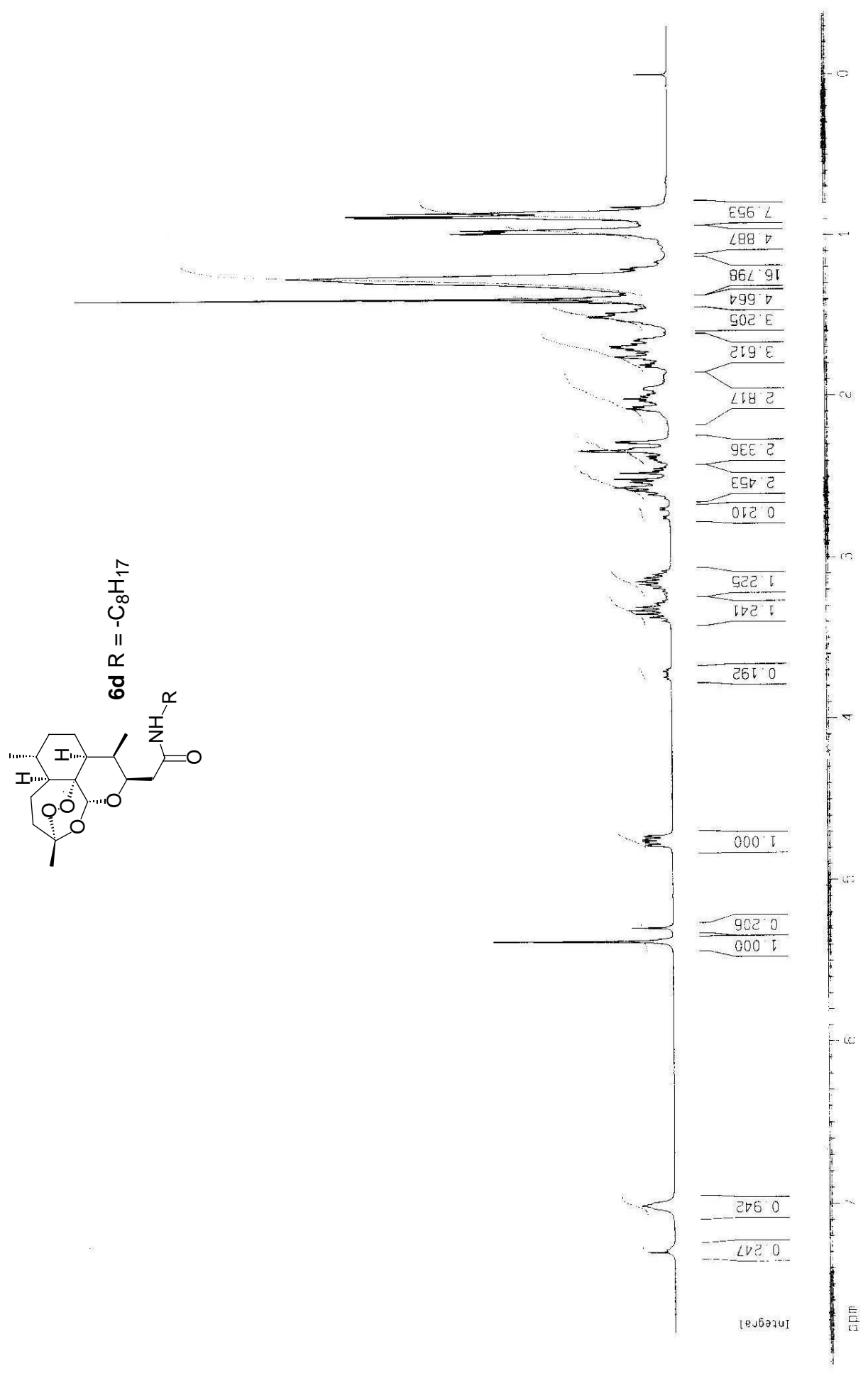




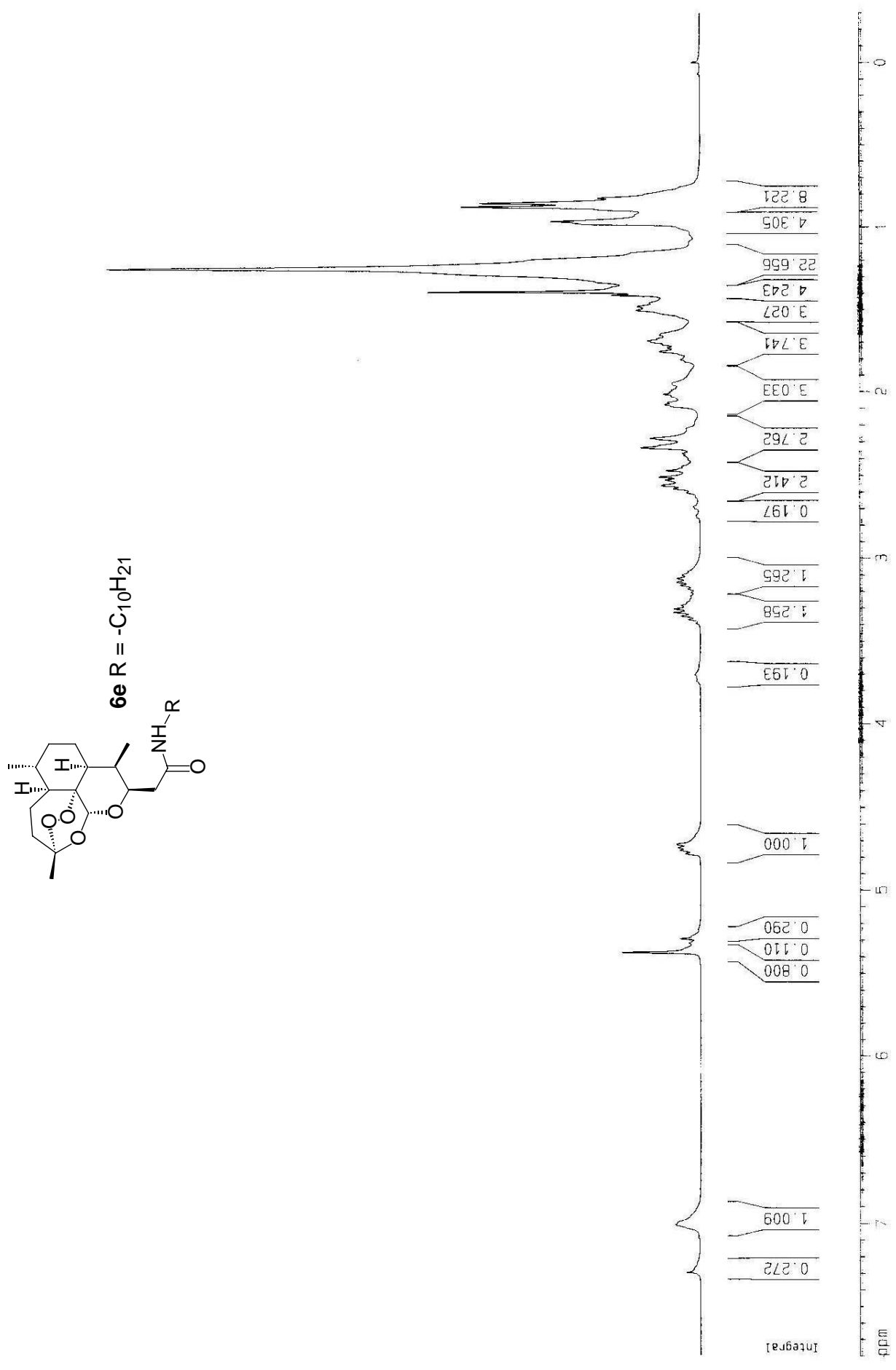




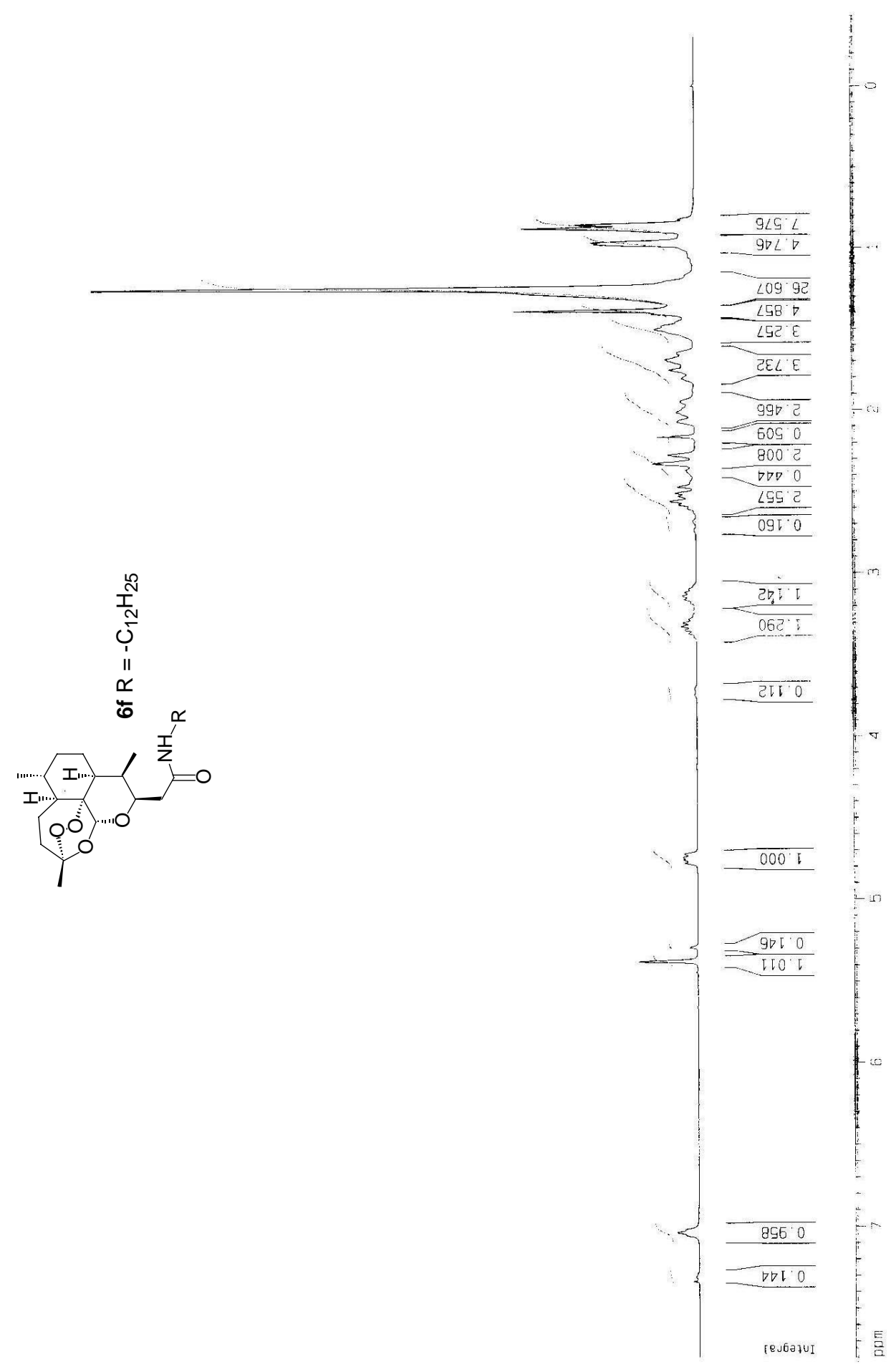




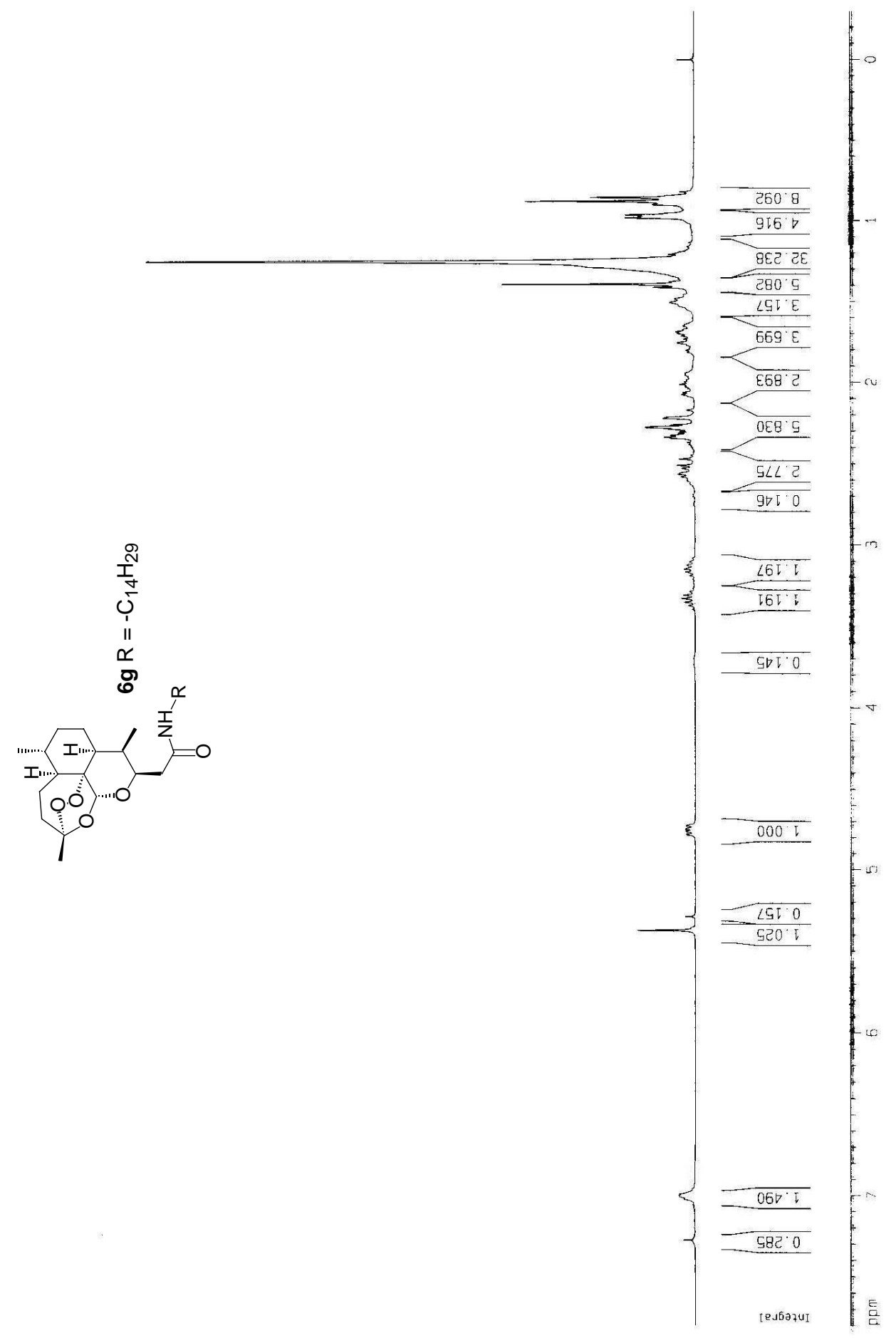




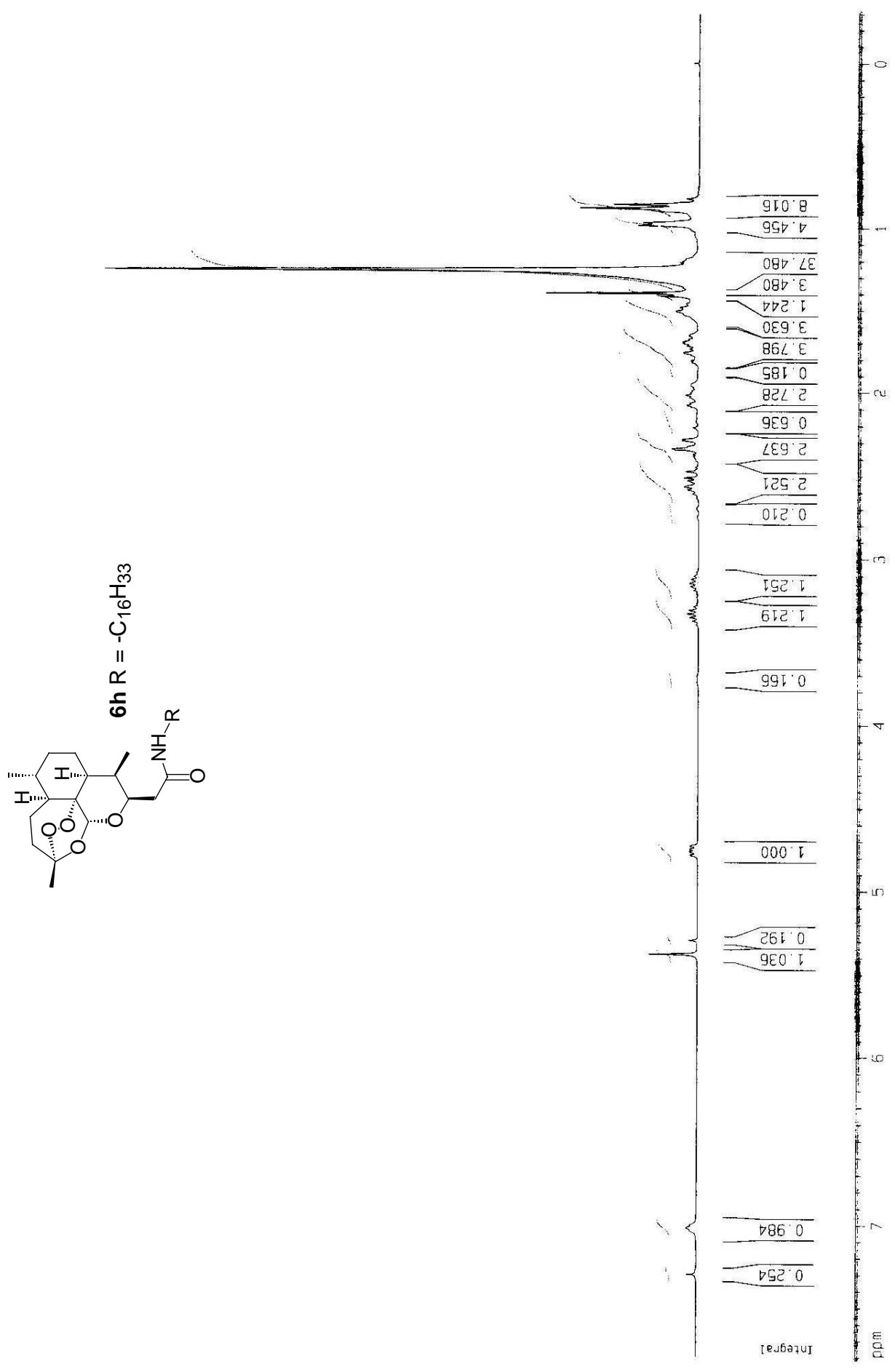




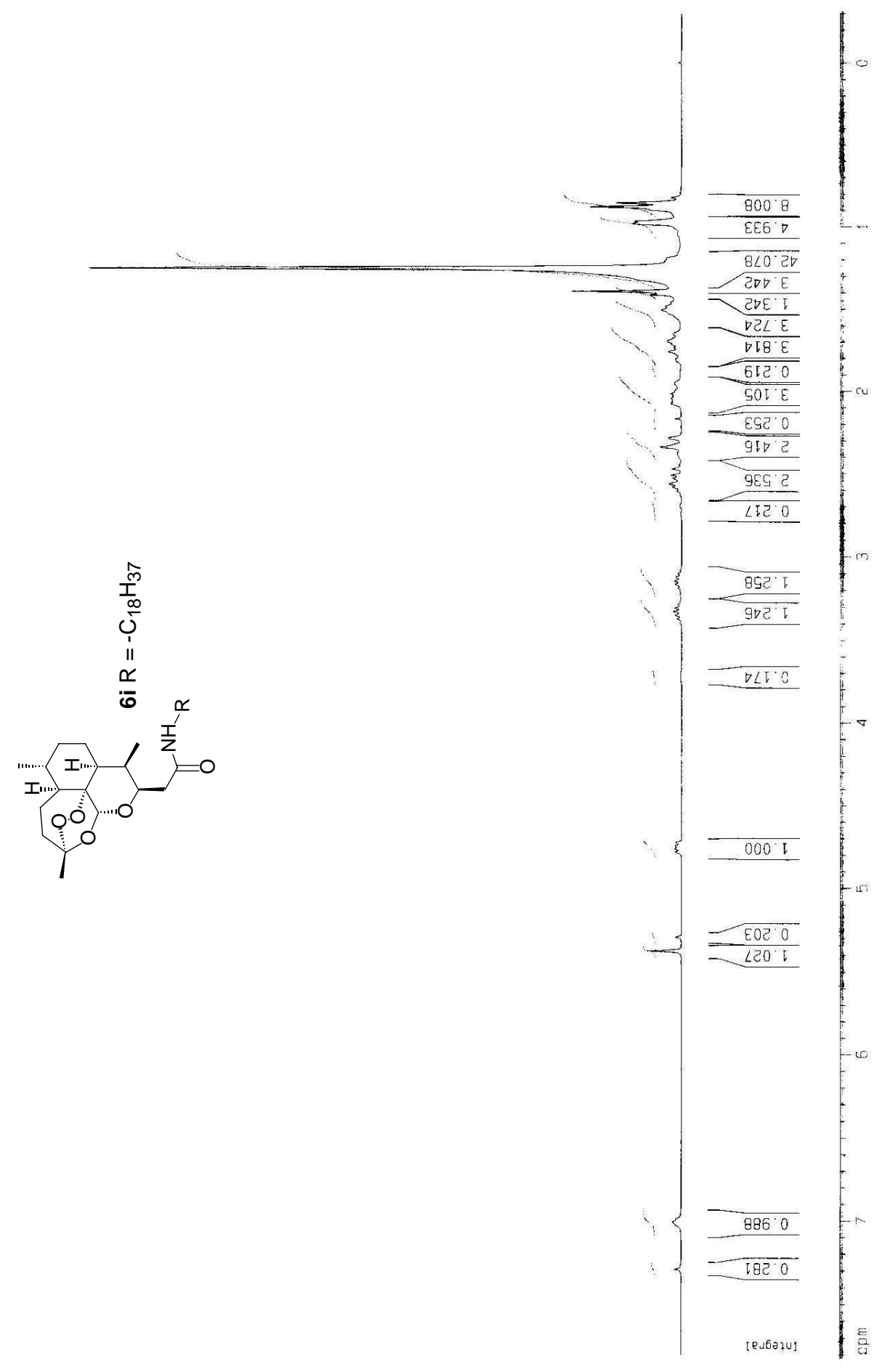




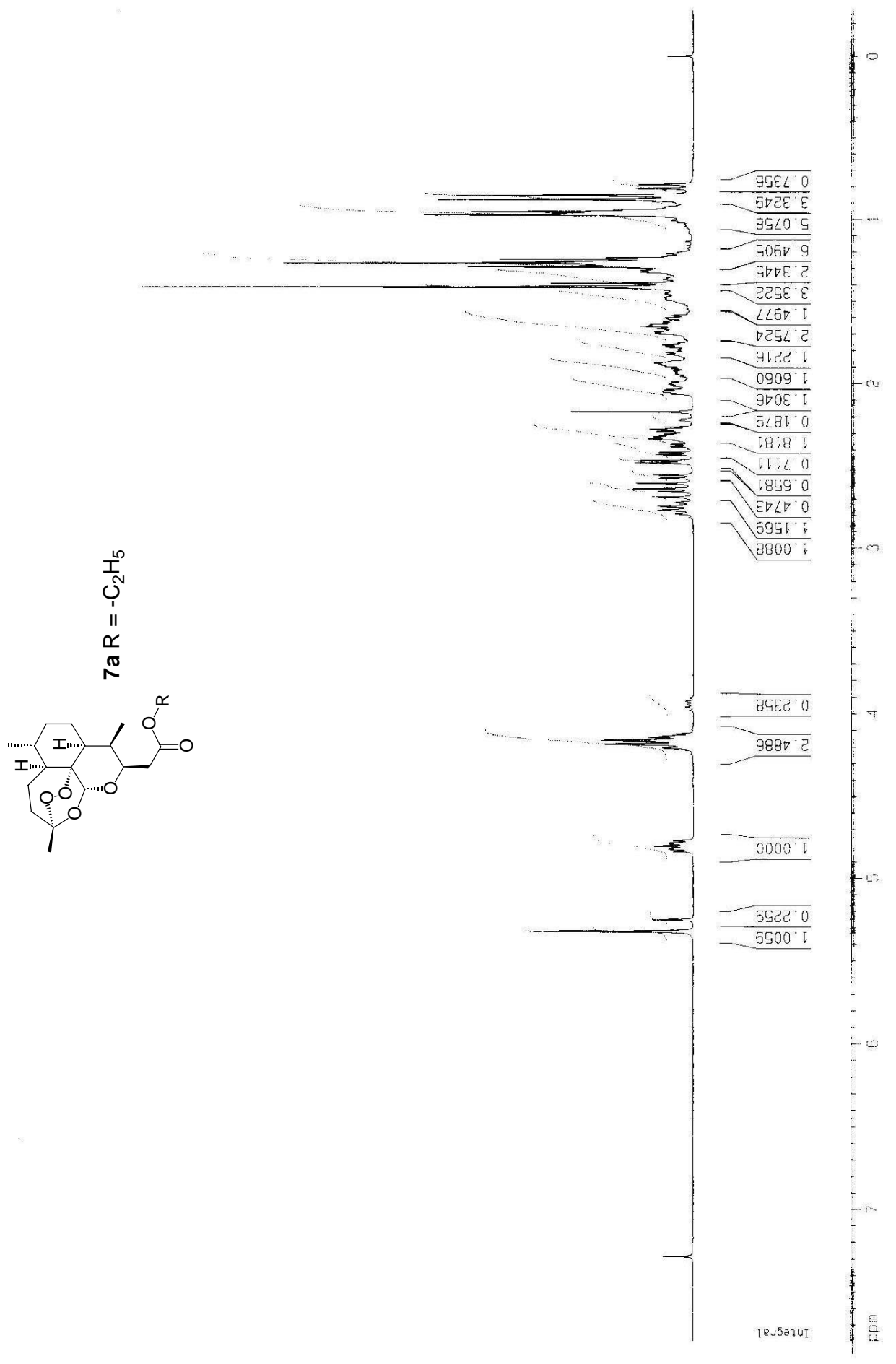




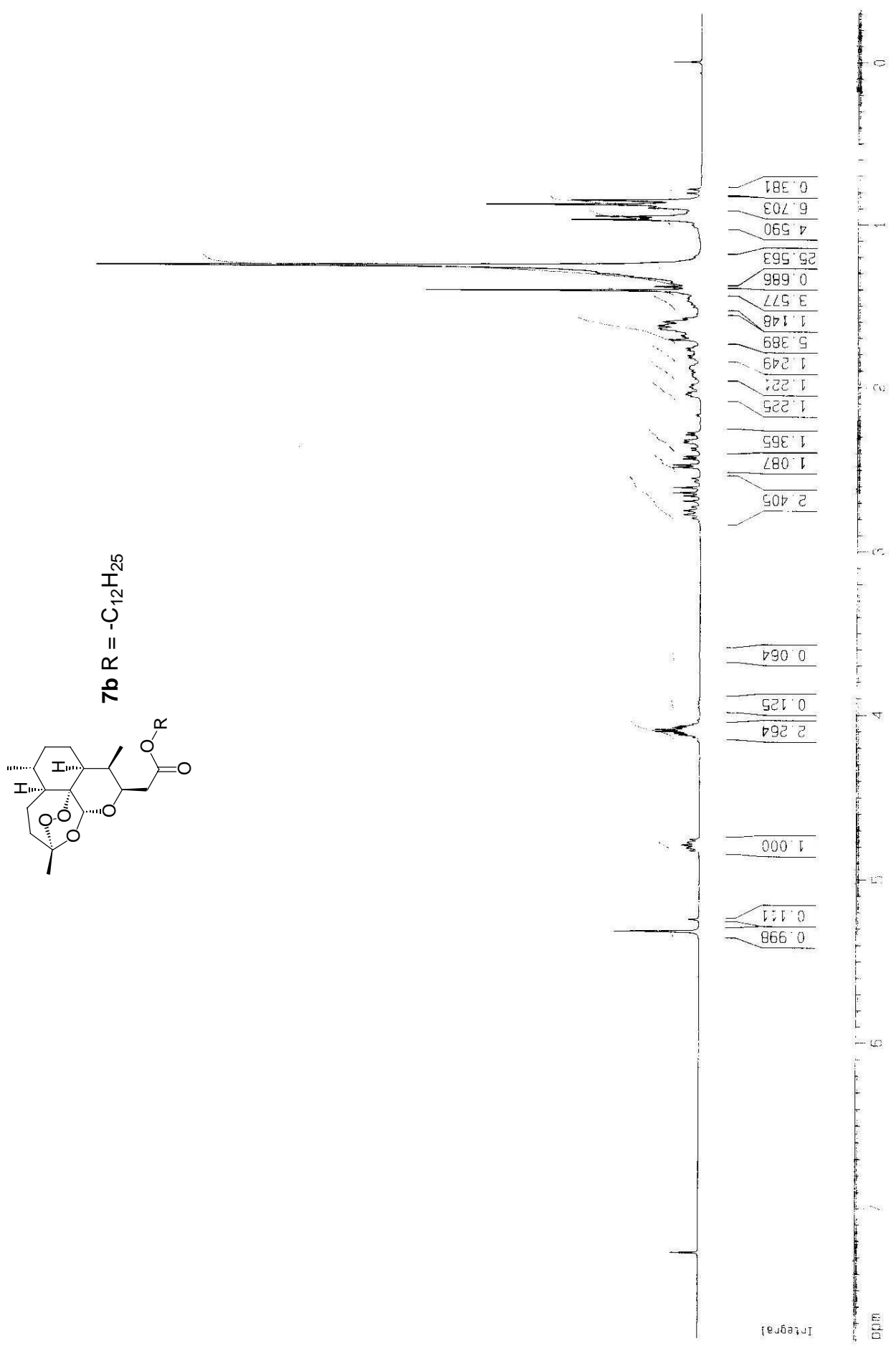




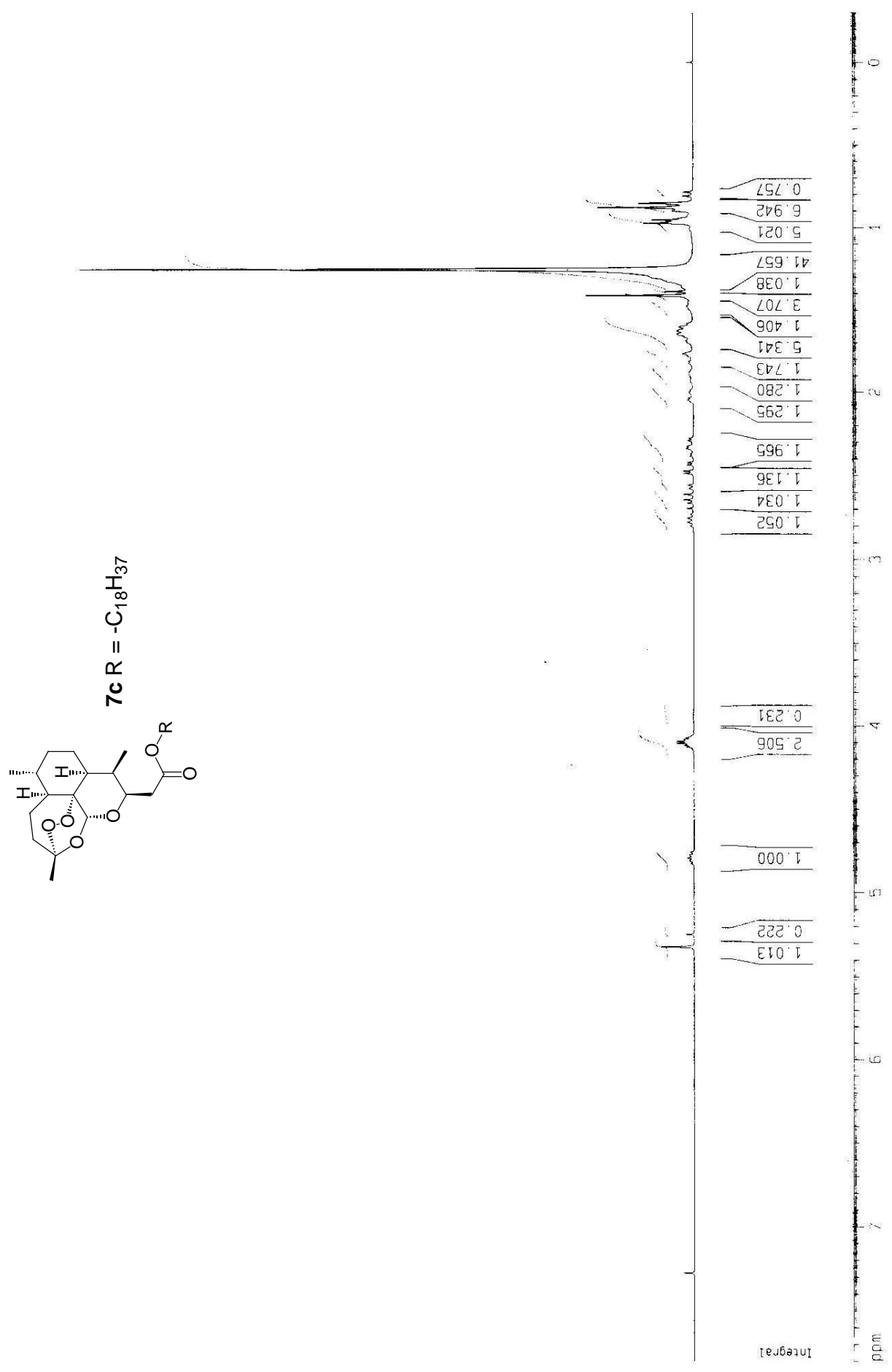




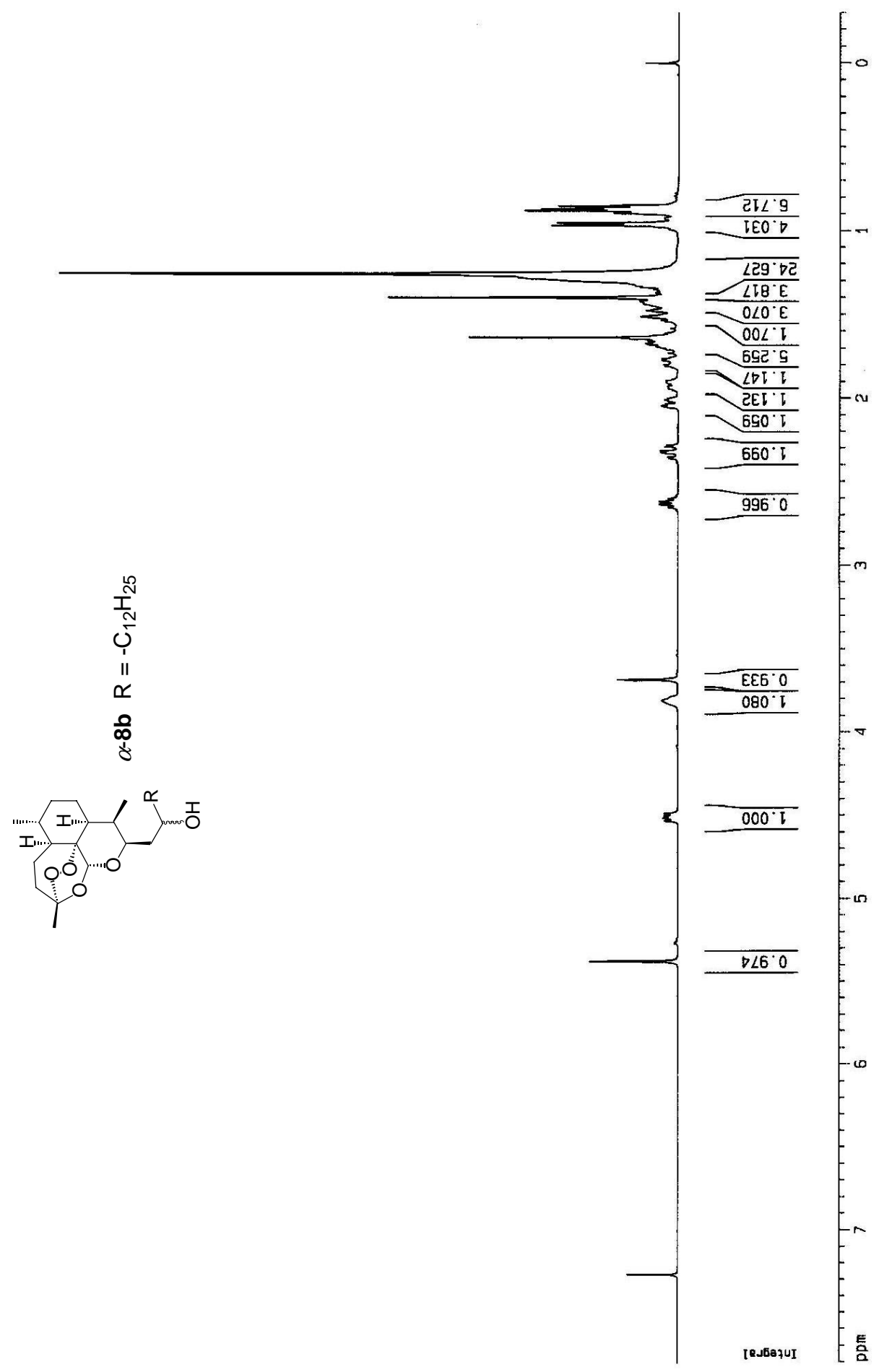




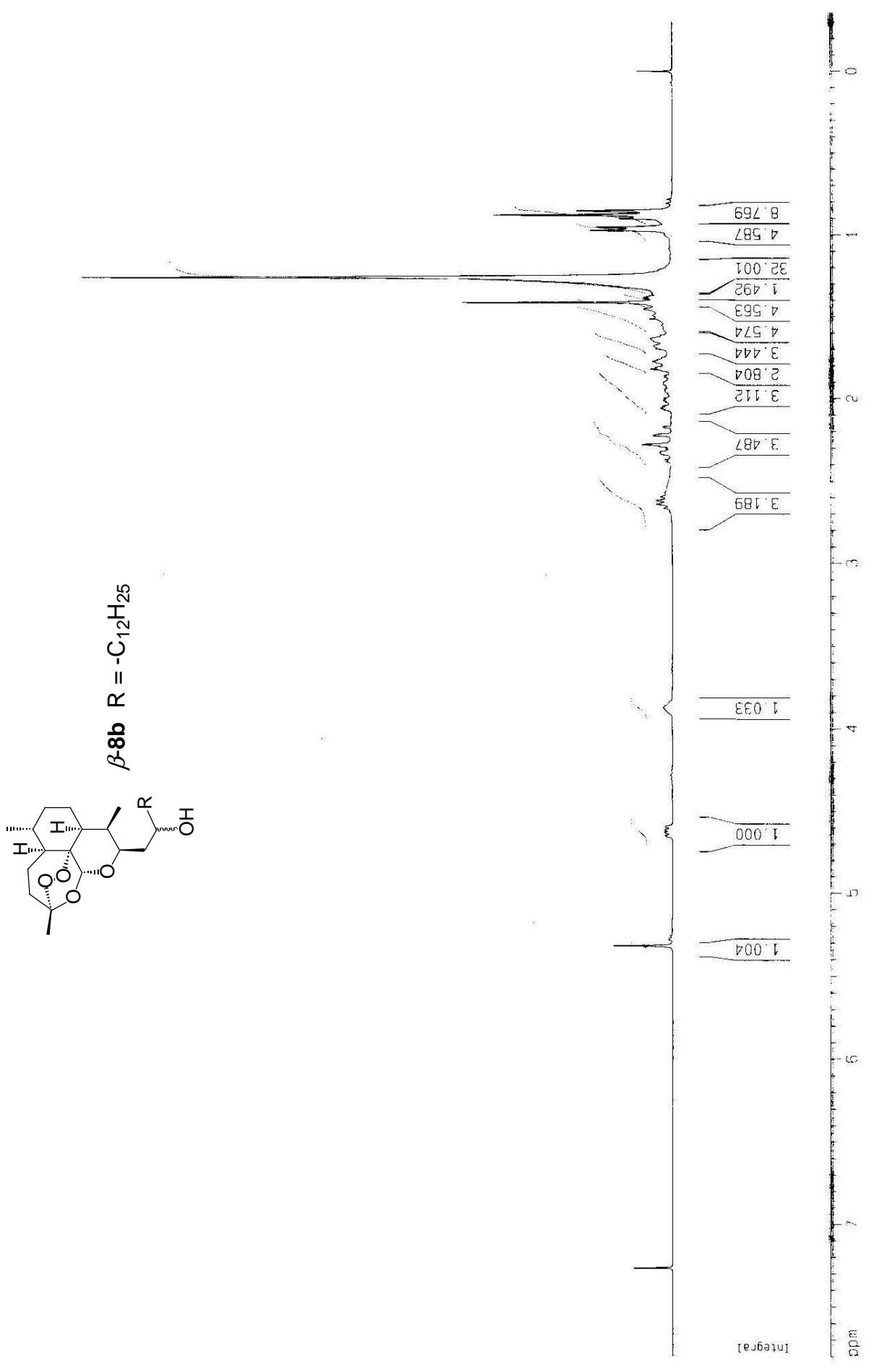




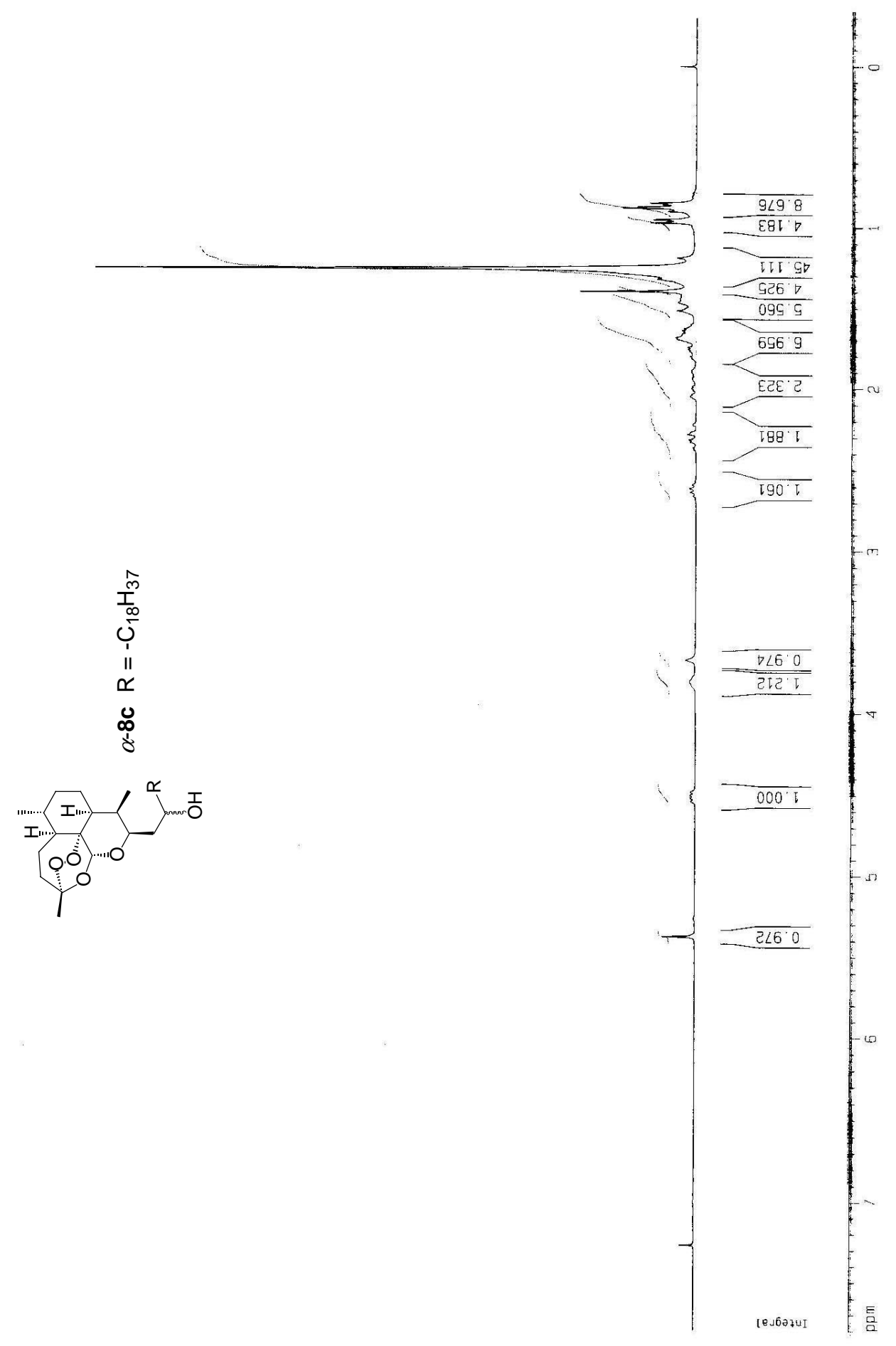




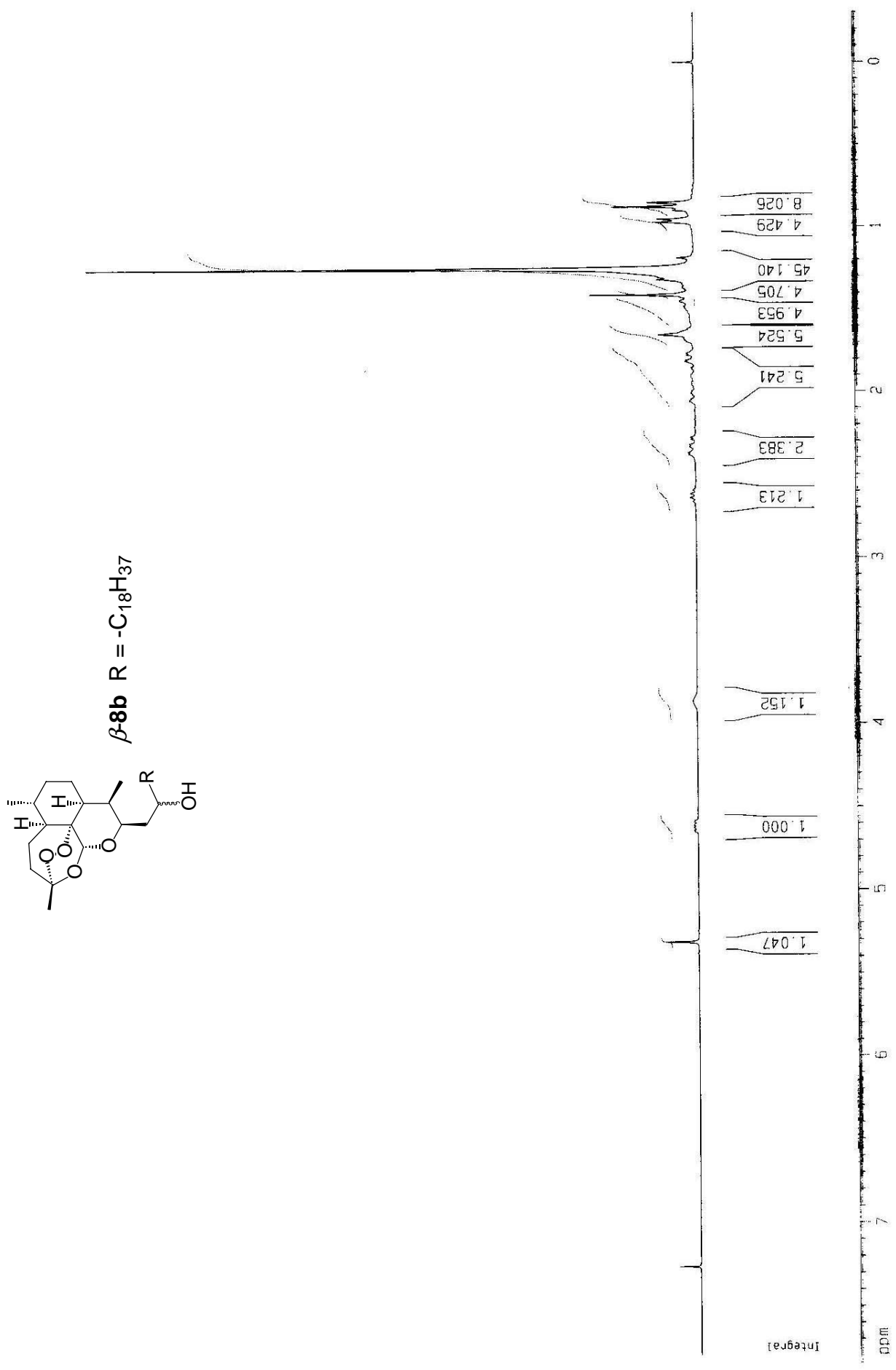




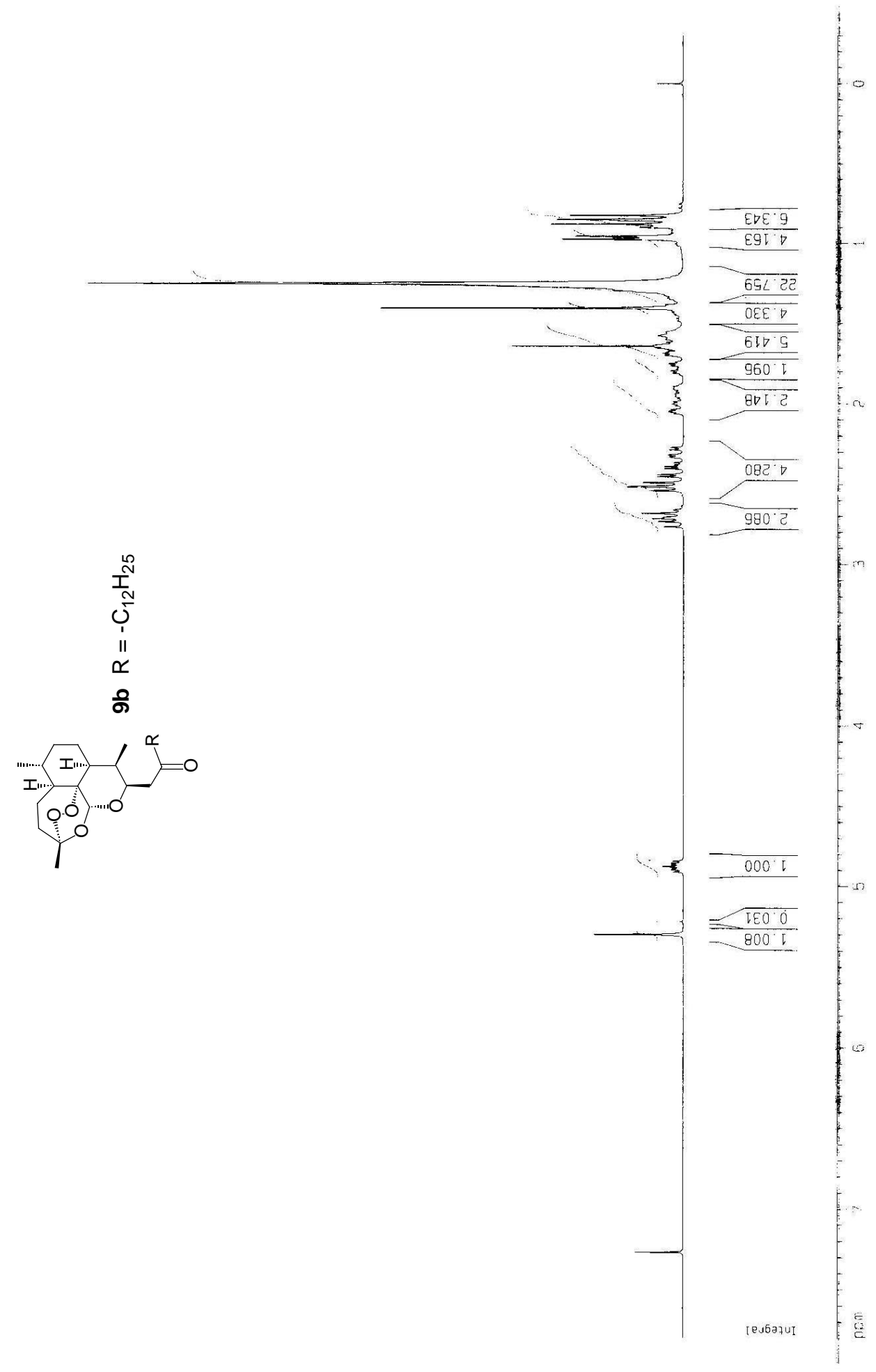




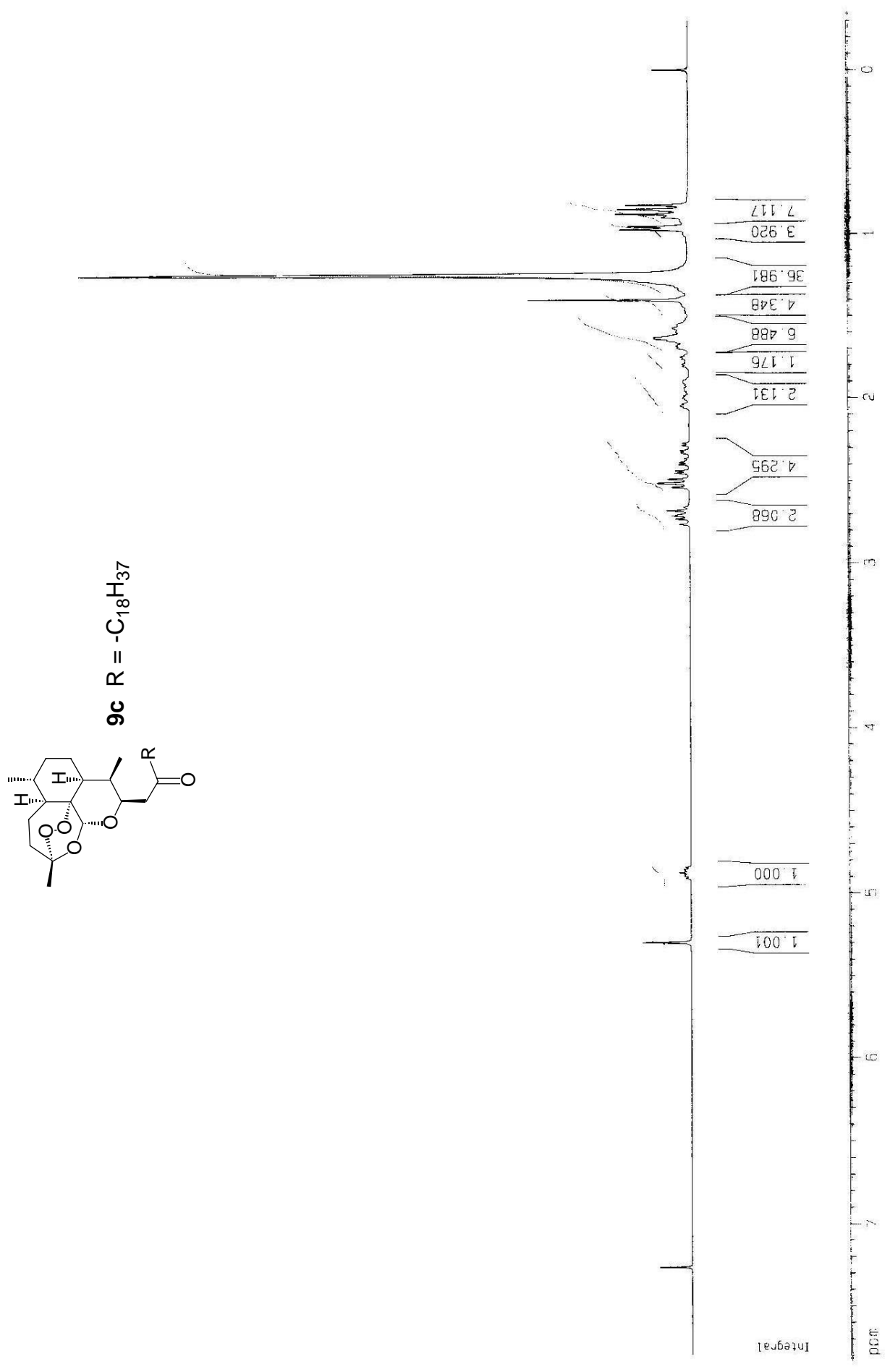




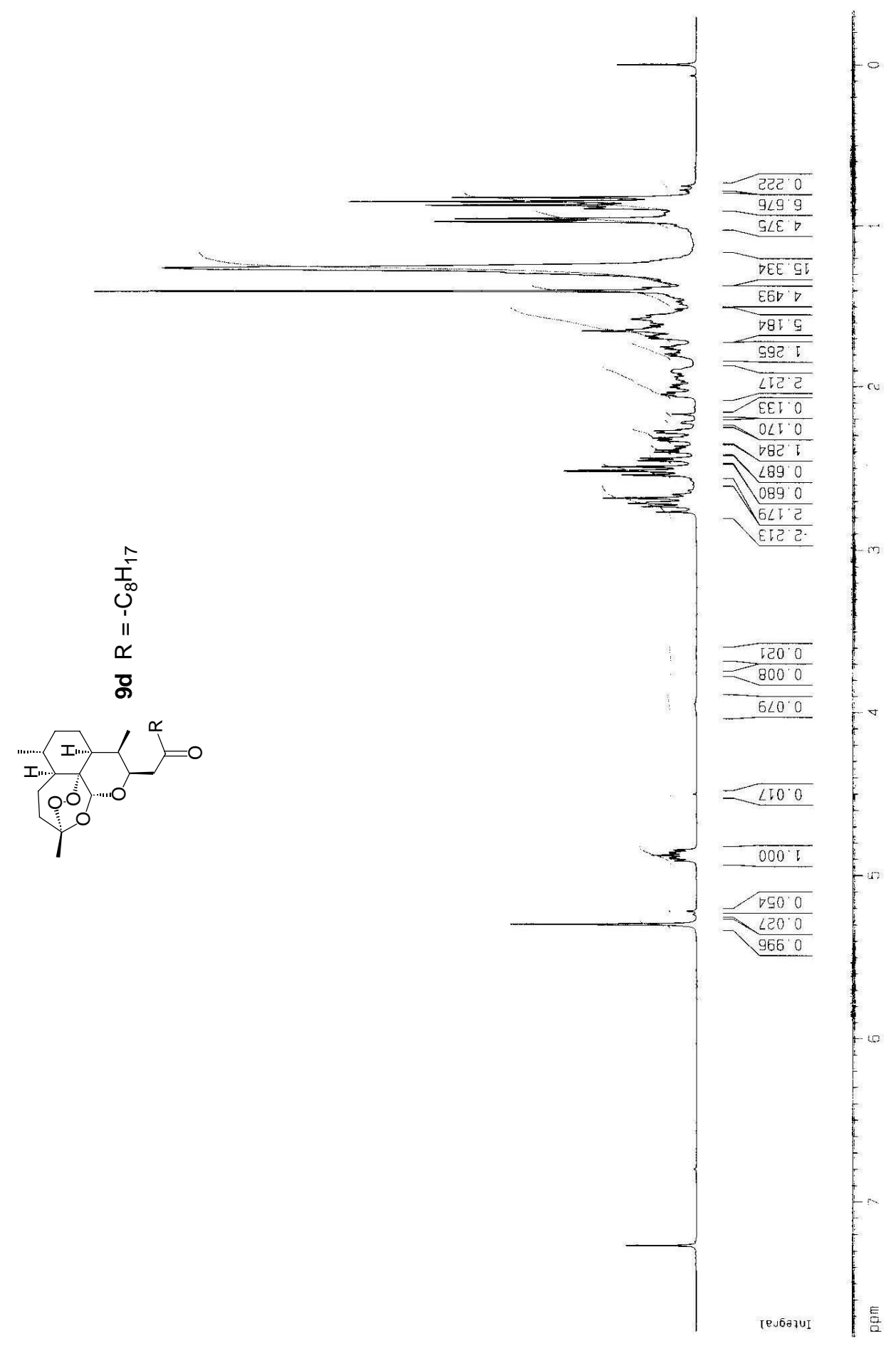




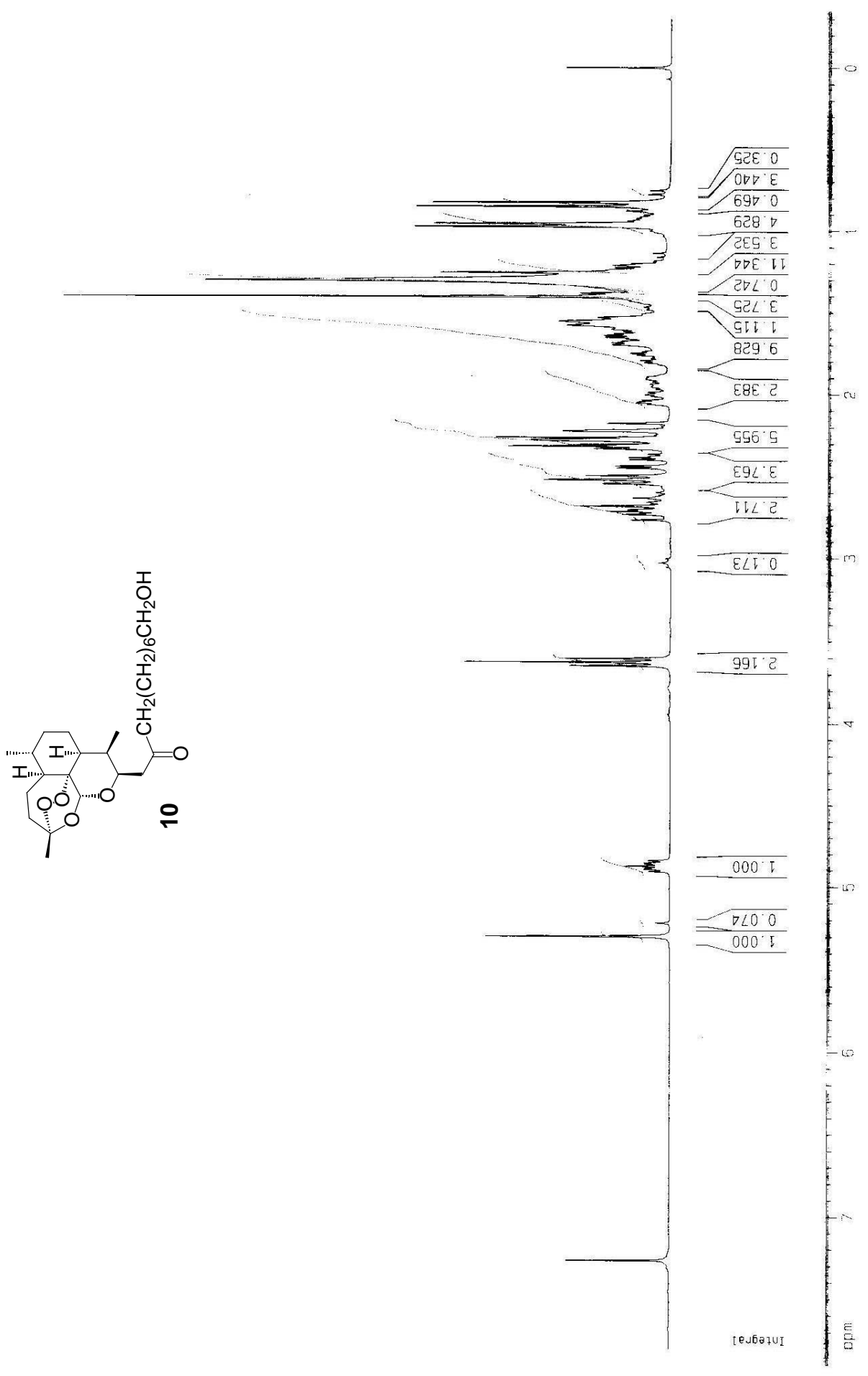




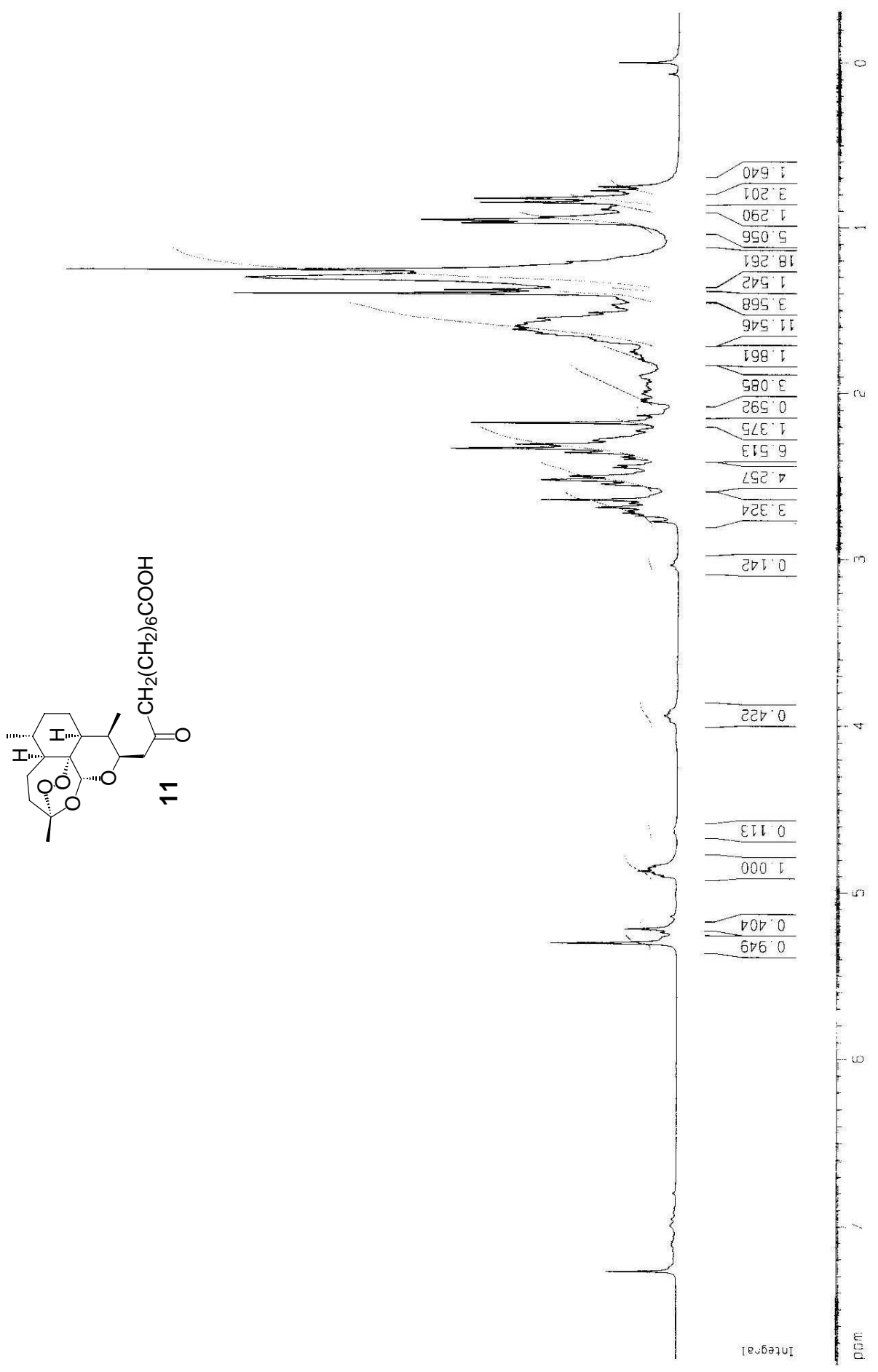




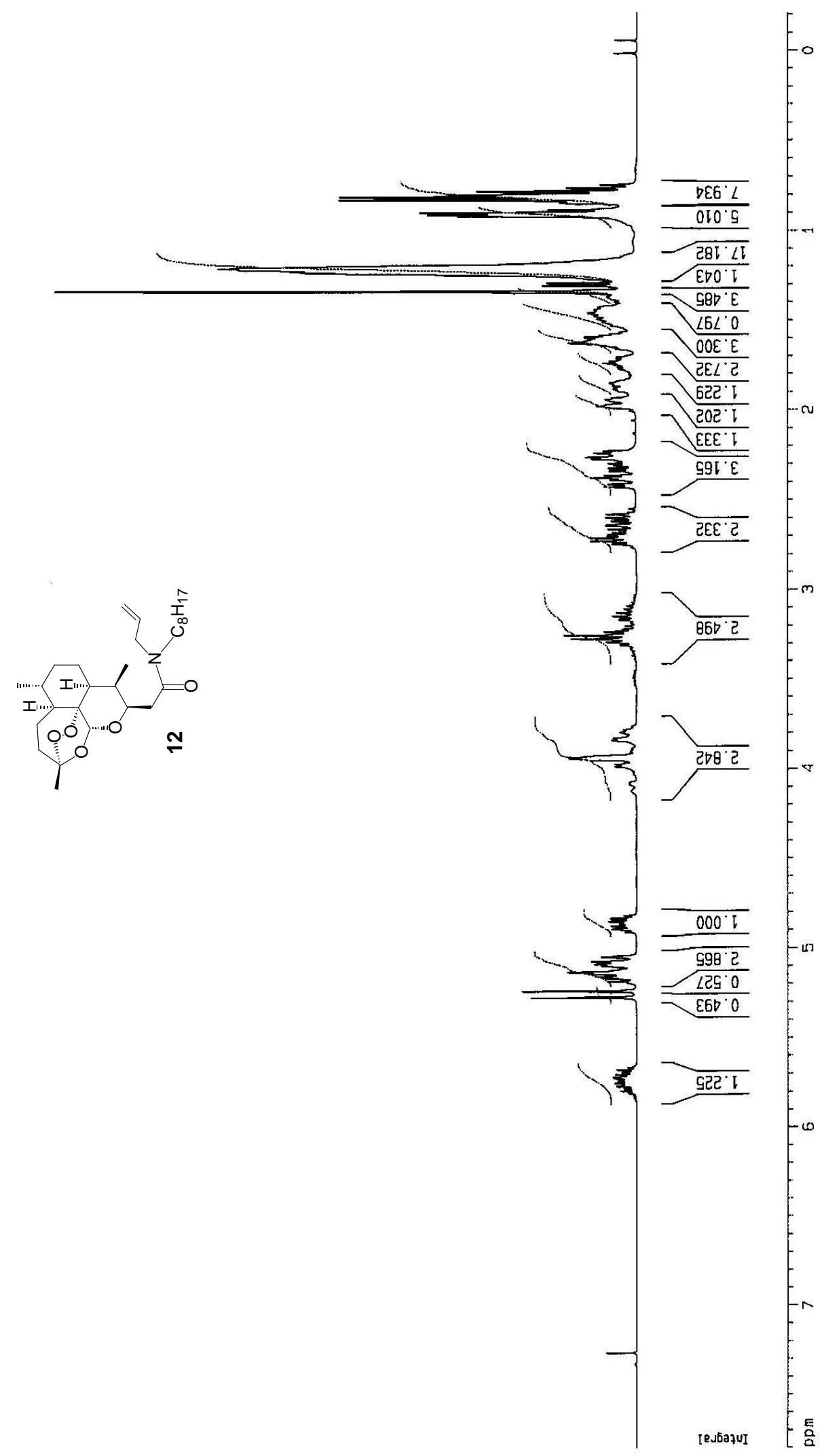




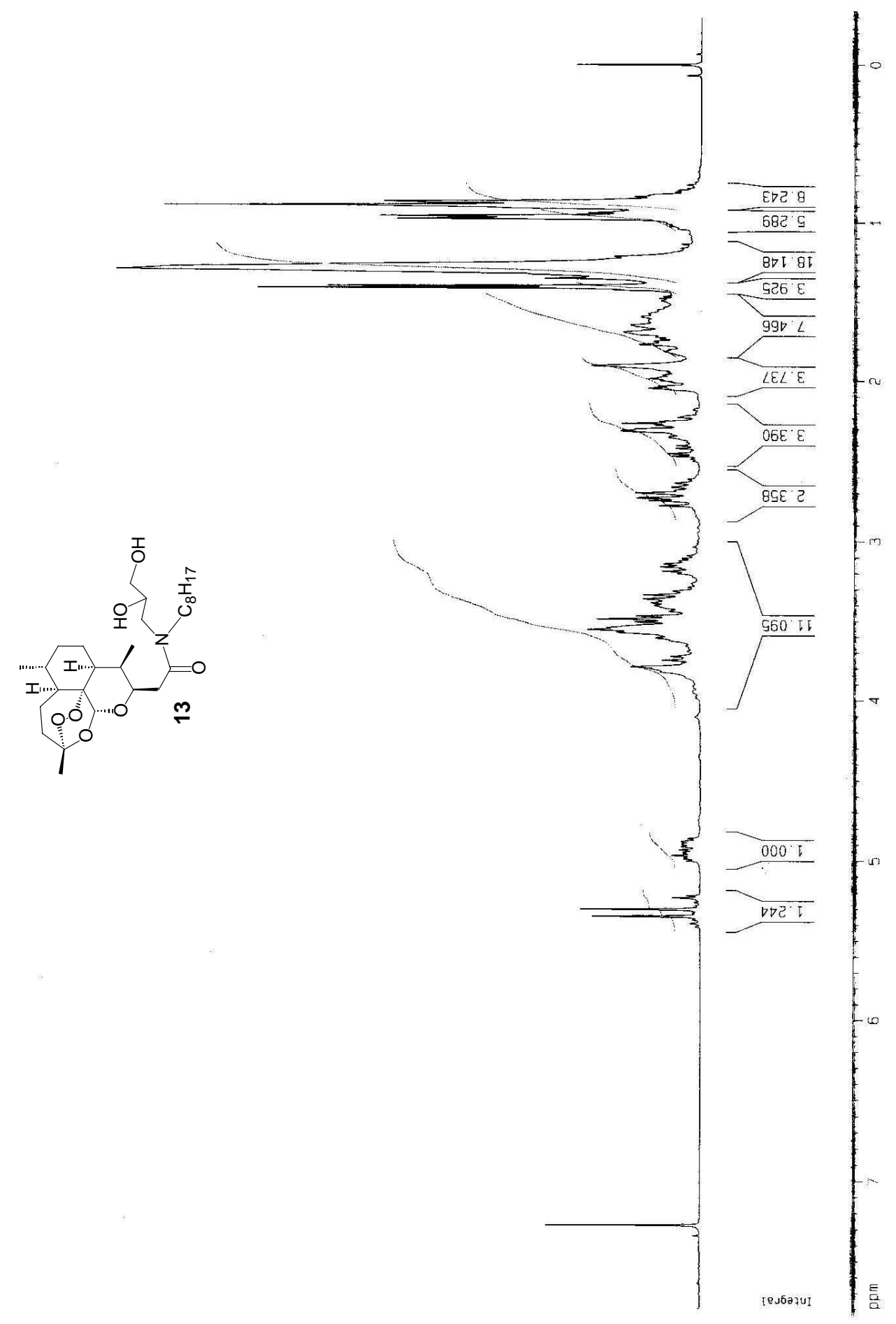




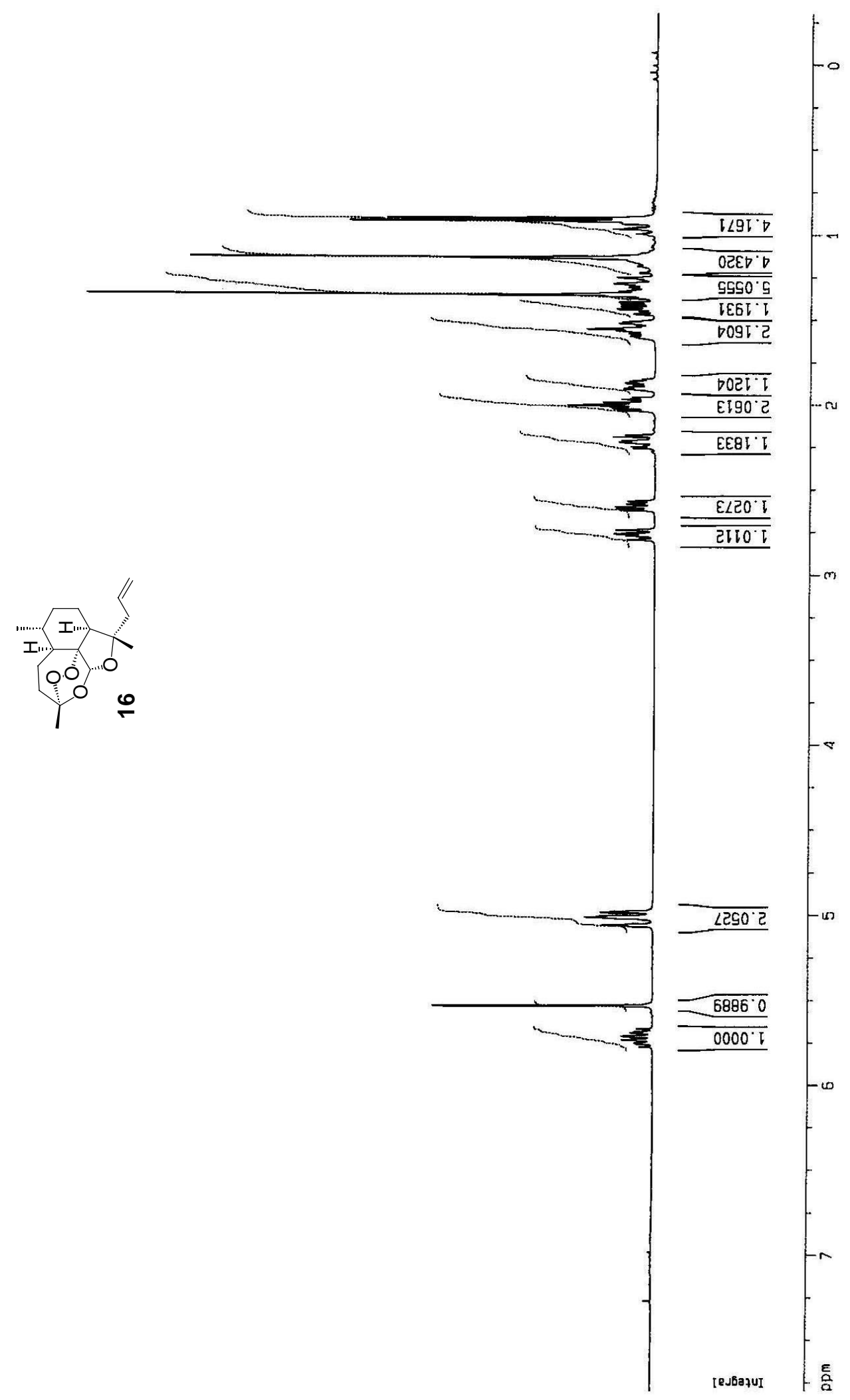




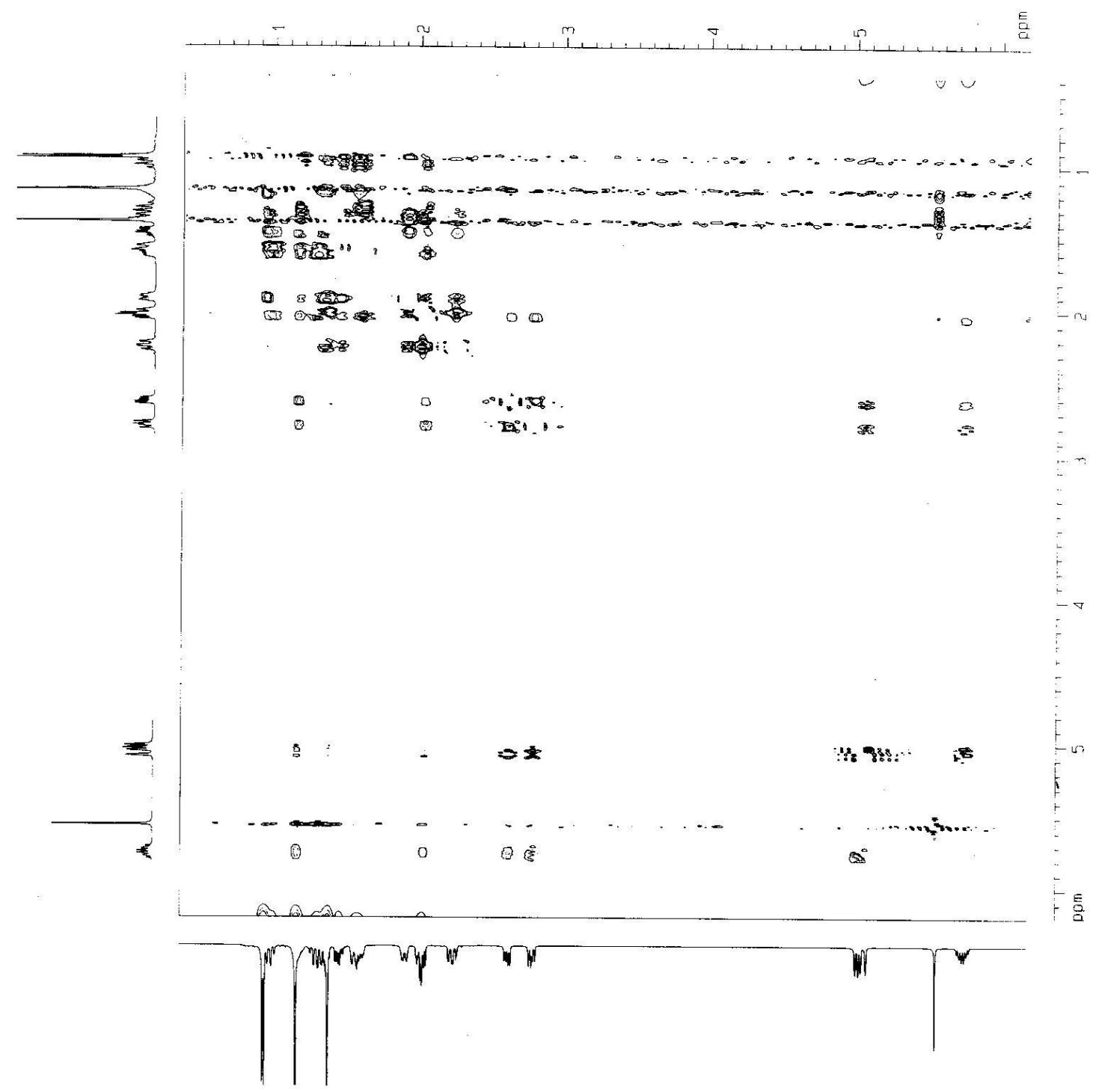

(I) 


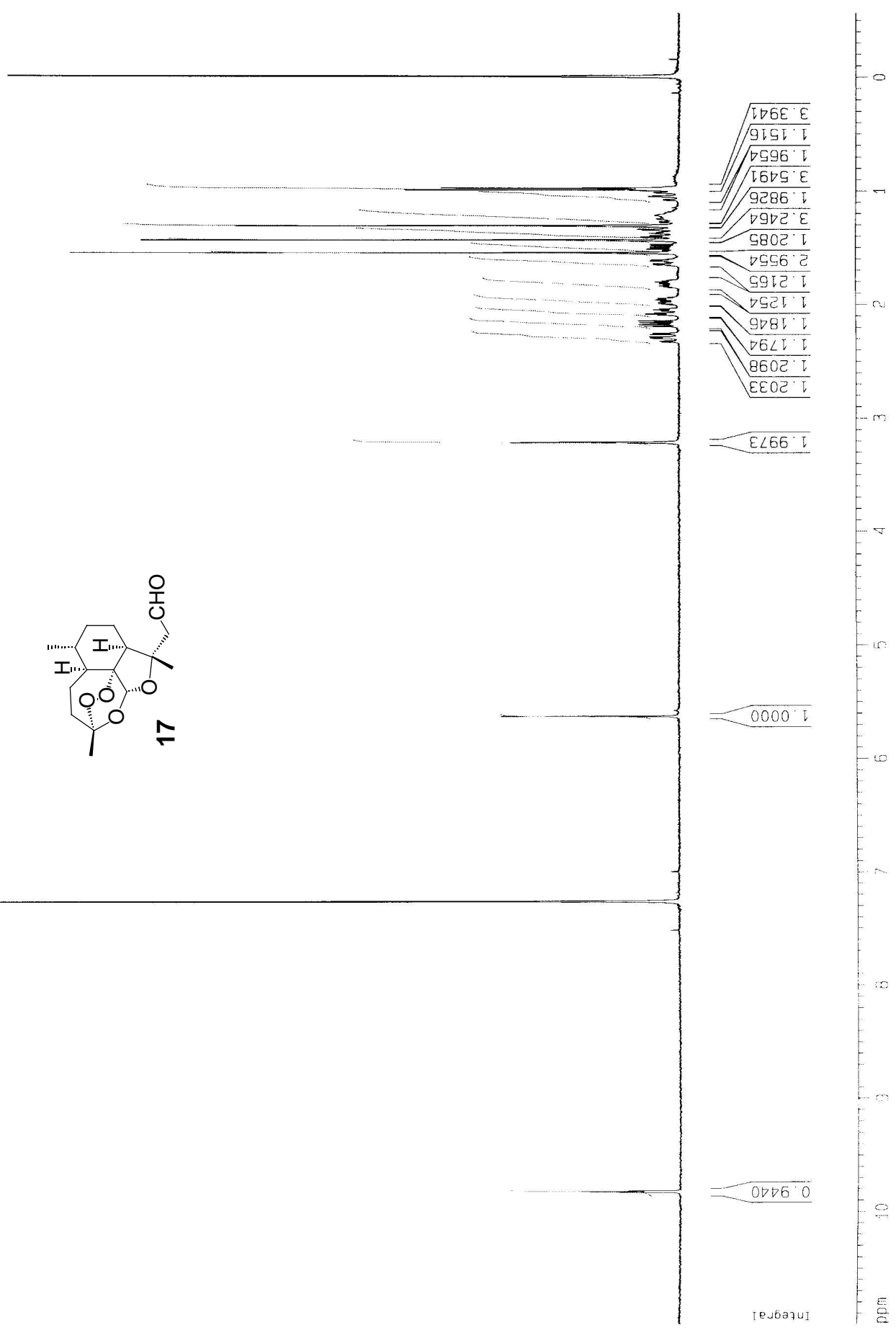




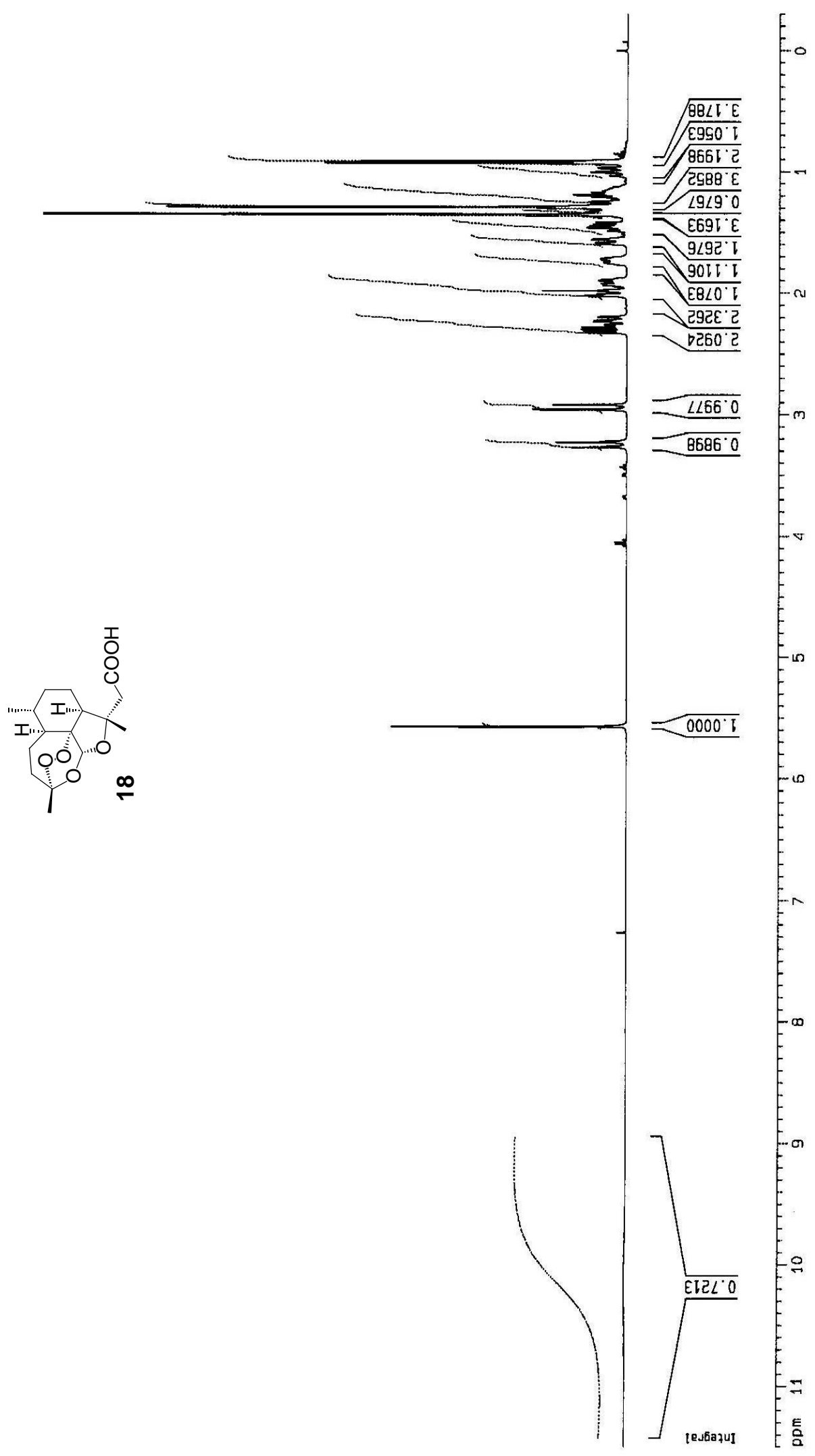




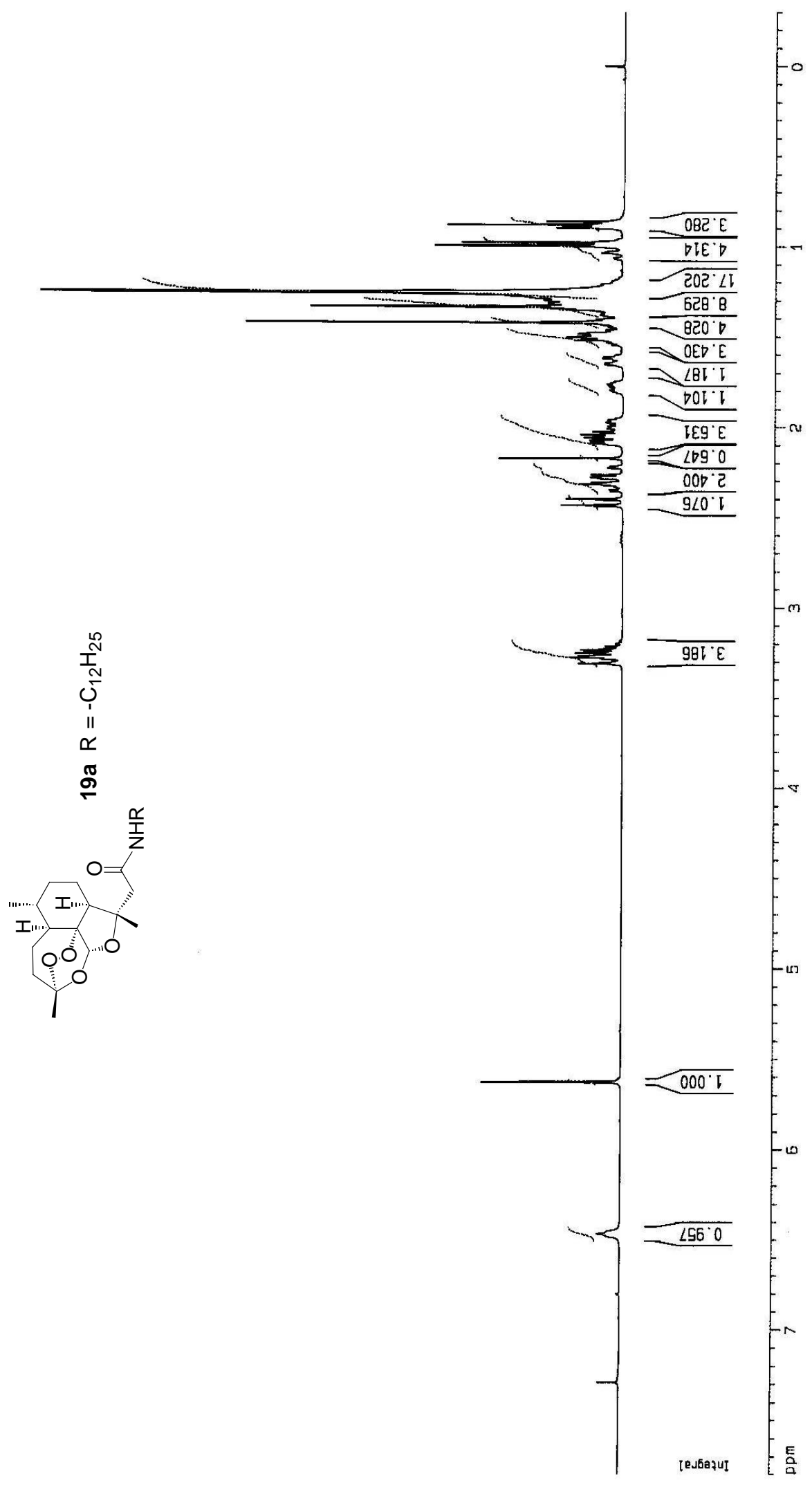




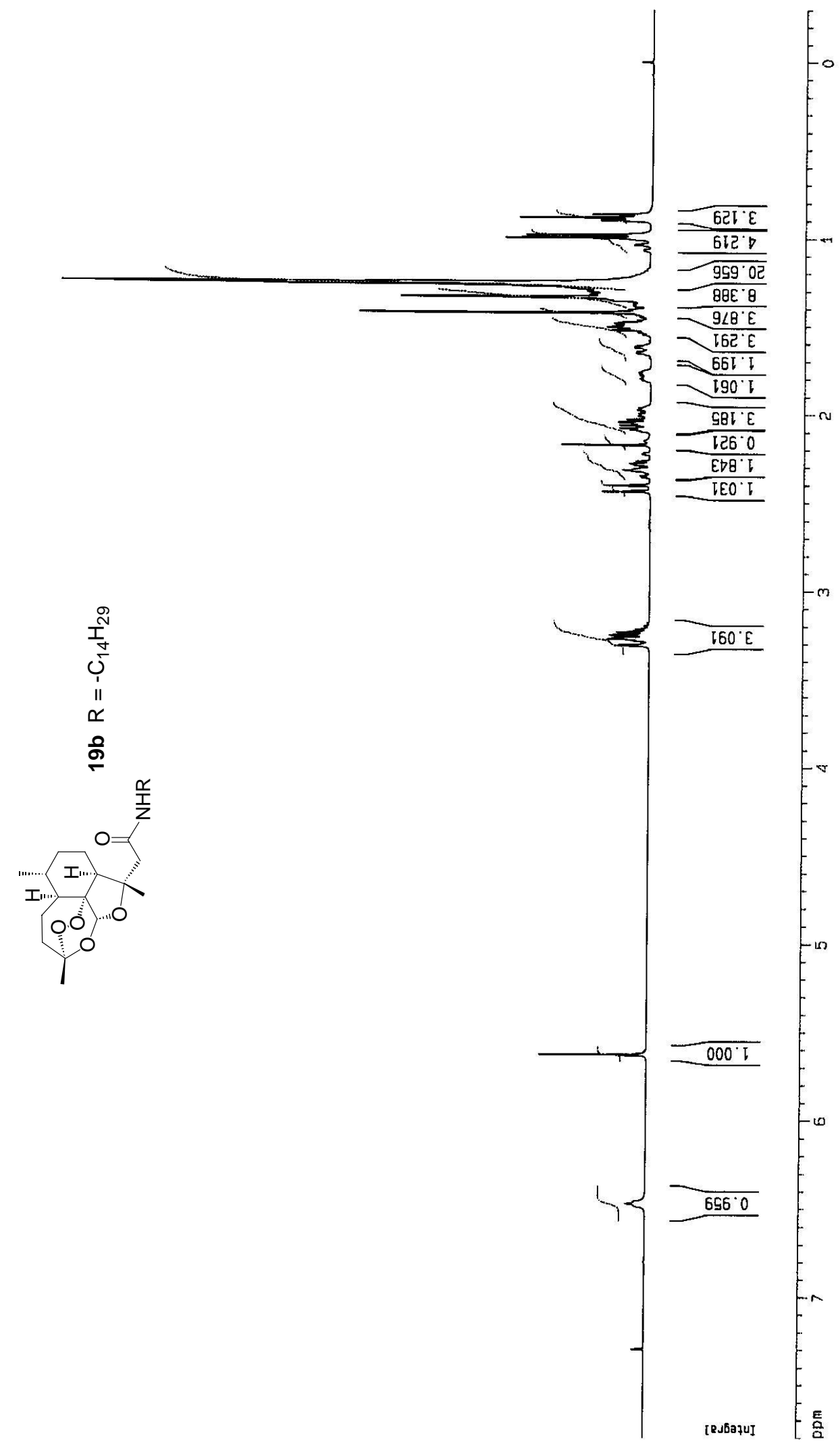




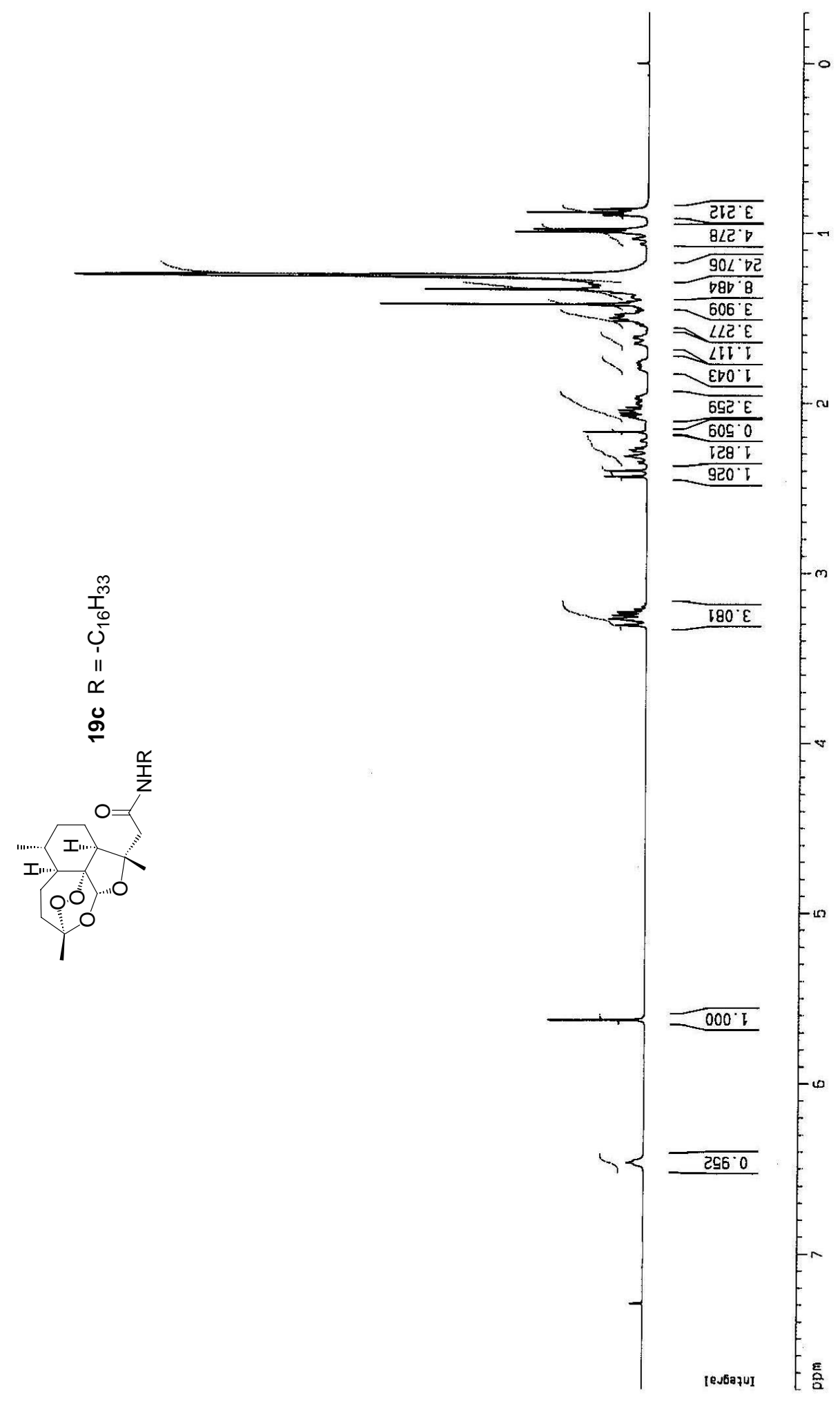




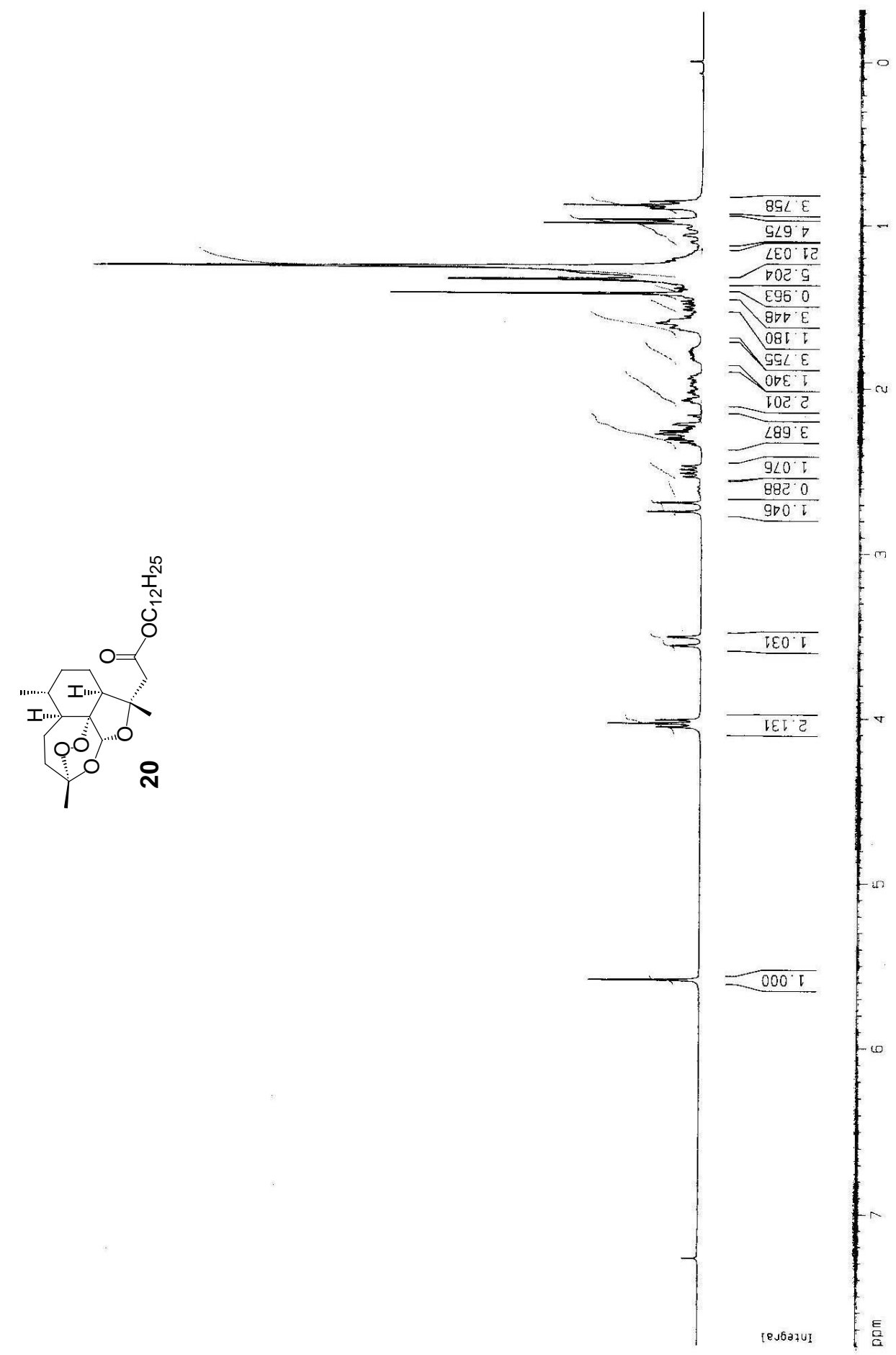




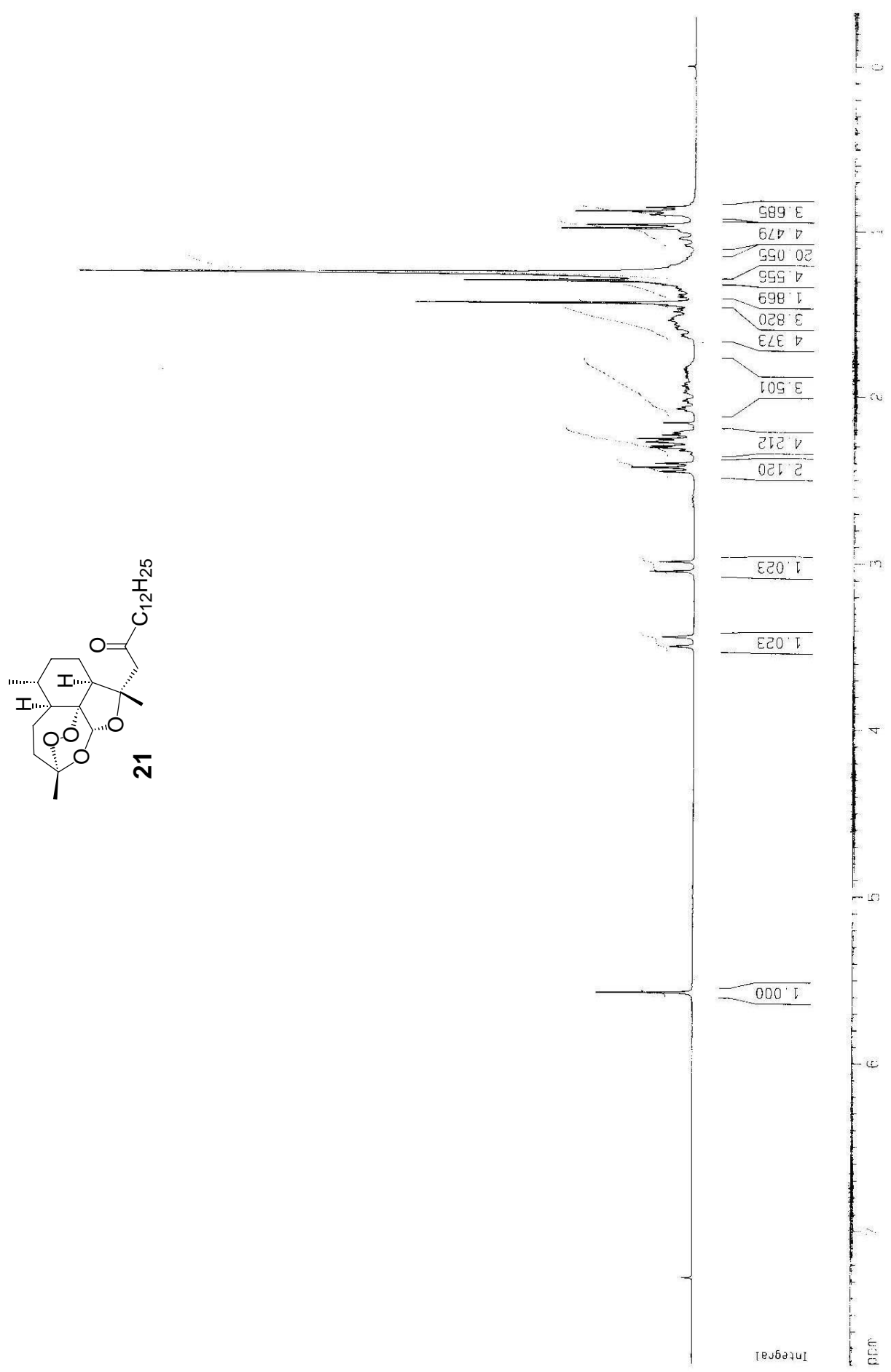




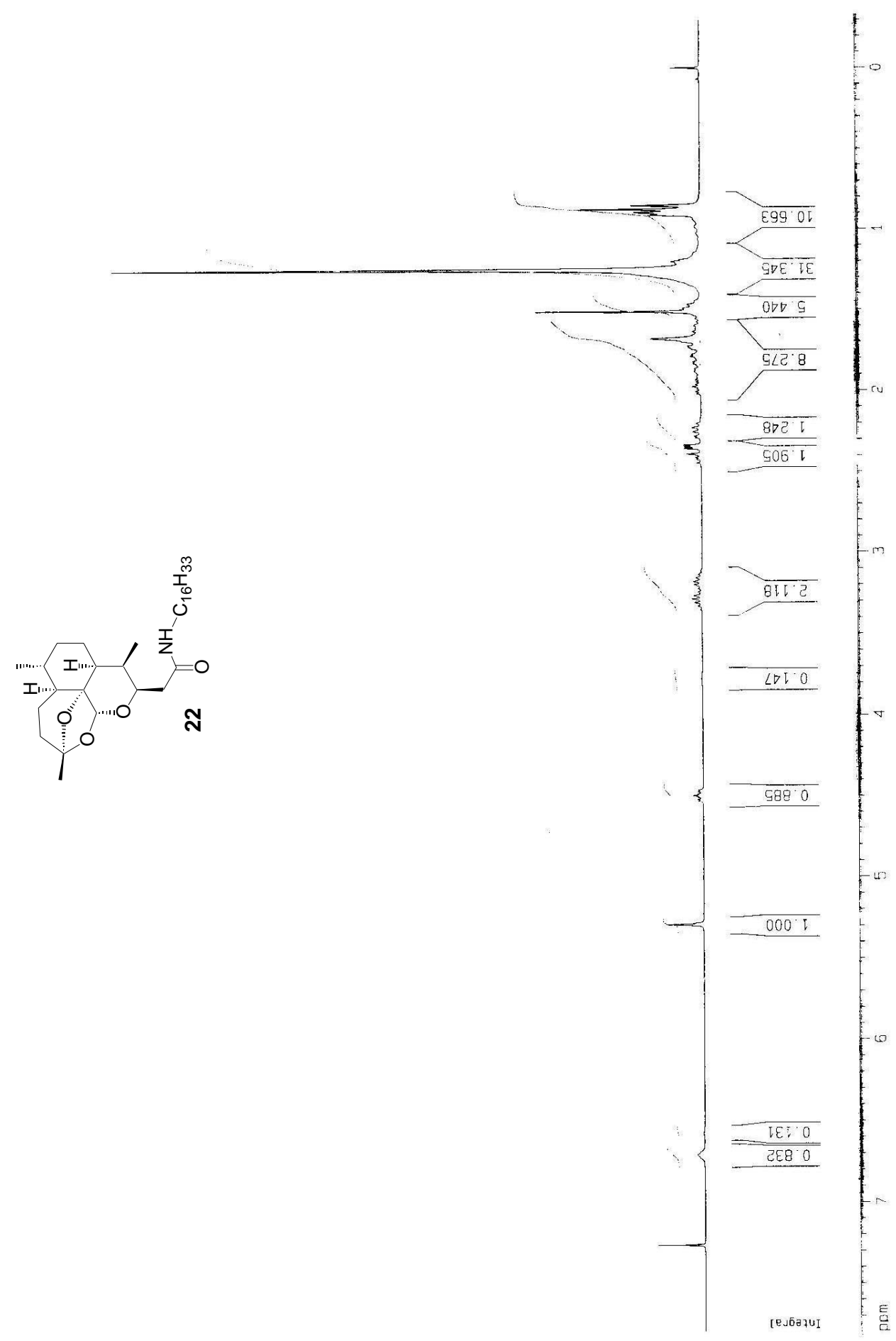

